\title{
Intrathecal baclofen therapy in children with intractable spastic cerebral palsy : a Dutch national study
}

Citation for published version (APA):

Hoving, M. A. (2008). Intrathecal baclofen therapy in children with intractable spastic cerebral palsy : a Dutch national study. [Doctoral Thesis, Maastricht University]. Datawyse / Universitaire Pers Maastricht. https://doi.org/10.26481/dis.20080523mh

Document status and date:

Published: 01/01/2008

DOI:

10.26481/dis.20080523mh

Document Version:

Publisher's PDF, also known as Version of record

\section{Please check the document version of this publication:}

- A submitted manuscript is the version of the article upon submission and before peer-review. There can be important differences between the submitted version and the official published version of record.

People interested in the research are advised to contact the author for the final version of the publication, or visit the DOI to the publisher's website.

- The final author version and the galley proof are versions of the publication after peer review.

- The final published version features the final layout of the paper including the volume, issue and page numbers.

Link to publication

\footnotetext{
General rights rights.

- You may freely distribute the URL identifying the publication in the public portal. please follow below link for the End User Agreement:

www.umlib.nl/taverne-license

Take down policy

If you believe that this document breaches copyright please contact us at:

repository@maastrichtuniversity.nl

providing details and we will investigate your claim.
}

Copyright and moral rights for the publications made accessible in the public portal are retained by the authors and/or other copyright owners and it is a condition of accessing publications that users recognise and abide by the legal requirements associated with these

- Users may download and print one copy of any publication from the public portal for the purpose of private study or research.

- You may not further distribute the material or use it for any profit-making activity or commercial gain

If the publication is distributed under the terms of Article $25 \mathrm{fa}$ of the Dutch Copyright Act, indicated by the "Taverne" license above, 
Intrathecal baclofen therapy in children with intractable spastic cerebral palsy

\author{
A Dutch national study
}


(C) Marjanke A. Hoving, Maastricht 2008

The copyright of the articles that have been published or have been accepted for publication has been transferred to the respective journals.

ISBN: 978-90-5278-713-8

Design: Arjen van Prooijen

Layout: Tiny Wouters

Production: Datawyse | Universitaire Pers Maastricht

The Dutch national ITB study was financially supported by the 'Profileringsfonds' of the University Hospital Maastricht.

The publication of this thesis was financially supported by Bayer Schering Pharma, Boehringer Ingelheim bv, GlaxoSmithKline BV, Ipsen Farmaceutica BV, IPC Neurobrain bv, Medtronic Trading NL B.V., Novartis Pharma B.V., SanofiAventis Netherlands B.V., Solvay Pharma, Teva Pharma NL and UCB Pharma B.V. 


\title{
Intrathecal baclofen therapy in children with intractable spastic cerebral palsy
}

\section{A Dutch national study}

\author{
PROEFSCHRIFT \\ ter verkrijging van de graad van doctor \\ aan de Universiteit Maastricht, \\ op gezag van de Rector Magnificus, \\ Prof. mr. G.P.M.F. Mols, \\ volgens het besluit van het College van Decanen, \\ in het openbaar te verdedigen \\ op vrijdag 23 mei 2008 om 14.00 uur
}

door

Marjanke Aaltje Hoving

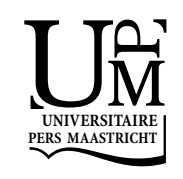




\section{Promotores:}

Prof. dr. J.S.H. Vles

Prof. dr. E.A.M. Beuls

\section{Copromotores:}

Dr. E.P.M. van Raak

Dr. G.H.J.J. Spincemaille

\section{Beoordelingscommissie:}

Prof. dr. M. van Kleef (voorzitter)

Prof. dr. J.G. Becher (Vrije Universiteit Medisch Centrum Amsterdam)

Prof. dr. O.F. Brouwer (Universitair Medisch Centrum Groningen)

Dr. L.J. van Rhijn

Prof. dr. L.J.I. Zimmermann 


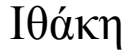

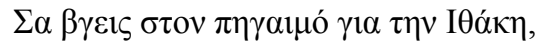

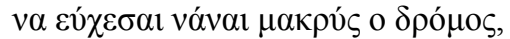

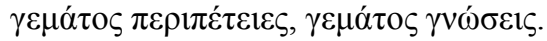

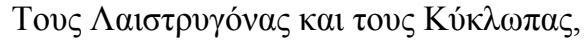

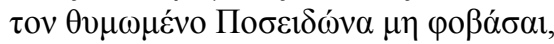

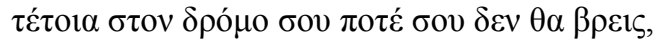

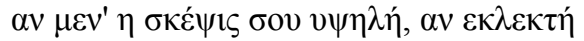

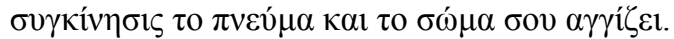

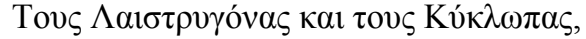

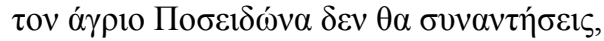

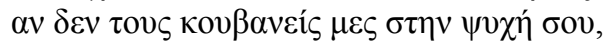

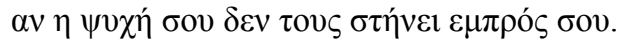

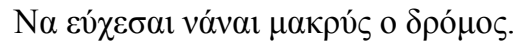

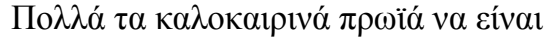

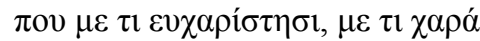

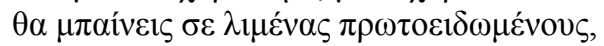

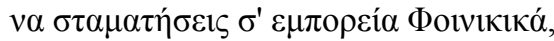
$\kappa \alpha 1 \tau \varepsilon \zeta \kappa \alpha \lambda \varepsilon \dot{\varepsilon} \varsigma \rho \rho \gamma \mu \alpha ́ \tau \varepsilon 1 \varepsilon \zeta v^{\prime} \alpha \pi 0 \kappa \tau \eta ́ \sigma \varepsilon 1 \zeta$,

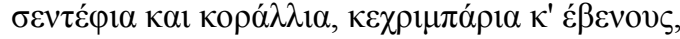

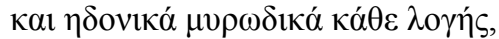

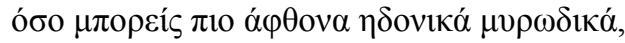

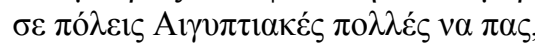

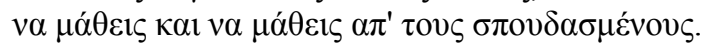

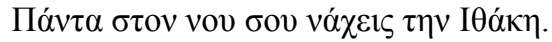

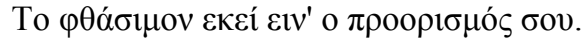

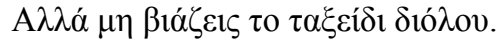

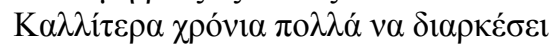

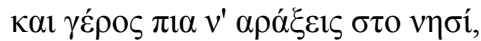

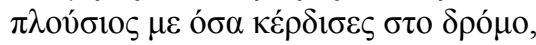

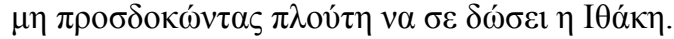

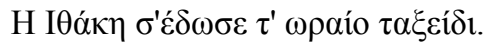

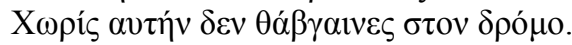

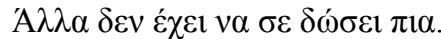

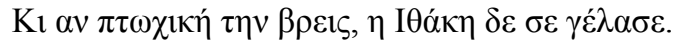

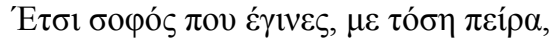

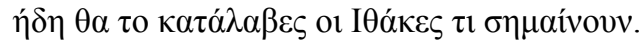

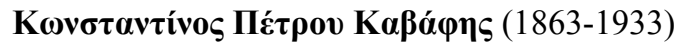





\section{CONTENTS}

Chapter $1 \quad$ General introduction 9

Chapter 2 Placebo controlled utility and feasibility study of the H-reflex

29 and flexor reflex in spastic children treated with intrathecal baclofen

Chapter 3 Intrathecal baclofen in children with spastic cerebral palsy: a double-blind, randomised, placebo-controlled, dose-finding study

Chapter 4 Efficacy of intrathecal baclofen therapy in children with intractable spastic cerebral palsy: a randomised controlled trial

Chapter 5 Safety and one-year efficacy of intrathecal baclofen therapy 79 in children with intractable spastic cerebral palsy

Chapter 6 The use of an Indium ${ }^{111}$ DTPA flow study in the evaluation of a lumbar swelling in a girl with a baclofen pump

Chapter 7 Intractable spastic cerebral palsy in children:

a Dutch cost of illness study

Chapter 8 Intrathecal baclofen therapy in children with intractable spastic cerebral palsy: a cost-effectiveness analysis

Chapter 9 General discussion

Summary

Samenvatting

Dankwoord

Curriculum vitae 



\section{CHAPTER 1}

General introduction 
10 Chapter 1 
This thesis addresses the results of the prospective Dutch national study on the efficacy and safety of intrathecal baclofen in the treatment of intractable spasticity in children with cerebral palsy.

\section{SPASTICITY}

In 1980, Lance defined spasticity as a motor disorder characterised by a velocitydependent increase in tonic stretch reflexes with exaggerated tendon jerks, resulting from hyperexcitability of the stretch reflex, as one component of the upper motor neuron (UMN) syndrome. ${ }^{1}$ More recent evidence suggests that spasticity is not a pure motor disorder and that it does not exclusively result from hyperexcitability of the stretch reflex. ${ }^{2}$ Moreover, the changes in resistance to imposed passive movement cannot be uniquely related to muscle activity and the phenomenon of velocity dependence is not exclusive to stretch reflex hyperexcitability. Therefore, the SPASM consortium redefined spasticity as a disordered sensori-motor control, resulting from an upper motor neuron lesion, presenting as intermittent or sustained involuntary activation of muscles. ${ }^{2}$

\section{Pathophysiology}

The UMN syndrome includes positive and negative phenomena. Positive phenomena are characterised by excessive or inappropriate motor activity, such as spasticity, hyperreflexia, extensor plantar responses and clonus. The negative phenomena are characterised by a reduction in motor activity, such as weakness, fatigue, slow effortful voluntary movement, impaired fine-motor function and difficulty in isolating individual movements. ${ }^{3}$ Upper motor neurons are neurons of any long descending tract that control movement and muscle tone. The descending tracts may be divided into pyramidal and parapyramidal tracts. Most features of the UMN syndrome involve lesions of the parapyramidal tracts, which mainly arise in the brainstem. The key tracts are the dorsal reticulospinal tract, medial reticulospinal tract and vestibulospinal tract. These descending pathways synapse upon interneural networks within the spinal cord that control spinal stretch reflexes, flexor and extensor reflexes. The medial reticulospinal tract and vestibulospinal tract have a predominantly excitatory influence. The dorsal reticulospinal tract is the main inhibitory pathway. Contrary to the other tracts, the inhibitory dorsal reticulospinal tract receives a strong cortical facilitatory influence. In its normal state, the excitatory and inhibitory influences are in balance. However, in the UMN syndrome there is an imbalance, caused by lesions affecting some or all of the descending tracts. For example, in cerebral palsy the facilitatory cortical influence of the inhibitory dorsal reticulospinal tract 
is decreased. As a result, the balance tips in favour of excitation, which may result in spasticity and other positive phenomena of the UMN syndrome.

\section{Signs and symptoms}

Spasticity can cause pain, sleeping disorders, increased energy requirements and interference with positioning, transfers, dressing and body hygiene. Secondary phenomena, such as contractures, pressure sores and heterotopic calcifications of joints or tendons can add to the treatment problems. ${ }^{3}$

\section{Spastic cerebral palsy}

Spasticity can result from cerebral or spinal injury. The most common aetiology of spasticity in children is cerebral palsy (CP). ${ }^{4} \mathrm{CP}$ describes a group of disorders of the development of movement and posture, causing activity limitation, that are attributed to non-progressive disturbances that occurred in the developing foetal or infant brain. The motor disorders of CP are often accompanied by disturbances of sensation, cognition, communication, perception, and/or behaviour, and/or by a seizure disorder. ${ }^{5}$ There is some evidence that damage of the spinal cord may also play a role in $\mathrm{CP} .{ }^{6,7} \mathrm{CP}$ is the most common cause of severe physical disability in childhood. ${ }^{8}$ In developed countries, the overall reported prevalence in children aged 3 to 10 years is 2.4 per 1000 children. ${ }^{9-11}$ The CP syndromes are traditionally subdivided into a spastic, dyskinetic, ataxic and mixed type. ${ }^{8}$ Spasticity accounts for 70 to $91 \%$ of the motor disorders associated with CP. ${ }^{8,12}$ The spastic CP syndromes are further divided according to the distribution of the upper motor neuron signs. Spastic diplegia is defined as greater involvement of the lower limbs, tetraplegia as an equal or greater involvement of the upper limbs, and hemiplegia as involvement of one side of the body. ${ }^{9}$

\section{SPASTICITY TREATMENT}

In the treatment of spasticity, the first aim is to elicit provocative factors, as spasticity is often highly state dependent. It may fluctuate with various internal and external stimuli, such as pain, fatigue, stress, excitement, cold, illness, sleep disturbance, immobility and hormonal changes. ${ }^{4}$ Despite lack of support for their efficacy, physical and occupational therapy remain important in the management of spasticity. ${ }^{13}$ These approaches aim at lengthening contracted muscles, improving muscle strength and coordination, increasing the range of motion of restricted joints and, developing compensatory strategies to accomplish tasks. ${ }^{14}$ They can be either primary treatments or an integral part of treatment programmes. 


\section{Focal treatments}

Focal treatments for spasticity include intramuscular injection of botulinum toxin, orthoses, orthopaedic surgery, selective peripheral neurotomy, selective dorsal rhizotomy and percutaneous radiofrequency lesioning of the dorsal root ganglion.

Botulinum toxin blocks the neuromuscular transmission by decreasing the presynaptic acetylcholine release at the motor nerve ending. The effect of botulinum toxin is temporary, lasting from 2 to 6 months. ${ }^{15}$

Orthopaedic surgery includes procedures to lengthen contracted myotendinous units, balance joint forces, transfer motor power, fuse unstable joints by arthrodesis, correct bony deformities and reduce joint subluxation and dislocation. The aims of orthopaedic surgery are to improve joint congruency, diminish pain and restore or stabilise spinal deformity. ${ }^{9}$ Selective peripheral neurotomy decreases spasticity by selectively sectioning both afferent and efferent fibres of the stretch-reflex at the level of the muscle's nerve. ${ }^{16}$

Selective dorsal rhizotomy is a surgical intervention for the treatment of lower extremity spasticity. Operative techniques involve a multilevel laminectomy and the transection of carefully selected lumbosacral sensory rootlets. ${ }^{17}$ Dorsal rhizotomy reduces the amount of excitation of the alpha motor neurons, decreasing spasticity in the muscles associated with the transected nerves. ${ }^{18}$ The best candidates for selective dorsal rhizotomy are children, aged between 3 and 8 years, with spastic diplegia and reasonably well-preserved leg strength. ${ }^{19}$

A less invasive and safe alternative for selective dorsal rhizotomy is percutaneous radiofrequency lesioning of the dorsal root ganglion. De Louw et al. conducted a pilot study considering the effects of percutaneous radiofrequency lesioning of the dorsal root ganglion in six children with spastic CP. The results of this study showed that ease of care and lower-extremity muscle tone improved both at 4 weeks and 6 months after the lesioning. ${ }^{20}$

\section{Generalised treatments}

Generalised treatments for spasticity include therapy with oral spasticity reducing agents such as baclofen, dantrolene, tizanidine, and benzodiazepines. ${ }^{21}$ One of the most common used anti-spastic drugs is baclofen. ${ }^{22}$ Baclofen acts as a $\gamma$ aminobutyric acid (GABA-B) agonist, which is a major inhibitory neurotransmitter. In the mammalian spinal cord, GABA is highest concentrated in the dorsal grey matter, followed by the ventral grey matter, with only minimal amounts in the white matter. ${ }^{23}$ In the dorsal horn, GABA-B is mainly found in laminae I-III in interneurons, which are presynaptic to dendrites, cell bodies, and other axon terminals. ${ }^{23}$ Besides decreasing muscle tone, baclofen has antinociceptive effects. ${ }^{24}$ It is postulated that the presynaptic inhibition and other gating mechanisms related to pain and flexor spasms take place in the dorsal 
horn. ${ }^{25}$ There is evidence that nitric oxide mediated cyclic guanosine $3^{\prime}, 5^{\prime}$ monophosphate (cGMP) synthesis plays a role in nociception in the spinal cord and that an increased level of cGMP in the dorsal horn is associated with hyperalgesia. ${ }^{26}$ In the rat cervical spinal cord, baclofen had an inhibitory effect on the atrial natriuretic peptide-mediated cGMP synthesis in laminae I-III of the dorsal horn. ${ }^{26}$ The effects of baclofen in the spinal cord are considered to be at least partially mediated by nitric oxide cGMP. ${ }^{26}$ The muscle relaxant effect of baclofen takes place in the ventral horn, where GABA is localised in interneurons presynaptic to motoneuron cell bodies and small and large dendrites. ${ }^{23}$

Baclofen passes the blood-brain barrier poorly; as a result, taking oral baclofen leads to high blood levels and virtually undetectable levels in the cerebrospinal fluid. As a consequence, patients easily experience side effects such as drowsiness and lethargy, without an adequate reduction in spasticity.

\section{Treating intractable spasticity}

A substantial group of children with serious spasticity does not respond to regular treatments (intractable spasticity). Children with intractable spasticity often have a low health related quality of life. ${ }^{27,28}$ Continuous infusion of intrathecal baclofen (CITB) is a promising treatment option for intractable spasticity. ${ }^{29-31}$ The bloodbrain barrier is being by-passed, because baclofen is directly infused into the cerebrospinal fluid, which surrounds the spinal cord. Because the GABA-B receptors are located superficially in the spinal cord, baclofen can easily reach these receptors. Administration of a hundredth part of the oral baclofen dose intrathecally can relieve spasticity without the side effects often encountered with high baclofen doses taken orally. ${ }^{32}$ Intrathecal baclofen (ITB) can be delivered continuously by a programmable infusion pump implanted in an abdominal subcutaneous or subfascial pocket, and a connecting catheter, which is inserted in the intrathecal space.

\section{INTRATHECAL BACLOFEN IN CHILDREN WITH SPASTIC CP: A LITERATURE OVERVIEW}

In 1985, Penn and Kroin established the effectiveness of CITB in patients with spasticity of spinal origin. ${ }^{33}$ In the same year, Dralle et al. reported on the beneficial effect of ITB in a child with spasticity of cerebral origin. ${ }^{34}$ Since then, the use of ITB for both spinal and cerebral spasticity has been addressed in several studies. In 2000, the American Academy for Cerebral Palsy and Developmental Medicine (AACPDM) published a systematic review on the degree of evidence about ITB treatment for spasticity in individuals with CP. ${ }^{35}$ It appeared that only a small and uncertain number of individuals had been 
studied. Except for two case reports, none of the studies solely concerned children. Few outcomes beyond muscle tone had been measured more than once. Moreover, the research methodology employed in three quarters of the available studies was not capable of confirming treatment effect. The AACPDM underlined the need for further prospective, randomised trials that use valid and reliable outcome measures, in well-described and homogeneous patient groups. Therefore, we started a Dutch national study on the efficacy and safety of ITB in the treatment of children with intractable spastic CP in 2002.

\section{Literature published since the start of the Dutch national ITB study}

2002 In a consecutive case-series (1997-2001), Murphy et al. retrospectively studied the efficacy and complications of CITB in 23 children with CP. ${ }^{36}$ Before pump implantation, 24 children underwent a screening trial, 21 via bolus injections and three via catheter infusions. All but one child went on to pump implantation. Further information on the design of the screening trial or the effective ITB dose was not provided. The average Ashworth score of both the lower and upper extremities had decreased significantly after 6 months of CITB. A limitation of this study was the use of the Ashworth scale as single outcome measure. Eleven $(44 \%)$ of the implanted pumps had to be explanted, mainly because of wound dehiscence with secondary infection. Side effects were not addressed. ${ }^{36}$

Campbell et al. reviewed the long-term safety and efficacy of CITB in the treatment of 21 children and adolescents. ${ }^{31}$ Their study was for the greater part retrospective (1994-1998) and included patients with spastic CP, mixed type CP, and patients with other causes of cerebral spasticity. ${ }^{31}$ All participants responded to an ITB test dose of 50 or $100 \mu$ g. Data on the participants' weights, the design of the test treatment and the incidence of adverse events during the test treatment were lacking. After pump implantation, no improvement on the Gross Motor Function Measure and the Pediatric Evaluation Disability Inventory was observed. During 80 patient-years, there were 153 possible treatment related adverse effects, of which 27 device related. The most common non-device related adverse events included decreased function $(n=19)$, pressure sores $(n=13)$, increased tone $(n=12)$, constipation $(n=10)$ and lethargy $(n=9)$. Four children died. There was no evidence of pump malfunction or catheter displacement in these children before or at the time of death. A single, prospective telephone survey was used in the 17 participants who still had a pump in 1999. The aim of this survey was to obtain information on the treatment goals and the caregivers' overall satisfaction with CITB. The status of the treatment goals was reported by the participants or their caregivers without using an outcome measure, such as a visual analogue scale or goal attainment scaling. Caregiver satisfaction was high. Of 108 initial treatment goals, $78(72 \%)$ were 
completely or almost completely achieved and 101 (94\%) were at least partly achieved. Treatment goals included improvements in dressing, positioning, pain, sleep and independent mobility. Fourteen of the 17 caregivers stated that they would have their child's pump replaced if it had to be removed for any reason, two were indecisive and one would not have the pump replaced, because of the child's fear of needles at times of pump refilling. Fifteen caregivers would recommend CITB to others. ${ }^{31}$

2003 Awaad et al. reported the efficacy of CITB in 29 patients with spastic CP, focussing on impairments, functional limitations and disability. ${ }^{37}$ Adverse events were not structurally addressed. This prospective study did not only include children, but adults as well. Patients with severe contractures were excluded. Besides CITB, patients received individualised rehabilitation to maximise the functional effects of CITB. Forty-nine eligible candidates for CITB therapy underwent a test treatment with a lumbar $50 \mu \mathrm{g}$ ITB bolus injection. A one-point reduction of the average Ashworth score in the lower extremities was considered a positive response to the test treatment. Thirty-nine patients decided to have a pump implanted. Reported reasons for the 10 patients who did not have a pump implanted included the following: three patients chose using oral medication; two had family issues; one child was too small for implantation; one child died, unrelated to the baclofen test treatment; one child underwent spinal fusion; one child had medical issues; and one family decided not to undergo an implantation at the time of the study. The authors did not provide any specific information about the results of the test treatments. After pump implantation, the outcome measures were complete for only 29 of the 39 patients. The mean Ashworth score had significantly decreased during all follow-up visits $(p<0.0005)$. The mean Pediatric Evaluation Disability Inventory scores showed significant gains in the Functional Skills self-care domain score from 6 months of treatment with CITB and in the Caregiver Assistance mobility domain score at the 6,12 and 18-month follow-up visits. ${ }^{37}$

2004 Between 1996 and 2001, Albright et al. prospectively evaluated the complications associated with CITB via a Synchromed EL 10-ml pump in 100 children of whom 90 were diagnosed with CP. ${ }^{38}$ It was a prospective, open-label, non-blinded study, conducted in 11 United States medical centres. The study did not address efficacy and possible side effects of CITB. ${ }^{38}$ The Ashworth scores decreased significantly in the upper and lower extremities at 6 and 12 months after pump implantation $(p<0.001)$. There were 69 procedure and device related complications during a follow-up of 1178 patient-months. Forty-seven complications were serious. The one-year complication-free rate was $79 \%{ }^{38}$

2005 Vloeberghs et al. summarised the preliminary results of ITB therapy in children (about 90\% with CP) at Queens Medical Centre in Nottingham. ${ }^{39}$ During the test treatment, an ITB $50 \mu \mathrm{g}$ bolus, or $30 \mu \mathrm{g}$ bolus in the smallest children, was administered via a lumbar catheter. The caregiver had to assess the results of 
the ITB bolus and consequently had to decide whether or not the child would have a pump implanted. The investigators considered it not useful to quantify the effects of the ITB bolus during the test treatment. Eighty-three children underwent a test treatment and 63 children had a pump implanted. In absence of adequate objective measures for assessing the effect of CITB treatment, no outcome measures were used to assess the effects of CITB after pump implantation. Complications requiring surgery were reported in 13 children, including three infections, five catheter migrations, four catheter fractures and one pressure sore of the skin covering the pump. ${ }^{39}$

2006 Vender et al. reviewed the complications encountered in a series of 314 pump and catheter related procedures in a group of 195 paediatric and adult patients with intractable spasticity or dystonia. ${ }^{40}$ This retrospective study included 128 children (108 with $\mathrm{CP}$ ) and 67 adults. The complications were not specified for children with spastic CP. In comparison with the adults, both the overall complication rate and, specifically, the wound complication rate were significantly higher in children. ${ }^{40}$

2007 Motta et al. retrospectively evaluated the incidence of three common CITB complications in 200 children (175 with CP) without addressing other safety aspects. ${ }^{41}$ They recorded 76 complications during a follow-up of 10,142 patientmonths. Twenty children (10\%) had an infection, 34 (17\%) leakage of cerebrospinal fluid (one pump removal) and 21 (10.5\%) catheter-associated complications (15 pump removals). The incidence of infections decreased from $10 \%$ to $4.8 \%$ after adoption of the subfascial implantation technique and modification of the preoperative prophylaxis procedures. ${ }^{41}$

De Lissovoy et al. retrospectively studied the cost-effectiveness of CITB in American children with severe spasticity of cerebral origin. ${ }^{42}$ They concluded that CITB offers good value for money.

\section{Conclusions based on the literature overview}

Most of the above reported studies were retrospective and none of the prospective studies was randomised. Though the test treatment is an important phase ahead of definite treatment with CITB, the reports did not pay much attention to the design and results of the test treatment. Moreover, in spite of controversy about the importance of the placebo effect of intrathecal bolus injections during screening of patients with cerebral spasticity, none of the above reported test treatments was placebo-controlled. ${ }^{29,43}$ After pump implantation for CITB, muscle tone as measured with the Ashworth scale decreased significantly according to several reports. In only two studies, outcome measures beyond muscle tone were used. Prospective studies on the cost-effectiveness of CITB in children with intractable spastic CP are lacking. In conclusion, there still is a need for further high-level research in the form of prospective, randomised trials 
that use valid and reliable outcome measures. The prospective Dutch ITB study addressed these needs and included a cost-effectiveness analysis.

\section{OUTCOME MEASURES}

We selected a broad choice of outcome measures for the Dutch ITB study and used the International Classification of Functioning, Disability and Health (ICF). ${ }^{44}$ The ICF comprises a universal classification of human functioning that can be used to document functional status associated with health conditions. It provides a framework which uses unifying terminology for the classification of diseases and their effect on body structures and functioning, execution of tasks and actions (activities), and involvement in life situations (participation). Contextual factors, including environmental and personal factors, are added to represent the background of an individual's life (Figure 1.1).

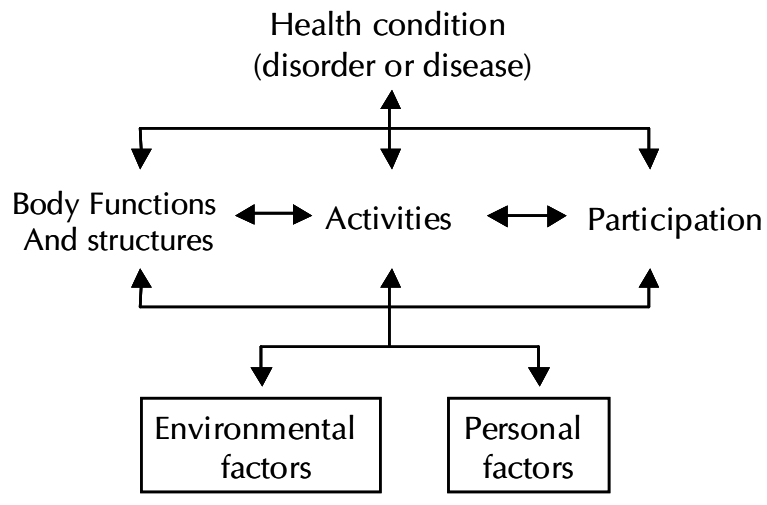

Figure 1.1 International Classification of Functioning, Disability and Health (ICF) model of Disability

ICF domain of body functions and structures

In spite of its limitations, the Ashworth scale is often used for measuring spasticity. ${ }^{45,46}$ The Ashworth scale is a score for grading muscle tone and does not exclusively quantify spasticity. It assesses muscle tone by scoring the resistance encountered in a specific muscle group by passively moving a limb at a nonspecified velocity through its range of motion. It lacks sensitivity for the detection of small changes in muscle tone, there is no consensus on the exact scoring procedure, and the test requires some cooperation of the patient, which is often limited in children or patients with cognitive deficits. ${ }^{45}$ However, the Ashworth 
scale also has its strengths. First, it quickly provides information on muscle tone and only one assessor is needed. Therefore, it can be easily measured several times a day. Second, the Ashworth scale can be used on the ward, while the patient lies in its hospital bed. ${ }^{45}$ The latter advantages are particularly of use during an ITB test treatment, when muscle tone changes within hours. Therefore, we included the Ashworth scale as an outcome measure in the Dutch ITB study. According to the definition of spasticity, the Tardieu scale would be a suitable instrument to measure spasticity. ${ }^{47}$ According to Tardieu, spasticity is assessed by passively moving a joint at three different velocities. The intensity and duration of the muscle reaction to stretch is rated on a 5-point scale together with the joint angle at which the muscle response is first felt. However, because this method is very time-consuming, its feasibility is questioned, especially for use in children. Another weakness of the Tardieu scale is that it lacks standardisation of the three different velocities. Therefore, we did not use the Tardieu scale as an outcome measure in our study.

There has so far been no objective measure that is used in daily clinical practice to evaluate the spinal cord neuronal response to ITB administration in children. From a pathophysiological point of view, both the soleus $\mathrm{H}$-reflex and the flexor reflex could be useful and sensitive objective outcome measures. The normal flexor reflex, elicited at supramaximal electrical stimulation of the tibial nerve behind the ankle, is a two component exteroceptive reflex. ${ }^{49-50}$ Both components are changed by supraspinal influences and it is the second component which is associated with the withdrawal response..$^{50}$ In patients with supratentorial lesions, the flexor reflex mostly appears as a single component response of prolonged latency and duration. ${ }^{48,50}$ Flexor spasms are the clinical counterpart of hyperactive flexor withdrawal reflexes. ${ }^{50}$ The flexor reflex threshold is often decreased in spasticity and tends to normalise with oral baclofen. ${ }^{25,51}$

The H-reflex can be used as a tool to measure the excitability of the neural components of the stretch reflex arc, bypassing the effects of gamma motoneurons and of muscle spindle discharges..$^{52-54}$ The ratio of the peak-to-peak maximal $\mathrm{H}$-amplitude to maximal $\mathrm{M}$-amplitude indicates the part of motoneurons within the pool that can be recruited reflexively and is therefore a measure of motoneuron pool excitability. ${ }^{55}$

\section{ICF domains of activities and participation}

In the ICF domains of activities and participation, we used the Pediatric Evaluation of Disability Inventory (PEDI) and the Gross Motor Function Measure (GMFM), both valid and reliable measures. ${ }^{56}$ The PEDI is a judgement-based structural interview for parents used by professionals. It has been primarily designed to measure functional status in children aged between 6 months to 7.5 years. However, it can also be used for older children whose functional status is 
less than children of 7.5 years without disabilities. ${ }^{57}$ The PEDI measures both capability (what the child can do) and performance (what the child actually does) of routine daily childhood activities. There are three content domains, including self-care, mobility and social functioning.

The GMFM is a criterion-referenced observational measure for addressing change in gross motor function for children with CP. The 88 items of the GMFM are scored on a 4-point ordinal scale and grouped into five dimensions: 1) lying and rolling, 2) sitting, 3) crawling and kneeling, 4) standing, and 5) walking, running and jumping. Five-year-old children without motor delays are usually able to accomplish all GMFM items.

\section{Measuring individual problems or goals}

Children with spastic CP all have their own spasticity associated problems and subsequent treatment goals. Because changes in these individual problems and/or goals may not be addressed by standardised outcome measures, highly individualised, subjective measures such as the visual analogue scale (VAS) or goal attainment scaling (GAS) should be used.

The VAS is a valid and reliable measure in rating pain intensity in adults and children over 6 years of age. ${ }^{58-60}$ It has also been used for measuring satisfaction, feelings, quality of sleep, dyspnoea, emotional function, and fatigue, and appeared to be responsive and valid. ${ }^{61-64}$ In a population of children with different problems, the VAS can be used for measuring the severity of the individually formulated problems. The VAS for pain is a straight 10 centimetre horizontal line with anchor points of 'no pain' (score 0) and 'unbearable pain' (score 10). ${ }^{59}$ The anchor points can be changed in 'very dissatisfied' (score 0) and 'very satisfied' (score 10) to permit the uniform use of the VAS for the defined individual problems. Depending on both the ability to understand the test and to draw a vertical line, the VAS can be rated by the child or by a caregiver. Because we considered any improvement in the children's individually formulated problems as most important, we used the VAS for individual problems as a primary outcome measure.

Goal attainment scaling (GAS) is another method to measure individual progress towards individual goals. ${ }^{65}$ These goals should be clear, relevant and realistic. GAS is originally based on an ordinal 5-point scale. A score of 0 represents the expected level of success, based on pre-established criteria. In case a patient has more progress than expected, a score of +1 or +2 is given, depending on the degree of progress. In case the expected goal is not reached, a score of -1 or -2 is given. GAS with scales of three, six or seven points are also used. GAS has the disadvantage of being time-consuming and its use requires training. The reliability of GAS in children is largely unknown. The validity of GAS is ambiguous; though its concurrent validity is low, it can exactly measure what 
needs to be measured.$^{65}$ In our study, we preferred using the VAS for individual problems and did not include GAS.

Health related quality of life measures

Health related quality of life ( $\mathrm{HRQL})$ measurement has a high priority in current $\mathrm{CP}$ research, because clinical measurements fail to reflect the well-being of the child and its family. ${ }^{66}$ Because CP specific HRQL measures were lacking, we used the Child Health Questionnaire-Parent Form 50. This is a generic child health instrument designed to measure the physical and psychosocial well-being of children aged 5 years and older. ${ }^{67}$ 


\section{THESIS OUTLINE}

The Dutch ITB study comprised four phases: 1) the selection phase, 2) the test treatment phase, 3) the pump implantation phase, and 4) the follow-up phase. Furthermore, the Dutch ITB study included two substudies. The first concerned a clinical neurophysiological study, which was embedded in the double-blind, randomised, placebo-controlled test treatment phase. We prospectively evaluated the soleus H-reflex and flexor reflex as promising objective outcome measures of CITB in the ICF domain of body structures and functions. The second substudy comprised a cost of illness study and a cost-effectiveness analysis.

Chapter 2 addresses the substudy on the utility and feasibility of the soleus H-reflex and flexor reflex in identifying spinal cord neuronal response to ITB bolus administration in children with intractable spastic CP. Chapter 3 describes the double-blind, randomised, placebo-controlled, dose-finding ITB test treatment. The aims were to: 1) select children eligible for CITB treatment, 2) assess the effective ITB bolus dose, and 3) evaluate the effects, side effects, complications, and procedures. Chapter $\mathbf{4}$ is about the prospective, randomised controlled, open-label, implantation phase. In a randomised controlled trial, we studied the 6-month efficacy of CITB in comparison with standard treatment only, in the treatment of children with problems caused by intractable spastic CP. Chapter 5 comprises the follow-up phase, in which we prospectively studied the one-year efficacy of CITB, and its safety from pump implantation up to 24 months of follow-up. Chapter 6 describes the use of an Indium ${ }^{111}$ DTPA flow study in the evaluation of a lumbar swelling in a girl with a baclofen pump. Chapter 7 concerns a cost of illness study in which we estimated and categorised the expenditures for children with intractable spastic CP. In Chapter 8 we address the cost-effectiveness of CITB in the treatment of children with intractable spastic CP. Chapter 9 is the general discussion in which we discuss the findings, as presented in this thesis. We also put forward some ideas to optimise intrathecal baclofen therapy in children with intractable spastic CP. 
The Dutch national ITB study has been conducted on behalf of the Dutch Study Group on Child Spasticity. The members of this study group are:

J.G. Becher, VU Medisch Centrum, Amsterdam

O.F. Brouwer, Universitair Medisch Centrum Groningen, Groningen

C.E. Catsman-Berrevoets, Erasmus Medisch Centrum, Rotterdam

J. Gerritsen, Isala Klinieken, Zwolle

M.J.P.M. Geerts, Revalidatiecentrum Leijpark, Tilburg

P.H. Jongerius, Sint Maartenskliniek, Nijmegen

C.G.B. Maathuis, Universitair Medisch Centrum Groningen, Groningen

O. van Nieuwenhuizen, Universitair Medisch Centrum Utrecht, Utrecht

J.J. Rotteveel, Universitair Medisch Centrum St Radboud, Nijmegen

L.A.W.M. Speth, Hoensbroeck Revalidatiecentrum, lokatie Franciscusoord, Valkenburg

H. Stroink, Sint Elisabeth Ziekenhuis, Tilburg

R.J. Vermeulen, VU Medisch Centrum, Amsterdam

J.S.H. Vles, Academisch Ziekenhuis Maastricht, Maastricht

E.G. van der Ziel, Revalidatiecentrum Het Roessingh, Enschede

The Dutch national ITB study could not have been conducted without the following referring medical specialists:

M. Feldmann, Revalidatiecentrum Het Roessingh, Enschede

J.W. Gorter, Universitair Medisch Centrum Utrecht, Utrecht

D.W. Jaeken, Hoensbroeck Revalidatiecentrum, locatie Franciscusoord,

Valkenburg

G.H.F. van der Leeuw, Franciscus Ziekenhuis, Roosendaal

R.F. Pangalila, Revalidatiecentrum Rijndam, Rotterdam

M.J. Poelma, Sint Maartenskliniek, Nijmegen

R.J. Soorani, Universitair Medisch Centrum Groningen, Groningen

J.W. Weber, Academisch Ziekenhuis Maastricht, Maastricht 


\section{REFERENCES}

1. Lance JW. The control of muscle tone, reflexes, and movement: Robert wartenberg lecture. Neurology 1980;30:1303-1313.

2. Pandyan AD, Gregoric M, Barnes MP, Wood D, Van Wijck F, Burridge J, Hermens H, Johnson GR. Spasticity: clinical perceptions, neurological realities and meaningful measurement. Disabil Rehabil 2005;27:2-6.

3. Sheean G. Spasticity rehabilitation. London: Churchill Communications Europe Ltd.; 1998.

4. Goldstein EM. Spasticity management: An overview. J Child Neurol 2001;16:16-23.

5. Bax M, Goldstein M, Rosenbaum P, Leviton A, Paneth N, Dan B, Jacobsson B, Damiano D. Proposed definition and classification of cerebral palsy, april 2005. Dev Med Child Neurol 2005;47:571-576.

6. de Louw AJ, de Vente J, Steinbusch HP, Gavilanes AW, Steinbusch HW, Blanco CE, Troost J, Vles JSH. Apoptosis in the rat spinal cord during postnatal development; the effect of perinatal asphyxia on programmed cell death. Neuroscience 2002;112:751-758.

7. Groenendaal F, Vles JSH, Lammers H, De Vente J, Smit D, Nikkels PG. Nitrotyrosine in human neonatal spinal cord after perinatal asphyxia. Neonatology 2007;93:1-6.

8. Surveillance of cerebral palsy in Europe: a collaboration of cerebral palsy surveys and registers. Surveillance of Cerebral Palsy in Europe (SCPE). Dev Med Child Neurol 2000; 42:816-824.

9. Koman LA, Smith BP, Shilt JS. Cerebral palsy. Lancet 2004;363:1619-1631.

10. Stanley F, Blair E, Alberman E. How common are the cerebral palsies? In: Bax MCO, ed. Cerebral palsies: Epidemiology and causal pathways. London: Mac Keith Press; 2000:22-39.

11. Wichers MJ, van der Schouw YT, Moons KG, Stam HJ, van Nieuwenhuizen O. Prevalence of cerebral palsy in the netherlands (1977-1988). Eur J Epidemiol 2001;17:527-532.

12. Surman G, Bonellie S, Chalmers J, Colver A, Dolk H, Hemming K, King A, Kurinczuk JJ, Parkes J, Platt MJ. UKCP: a collaborative network of cerebral palsy registers in the United Kingdom. J Public Health (Oxf) 2006;28:148-156.

13. Tilton AH. Management of spasticity in children with cerebral palsy. Semin Pediatr Neurol 2004; 11:58-65.

14. Goldstein M. The treatment of cerebral palsy: what we know, what we don't know. J Pediatr 2004;145:S42-46.

15. Lannin N, Scheinberg A, Clark K. AACPDM systematic review of the effectiveness of therapy for children with cerebral palsy after botulinum toxin a injections. Dev Med Child Neurol 2006; 48:533-539.

16. Sindou MP, Simon F, Mertens P, Decq P. Selective peripheral neurotomy (SPN) for spasticity in childhood. Childs Nerv Syst 2007;23:957-970.

17. McLaughlin J, Bjornson K, Temkin N, Steinbok P, Wright V, Reiner A, Roberts T, Drake J, O'Donnell M, Rosenbaum P, Barber J, Ferrel A. Selective dorsal rhizotomy: meta-analysis of three randomized controlled trials. Dev Med Child Neurol 2002;44:17-25.

18. Steinbok P. Selective dorsal rhizotomy for spastic cerebral palsy: a review. Childs Nerv Syst 2007;23:981-990.

19. Steinbok P. Selection of treatment modalities in children with spastic cerebral palsy. Neurosurg Focus 2006;21:e4.

20. de Louw AJ, Vles JSH, Freling G, Herpers MJ, Arends JW, Kleef M. The morphological effects of a radio frequency lesion adjacent to the dorsal root ganglion (RF-DRG)-an experimental study in the goat. Eur J Pain 2001;5:169-174.

21. Montane E, Vallano A, Laporte JR. Oral antispastic drugs in nonprogressive neurologic diseases: a systematic review. Neurology 2004;63:1357-1363.

22. Sheean G. The pathophysiology of spasticity. Eur J Neurol 2002;9 Suppl 1:3-9; dicussion 53-61.

23. Malcangio M, Bowery NG. Gaba and its receptors in the spinal cord. Trends Pharmacol Sci 1996;17:457-462.

24. Slonimski M, Abram SE, Zuniga RE. Intrathecal baclofen in pain management. Reg Anesth Pain Med 2004;29:269-276. 
25. Shahani BT, Young RR. Human flexor spasms. In: Desmedt JE, ed. New developments in electromyography and clinical neurophysiology. Basel: Karger; 1973:734-743.

26. de Louw AJ, de Vente J, Steinbusch HP, Steinbusch HW, Troost J, Vles JSH. Baclofen inhibits anp-mediated cyclic gmp synthesis in the rat cervical spinal cord. Neurosci Lett 2002;321:120122.

27. Vargus-Adams J. Longitudinal use of the Child Health Questionnaire in childhood cerebral palsy. Dev Med Child Neurol 2006;48:343-347.

28. Liptak GS, O'Donnell M, Conaway M, Chumlea WC, Wolrey G, Henderson RC, Fung E, Stallings VA, Samson-Fang L, Calvert R, Rosenbaum P, Stevenson RD. Health status of children with moderate to severe cerebral palsy. Dev Med Child Neurol 2001;43:364-370.

29. Gilmartin R, Bruce D, Storrs BB, Abbott R, Krach L, Ward J, Bloom K, Brooks WH, Johnson DL, Madsen JR, McLaughlin JF, Nadell J. Intrathecal baclofen for management of spastic cerebral palsy: Multicenter trial. J Child Neurol 2000;15:71-77.

30. Albright AL, Gilmartin R, Swift D, Krach LE, Ivanhoe CB, McLaughlin JF. Long-term intrathecal baclofen therapy for severe spasticity of cerebral origin. J Neurosurg 2003;98:291-295.

31. Campbell WM, Ferrel A, McLaughlin JF, Grant GA, Loeser JD, Graubert C, Bjornson K. Longterm safety and efficacy of continuous intrathecal baclofen. Dev Med Child Neurol 2002;44: 660-665.

32. Kroin JS. Intrathecal drug administration. Present use and future trends. Clin Pharmacokinet 1992;22:319-326.

33. Penn RD, Kroin JS. Continuous intrathecal baclofen for severe spasticity. Lancet 1985;2: 125-127.

34. Dralle D, Muller H, Zierski J, Klug N. Intrathecal baclofen for spasticity. Lancet 1985;2:1003.

35. Butler C, Campbell S. Evidence of the effects of intrathecal baclofen for spastic and dystonic cerebral palsy. AACPDM Treatment Outcomes Committee Review Panel. Dev Med Child Neurol 2000;42:634-645.

36. Murphy NA, Irwin MC, Hoff C. Intrathecal baclofen therapy in children with cerebral palsy: Efficacy and complications. Arch Phys Med Rehabil 2002;83:1721-1725.

37. Awaad Y, Tayem H, Munoz S, Ham S, Michon AM, Awaad R. Functional assessment following intrathecal baclofen therapy in children with spastic cerebral palsy. J Child Neurol 2003;18: 26-34.

38. Albright AL, Awaad Y, Muhonen M, Boydston WR, Gilmartin R, Krach LE, Turner M, Zidek KA, Wright E, Swift D, Bloom K. Performance and complications associated with the synchromed 10-ml infusion pump for intrathecal baclofen administration in children. J Neurosurg 2004; 101:64-68.

39. Vloeberghs $M$, Keetley R, Morton R. Intrathecal baclofen in the management of spasticity due to cerebral palsy. Pediatr Rehabil 2005;8:172-179.

40. Vender JR, Hester S, Waller JL, Rekito A, Lee MR. Identification and management of intrathecal baclofen pump complications: a comparison of pediatric and adult patients. J Neurosurg 2006;104:9-15.

41. Motta F, Buonaguro V, Stignani C. The use of intrathecal baclofen pump implants in children and adolescents: safety and complications in 200 consecutive cases. J Neurosurg 2007;107: 32-35.

42. de Lissovoy G, Matza LS, Green H, Werner M, Edgar T. Cost-effectiveness of intrathecal baclofen therapy for the treatment of severe spasticity associated with cerebral palsy. J Child Neurol 2007;22:49-59.

43. Van Schaeybroeck P, Nuttin B, Lagae L, Schrijvers E, Borghgraef C, Feys P. Intrathecal baclofen for intractable cerebral spasticity: a prospective placebo-controlled, double-blind study. Neurosurgery 2000;46:603-609; discussion 609-612.

44. International Classification of Functioning, Disability and Health, World Health Organization, Geneva, 2002.

45. Damiano DL, Quinlivan JM, Owen BF, Payne P, Nelson KC, Abel MF. What does the Ashworth scale really measure and are instrumented measures more valid and precise? Dev Med Child Neurol 2002;44:112-118. 
46. Ashworth B. Preliminary trial of carisoprodol in multiple sclerosis. Practitioner 1964;192: 540-542.

47. Tardieu G, Shentoub S, Delarue R. Research on a technic for measurement of spasticity. Rev Neurol (Paris) 1954;91:143-144.

48. Fisher MA, Shahani BT, Young RR. Electrophysiologic analysis of the motor system after stroke: the flexor reflex. Arch Phys Med Rehabil 1979;60:7-11.

49. Hallett M, Berardelli A, Delwaide P, Freund HJ, Kimura J, Lücking C, Rothwell JC, Shahani BT, Yanagisawa N. Central EMG and tests of motor control. Report of an IFCN committee. Electroencephalogr Clin Neurophysiol 1994;90:404-432.

50. Shahani BT, Young RR. Human flexor reflexes. J Neurol Neurosurg Psychiatry 1971;34:616-627.

51. Milanov IG. Flexor reflex for assessment of common interneurone activity in spasticity. Electromyogr Clin Neurophysiol 1992;32:621-629.

52. Misiaszek JE. The H-reflex as a tool in neurophysiology: its limitations and uses in understanding nervous system function. Muscle Nerve 2003;28:144-160.

53. Schieppati $M$. The Hoffmann reflex: a means of assessing spinal reflex excitability and its descending control in man. Prog Neurobiol 1987;28:345-376.

54. Zehr PE. Considerations for use of the Hoffmann reflex in exercise studies. Eur J Appl Physiol 2002;86:455-468.

55. Fisher MA. $\mathrm{H}$ reflexes and $\mathrm{f}$ waves. Fundamentals, normal and abnormal patterns. Neurol Clin. 2002;20:339-360.

56. Ketelaar M, Vermeer A, Helders PJ. Functional motor abilities of children with cerebral palsy: a systematic literature review of assessment measures. Clin Rehabil 1998;12:369-380.

57. Custers JW, Wassenberg-Severijnen JE, Van der Net J, Vermeer A, Hart HT, Helders PJ. Dutch adaptation and content validity of the 'Pediatric Evaluation Of Disability Inventory (PEDI)'. Disabil Rehabil 2002;24:250-258.

58. Chapman CR, Casey KL, Dubner R, Foley KM, Gracely RH, Reading AE. Pain measurement: an overview. Pain 1985;22:1-31.

59. Wallenstein SL, Heidrich G, 3rd, Kaiko R, Houde RW. Clinical evaluation of mild analgesics: the measurement of clinical pain. Br J Clin Pharmacol 1980;10 Suppl 2:319S-327S.

60. Tyler DC, Tu A, Douthit J, Chapman CR. Toward validation of pain measurement tools for children: a pilot study. Pain 1993;52:301-309.

61. Guyatt G, Townsend M, Berman B, Keller JL. A comparison of likert and visual analogue scales for measuring change in function. J Chronic Dis 1987;40:1129-1133.

62. Aitken RC. Measurement of feelings using visual analogue scales. Proc R Soc Med 1969;62: 989-993.

63. Jaeschke R, Singer J, Guyatt G. A comparison of seven-point and visual analogue scales. Control Clin Trials 1990;11:43-51

64. Singer AJ, Thode HC. Determination of the minimal clinically significant difference on a patient visual analog satisfaction scale. Acad Emerg Med 1998;5:1007-1011.

65. Steenbeek D, Ketelaar M, Galama K, Gorter JW. Goal attainment scaling in paediatric rehabilitation: a critical review of the literature. Dev Med Child Neurol 2007;49:550-556.

66. Bjornson KF, McLaughlin JF. The measurement of health-related quality of life (HRQL) in children with cerebral palsy. Eur J Neurol 2001;8 Suppl 5:183-193.

67. Landgraf JM, Abetz L, Ware JE. The CHQ user's manual. Boston: The Health Institute, New England Medical Center, 1996. 



\section{CHAPTER 2}

Placebo controlled utility and feasibility study of the H-reflex and flexor reflex in spastic children treated with intrathecal baclofen

MA Hoving, VHJM van Kranen-Mastenbroek, EPM van Raak, GHJJ Spincemaille, ELM Hardy, JSH Vles, on behalf of the Dutch Study Group on Child Spasticity Clin Neurophysiol 2006;117:1508-1517 


\section{ABSTRACT}

\section{Objective}

To evaluate feasibility and utility of the soleus $\mathrm{H}$-reflex and tibialis anterior flexor reflex in identifying spinal cord neuronal response to intrathecal baclofen in children with severe spastic cerebral palsy.

\section{Methods}

During a randomised, double-blind, placebo-controlled dose-escalation test treatment, maximum $\mathrm{H}$-amplitude/maximum $\mathrm{M}$-amplitude ( $\mathrm{H} / \mathrm{M}$ ratio) and flexor reflex parameters were bilaterally recorded at baseline and 2 to 3 hours after intrathecal bolus administration of placebo and increasing doses of baclofen until both an improvement in the individual treatment goal(s) and a one-point reduction on the Ashworth scale were observed.

\section{Results}

Electrophysiological data of 14 children were studied. The H-reflex was feasible in 13 children, the flexor reflex threshold area in nine and the flexor reflex, elicited with supramaximal stimulation, in only one child. After intrathecal baclofen the $H / M$ ratio significantly decreased (left: $0.67 \pm 0.47$ to $0.15 \pm 0.18, p=0.005$; right: $0.55 \pm 0.32$ to $0.14 \pm 0.19, p=0.002$ ) without placebo effect. Flexor reflex threshold area after intrathecal baclofen, only decreased significantly in children not taking oral baclofen (left: $146 \pm 53 \mathrm{mVms}$ to $41 \pm 54 \mathrm{mVms}, p=0.000$; right: $156 \pm 80 \mathrm{mVms}$ to $66 \pm 48 \mathrm{mVms}$, $p=0.002$ ).

\section{Conclusions}

This is the first randomised, double-blind, placebo-controlled dose-escalation study in spastic children demonstrating the soleus $\mathrm{H}$-reflex to be a feasible and objective measure to quantify the decreasing motoneuron excitability in response to intrathecal baclofen bolus administration. Only in children not taking oral baclofen, flexor reflex threshold area can also be used as an objective outcome measure, yet feasibility is limited.

\section{Significance}

We suggest introducing the H-reflex as the electrophysiological gold standard for the evaluation of the effect of intrathecal baclofen in spastic children. 


\section{INTRODUCTION}

Cerebral palsy (CP) is the most common cause of severe physical disability in childhood. ${ }^{1}$ It is a term for a heterogeneous collection of clinical syndromes that are characterised by abnormal motor actions and postural mechanisms, and that are due to non-progressive abnormalities of the developing brain. ${ }^{2}$ Two thirds of the individuals with CP suffer from mild to severe spasticity. ${ }^{1}$ Spasticity is a motor disorder characterised by a velocity-dependent increase in tonic stretch reflexes with exaggerated tendon jerks, resulting from hyperexcitability of the stretch reflex. $^{3}$ An effective treatment option for otherwise untreatable spasticity is the continuous delivery of intrathecal baclofen (ITB). ${ }^{4-6}$

In daily clinical practice, there has been no objective outcome measure yet to evaluate the effect of ITB in spastic children. In spite of its clear limitations, the standard clinical scale for measuring spasticity is the Ashworth scale., The Ashworth scale is a score for grading muscle tone and does not exclusively quantify spasticity. It lacks sensitivity for the detection of small changes in muscle tone, there is no consensus on the exact scoring procedure and the test requires some cooperation of the patient, which is often limited in children or patients with cognitive deficits. ${ }^{7}$ The Ashworth scale should therefore not be used as the gold standard for measuring spasticity. ${ }^{9}$

From a pathophysiological point of view, both the soleus H-reflex and the flexor reflex (FR) could be useful and sensitive objective outcome measures for the spinal cord neuronal response to ITB administration. Baclofen is a selective agonist for gamma-aminobutyric acid (GABA)-B receptors. ${ }^{10}$ As baclofen influences both monosynaptic and polysynaptic reflexes, both the H-reflex and the FR have been previously considered as suitable, objective outcome measures in the evaluation of ITB treatment. ${ }^{11-13}$

The normal FR, elicited at supramaximal electrical stimulation of the tibial nerve behind the ankle, is a two-component exteroceptive reflex. ${ }^{14-16}$ Both components are changed by supraspinal influences and it is the second component, which is associated with the withdrawal response. ${ }^{16}$ In patients with supratentorial lesions, the FR mostly appears as a single component response of prolonged latency and duration. ${ }^{14,16}$ Flexor spasms are the clinical counterpart of hyperactive flexor withdrawal reflexes. ${ }^{16}$ The FR threshold is often decreased in spasticity and tends to normalise with oral baclofen. ${ }^{17,18}$

The H-reflex can be used as a tool to measure the excitability of the neural components of the stretch reflex arc, bypassing the effects of gamma motoneurons and of muscle spindle discharges. ${ }^{19-21}$ The ratio of the peak-to-peak maximal $H$-amplitude to maximal $M$-amplitude $(H / M)$ indicates the part of motoneurons within the pool that can be recruited reflexively and is therefore, a measure of motoneuron pool excitability. ${ }^{22}$ Since the 1960 s, the $H / M$ ratio has been considered as an index for spasticity, as it is increased in the majority of 
patients with spasticity. ${ }^{23-29}$ Nevertheless, the H-reflex has never been introduced in daily clinical practice. One explanation for this could be the large range of variation of the $H / M$ ratio in spastic and healthy people, limiting the diagnostic value of the $H / M$ ratio. ${ }^{23,29}$ A second reason could be the lack of strong correlation between the $\mathrm{H} / \mathrm{M}$ ratio and clinical assessment scales of muscle tone, such as the Ashworth scale. ${ }^{13,27-30}$ However, we would like to refute these argumentations. First, we believe the $H / M$ ratio can still be useful for evaluating changes in motoneuron excitability in response to ITB administration in single patients, as the reproducibility of the $H / M$ ratio is good. ${ }^{27,31,32}$ Secondly, it is not very useful to compare the H-reflex with the Ashworth scale, as the latter is no valid test for measuring spasticity.

This is the first report on a randomised, double-blind, placebo-controlled doseescalation study evaluating the utility and feasibility of the H-reflex and FR as objective outcome measures of the effect of ITB bolus administration in a relatively large group of severely spastic children with $\mathrm{CP}$.

\section{METHODS}

\section{Patients}

Children aged between 4 and 16 years, with a spastic diplegia or tetraplegia as part of $\mathrm{CP}$, who insufficiently responded to oral spasticity reducing medications, were included. Magnetic resonance imaging of the brain was mandatory to rule out progressive causes of spasticity. Exclusion criteria were hypersensitivity to baclofen, contraindications for general anaesthesia, intractable epileptic seizures, an infection of the lumbar skin and a systemic infection. Eligible children from all parts of the Netherlands were referred to the University Hospital of Maastricht.

\section{General study design}

The study was designed as a randomised, double-blind, placebo-controlled doseescalation test treatment during which the effects of intrathecal bolus injections with increasing doses of baclofen versus placebo were studied. All study phases, including the selection of referred children and hospitalisation, took place at the University Hospital of Maastricht. After admission, the neurosurgeon inserted an external lumbar catheter under general anaesthesia. The next morning, the first bolus with study medication was administered intrathecally via the catheter. The test regimen was as follows: the first two test days the bolus randomly contained ITB $25 \mu \mathrm{g}$ or placebo. The following six test days the bolus contained ITB $50 \mu \mathrm{g}$ or placebo, then ITB $75 \mu \mathrm{g}$ or placebo and finally ITB $100 \mu \mathrm{g}$ or placebo. For every patient, an individual randomisation list was used. Randomisation lists 
were generated by an independent statistician, allowing for a balanced distribution of sequences within the same child as well as between the children. Randomisation lists were given to the pharmacist, who prepared the study medication every day according to the child's individual randomisation list. The numbered study medication was then delivered to the investigator, who intrathecally administered it to the child. This means that, except for the pharmacist, all involved people were blinded to the contents of the study medication bolus.

To evaluate the effects of bolus administration, individual goals of treatment were formulated in close consultation with the child and/or its caregivers in case the child was not able to give an opinion. These individual goals were closely monitored throughout the test days. To quantify muscle tone, the Ashworth scale was used (Table 2.1). At baseline, Ashworth scores were bilaterally measured in seven lower extremity muscle groups (hip flexors, hip extensors, hip adductors, knee flexors, knee extensors, ankle dorsiflexors and ankle plantar flexors). The hip, knee and ankle related muscle groups with the highest tone were then selected from these 14 baseline Ashworth scores. This selection was done for the left as well as for the right legs in total identifying six muscle groups with a relatively high tone per child. For every child, the Ashworth score was measured by the same physical therapist each test day before bolus administration and 2, 4 and 6 hours after the bolus was administered.

Table 2.1 Original Ashworth Scale ${ }^{8}$

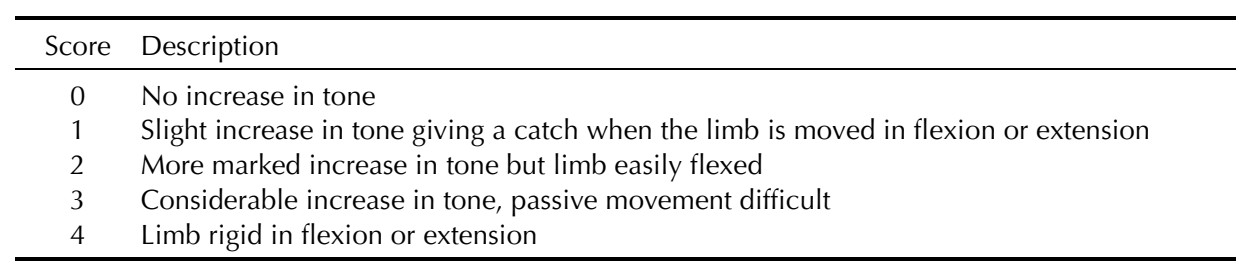

A positive clinical effect was achieved if the following two criteria were both met: 1) a satisfying improvement in the individual treatment goals as experienced by the child and/or observed by its caregivers, and 2) a minimal reduction of one point on the Ashworth scale in at least three of the six individually selected muscle groups. Furthermore, this one-point reduction had to last during two successive measurements after study medication bolus administration. On the day that a positive clinical response was observed, the test treatment was ended and the code was broken. Only if this positive clinical response was observed at the first test day, the child and/or parents were given the opportunity to experience the results of the second test day before the test treatment was ended. 
If the child had responded to ITB, it was considered eligible for further treatment with continuous delivery of ITB. If after eight test days still no positive clinical effect had occurred, the child was not eligible for pump implantation.

\section{Electrophysiological studies}

The H-reflex and FR recordings were carried out in each child at different moments during the study. Baseline recordings were carried out at the clinical neurophysiology department before the start of the test treatment. At that time, the children did not have a spinal catheter in situ yet. During the test treatment, the electrophysiological procedures were carried out at the children's ward. For every child, single recordings on the different test days took place at the same time interval after study medication bolus administration, which was on average 150 min (range between children was 120-180 min). All children were awake during the recordings and were examined in supine position.

The H-reflex was elicited by percutaneous stimulation of the posterior tibial nerve using handheld bipolar stimulation electrodes placed in the popliteal fossa. Stimulation was applied with $1 \mathrm{~ms}$ square wave pulses at a rate of $0.3 \mathrm{~Hz}$. The reflex was recorded with bipolar surface bar recording electrodes with a $3 \mathrm{~cm}$ interelectrode distance. These electrodes were placed on the soleus muscle in the furrow between the heads of the gastrocnemii. The position of the recording electrodes was marked with indelible ink to facilitate equal electrode placement on the following test days. Maximum soleus H-reflex $\left(H_{\max }\right)$ and maximum soleus motor response $\left(M_{\max }\right)$ recruitment curves were obtained in 20 trails. $H_{\max }$ and $M_{\max }$ were defined as peak-to-peak maximal amplitudes of the $H$ and $M$ responses, respectively. $H_{\max } M_{\max }$ and the $H / M$ ratio were determined, the latter defined as the ratio between $H_{\max }$ and $M_{\max }$.

The FR was evoked by electrical stimulation of the tibial nerve behind the medial malleolus. Stimulation consisted of trains of five $1 \mathrm{~ms}$ square wave pulses at 300 $\mathrm{Hz} .{ }^{33}$ The interval between stimulus trains was kept at $60 \mathrm{~s}$ to allow time for full recovery from the central excitability changes produced by the previous stimulus. ${ }^{15}$ Electromyographic (EMG) activity was recorded from the tibialis anterior muscle by placing two silver/silver chloride disk electrodes. The active electrode was placed on the belly of the tibialis anterior muscle, four fingers below the tibial tuberosity. The reference electrode was placed about $5 \mathrm{~cm}$ lower on the tibia. FR were recorded in a $1000 \mathrm{~ms}$ window amplified with a band pass of 30-3000 Hz. First, the FR threshold defined as the lowest intensity to elicit a reproducible $F R$, was registered in milliamperes $(\mathrm{mA})$. The stimulus intensity was then increased by $2.5 \mathrm{~mA}$ steps. With each stimulus intensity, one trial was recorded until the first FR was evoked. If an FR occurred, a second trial with the same stimulus intensity was performed to confirm reproducibility. Secondly, the concordant area of the FR was calculated by integrating the EMG activity of the 
response over the $1000 \mathrm{~ms}$ window, expressed in mVms. If a two-component FR would appear, the EMG activity of both components would be integrated to measure the FR area. The amplitude of the stimulus was then gradually increased to produce supramaximal stimulation (25\% more than the amplitude of the stimulus required to produce the FR with minimal latency). The area of the supramaximal response was measured as described above.

\section{Outcome measures}

If the children tolerated the tests at both legs at all different test moments, we considered the H-reflex and FR measurements feasible. The electrophysiological outcome measures included the values of $H_{\max }, H / M$ ratio, FR threshold, FR threshold area and the FR stimulus intensity and FR area of the response elicited with supramaximal stimulation.

\section{Statistical analysis}

SPSS for Windows statistical package, Release 11.0.1., was used for the statistical analyses. Baseline comparisons and comparisons between the children with and without oral baclofen were done using the non-parametric Mann-Whitney $U$ test. Paired-samples $t$ tests and non-parametric tests (Wilcoxon Signed Rank Test and Sign Test) were performed to compare the mean H-reflex and FR measurements at baseline, after administration of placebo and after administration of baclofen in all children. Three groups of separate analyses were performed: for both legs together, for the left legs separately and for the right legs separately. Results with $p$-values below or equal to 0.05 were considered statistically significant. Correction for multiple comparisons was done using the Hochberg procedure. ${ }^{34}$ According to both the $t$ tests and the non-parametric tests, the same comparisons were statistically significant. We chose to describe the results of the Pairedsamples $t$ tests, as the non-parametric tests only provided $p$-values.

\section{Ethical aspects}

The study was approved by the local medical ethical committee. The nature of the procedures was fully explained to the children and their parents. According to local legislation, written informed consent was obtained from the parents and also from the children themselves, if they were aged 12 years or older and capable of understanding the nature of the procedures. In case a child offered resistance or showed inconvenience during the recordings, we immediately stopped further testing without any consequences for the participation of the child in the study or its medical treatment in general. Children who were able to communicate were asked to alert the investigator in case of any discomfort or the wish to terminate the recordings. We relied on the parents' opinion in case a 
child was not able to communicate, as they recognised best the condition of their child.

\section{RESULTS}

\section{Patients}

Sixteen children, eight boys and eight girls, aged between 7 and 16 years (mean $13.06 \pm 2.82$ ), were included. All children suffered from intractable spasticity due to CP. According to the Gross Motor Function Classification System (GMFCS, Table 2.2), one child was classified in group III, two in group IV and thirteen in group V. ${ }^{35,36}$ The children classified in GMFCS group III and IV had a spastic diplegia and the children classified in GMFCS group $V$ had a spastic tetraplegia. Consistent with the clinical pictures of a spastic diplegia and tetraplegia, spasticity as assessed during neurological examination was about equal in both legs in the majority of children. As we often could not determine which side was more involved, analyses were performed for both the left legs and the right legs separately. The mean baseline Ashworth scores for the individually selected hip, knee and ankle related muscle groups with highest tone were at the left legs, respectively, $2.50 \pm 0.52,2.44 \pm 1.15$ and $2.63 \pm 0.89$. For the right legs these values were, respectively, $2.19 \pm 0.91,2.38 \pm 1.03$ and $2.31 \pm 0.95$. Seven children were taking oral baclofen (mean dose $1.10 \pm 0.31 \mathrm{mg} / \mathrm{kg}$ ) and they continued this during the study. Comparison of children with $(n=7)$ and without $(\mathrm{n}=9)$ the taking of oral baclofen showed no difference in baseline Ashworth scores, baseline $H_{\max } H / M$ ratio or FR threshold. However, baseline FR threshold area was significantly lower in the children taking oral baclofen (left legs of children with oral baclofen $51 \pm 27 \mathrm{mVms}$ and without oral baclofen $136 \pm 63$ $\mathrm{mVms}, p=0.019$; right legs of children with oral baclofen $70 \pm 58 \mathrm{mVms}$ and without oral baclofen $149 \pm 78 \mathrm{mVms}, p=0.052$ ).

\section{Clinical effects}

All children showed a positive clinical effect in response to intrathecal bolus administration of baclofen at some day during the test treatment and subsequently received a pump for the continuous delivery of ITB. The effective ITB dose was $12.5 \mu \mathrm{g}$ in one child, $25 \mu \mathrm{g}$ in 10 and $50 \mu \mathrm{g}$ in five children. For the child who already responded to ITB $12.5 \mu \mathrm{g}$, we deviated from the protocol by starting with this lower dose, as this child was known to easily experience side effects in response to different oral medications. The children who required ITB $50 \mu \mathrm{g}$ to experience a positive clinical response were significantly older $(p=0.033)$ and weighed more $(p=0.007)$ than the children who positively 
responded to ITB $12.5 \mu \mathrm{g}$ or ITB $25 \mu \mathrm{g}$. No significant difference was found for baseline GMFCS, $H_{\max }, H / M$ ratio or FR values. The test treatment included at least one placebo day for 14 children. Two children received ITB at their first test day and showed a clear positive clinical response at once. We did not include the electrophysiological data of these two children in the analyses, even though the recordings of the $\mathrm{H}$-reflex were feasible in both children and the recordings of the FR threshold in one child.

Table 2.2 Gross Motor Function Classification System (GMFCS) levels at ages 6 to 12 years

\begin{tabular}{cl}
\hline Level & Description \\
\hline I & Walks without restrictions; limitations in more advanced gross motor skills \\
II & Walks without assistive devices; limitations walking outdoors and in the community \\
III & Walks with assistive mobility devices; limitations walking outdoors and in the community \\
IV & Self mobility with limitations; children are transported or use power mobility outdoors \\
& $\begin{array}{l}\text { and in the community } \\
\text { V }\end{array}$
\end{tabular}

\section{H-reflex}

Feasibility of the H-reflex was $93 \%$ as 13 of the 14 children tolerated the evocation of the H-reflex in both legs during baseline measurements and during all test days. One child (effective ITB dose $50 \mu \mathrm{g}$ ) did not tolerate the electrophysiological measurements at all and was therefore excluded from this part of the study. Table 2.3 shows the results of the $H / M$ ratio measurements at baseline, after intrathecal administration of placebo and after intrathecal administration of the effective baclofen dose. Retrospectively, the baseline $M$-response in the left leg of one child proved to be unreliable, probably as the result of malpositioning of the electrodes. When we included this very low $M$-value, it would distort the calculations to such an extent that we decided to leave the particular leg out of account in the analyses of the H-reflex. Comparison of the results in children who did $(n=5)$ and did not take oral baclofen $(\mathrm{n}=8)$ showed no significant differences between $H_{\max }, M_{\max }$ or $H / M$ ratio at baseline, after placebo or after ITB. Therefore, the results of the H-reflex analyses include all children, irrespective of the taking of oral baclofen.

After the administration of placebo, $H_{\max }$ did not change significantly from baseline for both legs (left legs: $3.4 \pm 2.3 \mathrm{mV}$ at baseline and $3.4 \pm 2.2 \mathrm{mV}$ after placebo; right legs: $3.4 \pm 1.6 \mathrm{mV}$ at baseline and $3.4 \pm 2.1 \mathrm{mV}$ after placebo). The respective $M$-waves were also similar (left legs: $6.4 \pm 4.5 \mathrm{mV}$ at baseline and $6.9 \pm 4.2 \mathrm{mV}$ after placebo; right legs: $7.8 \pm 4.1 \mathrm{mV}$ at baseline and $7.7 \pm 3.9 \mathrm{mV}$ after placebo). Consequently, $\mathrm{H} / \mathrm{M}$ ratios were also similar (Table 2.3, Figure 
2.1A). In relative terms, $H / M$ ratios after placebo on the left and right legs measured on average $121 \%$ and $109 \%$ of the respective baseline values.

Table 2.3 Mean H/M ratio values with standard deviations at baseline and after administration of placebo and the effective baclofen dose

\begin{tabular}{lccccrrrc}
\hline Legs & $\mathrm{n}$ & $\begin{array}{c}\text { Baseline } \\
\text { mean } H / M\end{array}$ & $\begin{array}{c}\text { Placebo } \\
\text { mean } H / M\end{array}$ & $\begin{array}{c}\text { Baclofen } \\
\text { mean } H / M\end{array}$ & $\begin{array}{r}\text { Difference in } \\
\text { mean } H / M\end{array}$ & $95 \% \mathrm{Cl}$ & $p$ & $\begin{array}{c}\text { Corrected } \\
p\end{array}$ \\
\hline All & 25 & $0.61 \pm 0.40$ & $0.71 \pm 0.70$ & & $-0.10 \pm 0.47$ & $-0.29-0.09$ & 0.292 & 0.614 \\
& 25 & $0.61 \pm 0.40$ & & $0.14 \pm 0.18$ & $0.46 \pm 0.44$ & $0.28-0.65$ & 0.000 & 0.000 \\
Left & 12 & $0.67 \pm 0.47$ & $0.85 \pm 0.90$ & & $-0.17 \pm 0.56$ & $-0.53-0.18$ & 0.307 & 0.614 \\
& 12 & $0.67 \pm 0.47$ & & $0.15 \pm 0.18$ & $0.53 \pm 0.52$ & $0.20-0.86$ & 0.005 & 0.020 \\
Right & 13 & $0.55 \pm 0.32$ & $0.58 \pm 0.46$ & & $-0.03 \pm 0.37$ & $-0.26-0.19$ & 0.751 & 0.751 \\
& 13 & $0.55 \pm 0.32$ & & $0.14 \pm 0.19$ & $0.40 \pm 0.37$ & $0.18-0.63$ & 0.002 & 0.010 \\
\hline
\end{tabular}

Differences between the $H / M$ ratios are shown with the $95 \%$ confidence intervals $(\mathrm{Cl})$ and corresponding $p$-values

After the administration of ITB, $H_{\max }$ decreased significantly for both legs in comparison with baseline (left legs: $3.4 \pm 2.3 \mathrm{mV}$ at baseline and $0.9 \pm 1.2 \mathrm{mV}$ after ITB, $p=0.007$; right legs: $3.4 \pm 1.6 \mathrm{mV}$ at baseline and $0.6 \pm 0.7 \mathrm{mV}$ after ITB, $p=0.000$ ). The respective $M$-waves were similar to baseline (left legs: $6.4 \pm 4.5 \mathrm{mV}$ at baseline and $6.9 \pm 4.1 \mathrm{mV}$ after ITB; right legs: $7.8 \pm 4.1 \mathrm{mV}$ at baseline and $6.7 \pm 3.2 \mathrm{mV}$ after ITB). Consequently, after ITB the $H / M$ ratios significantly decreased for both legs (Table 2.3, Figure 2.1B). In relative terms, $H / M$ ratios after ITB on the left and right legs measured on average $25 \%$ and $33 \%$ of the respective baseline values. In $75 \%$ and $77 \%$ respectively, baseline $H / M$ ratio was reduced by at least half.
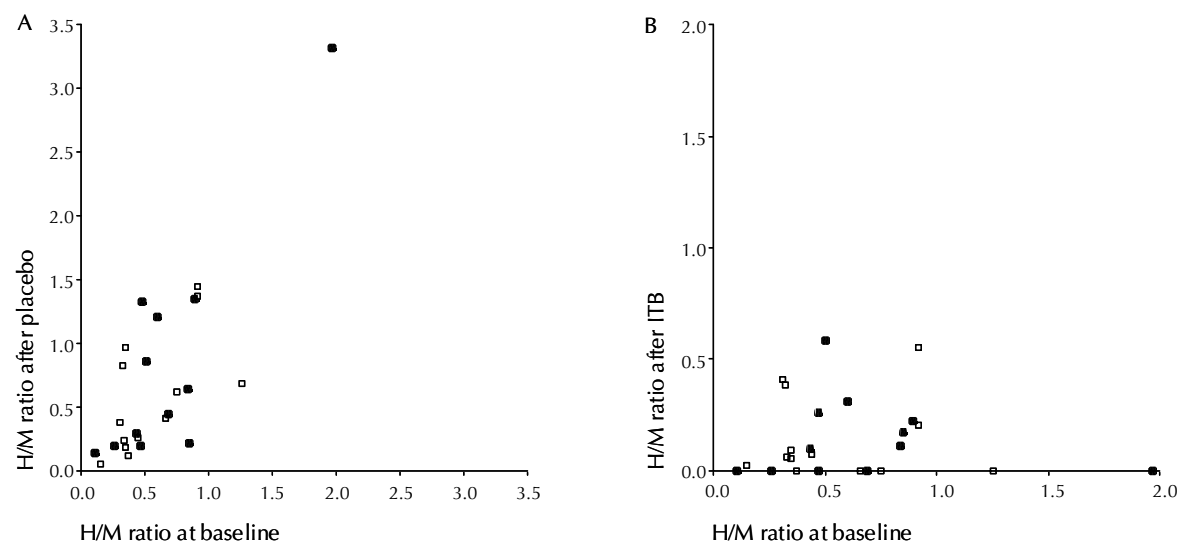

Figure 2.1 A H/M ratios at baseline and after administration of placebo (•left legs, $\square$ right legs) B H/M ratios at baseline and after bolus administration of the effective ITB dose $(\bullet$ left legs, $\square$ right legs). Note that most $\mathrm{H} / \mathrm{M}$ ratios substantially decreased with ITB 


\section{Flexor reflex}

Feasibility of the FR threshold and concordant FR threshold area was $64 \%$, as nine of the 14 children tolerated the evocation of the FR in both legs during baseline measurements and during all test days. In one of these children, the baseline recordings of the right leg were missing due to a filing error. Another child did not tolerate bilateral FR recordings every time, but all recordings in her right leg were accomplished. Thus, the results of 18 legs from 10 children are presented. Table 2.4 shows the results of the FR threshold and FR threshold area at baseline, after intrathecal administration of placebo and after intrathecal administration of the effective baclofen dose. Children taking oral baclofen $(n=3)$ had significantly lower FR threshold area values at these three test moments compared to children not taking oral baclofen $(n=7)$. Therefore, FR threshold area analyses were performed for both groups separately (Tables 2.4B and 2.4C). Unlike the FR threshold area, the FR threshold values did not show significant differences between the children who took oral baclofen and those who did not. Therefore, the results of the FR threshold analyses include all children, irrespective of the taking of oral baclofen (Table 2.4A).

After the administration of placebo, neither the FR threshold (Table 2.4A) nor the FR threshold area (Tables $2.4 \mathrm{~B}$ and $2.4 \mathrm{C}$ ) changed significantly from baseline for both legs. In relative terms, FR threshold after placebo at the left and right legs measured on average $90 \%$ and $118 \%$ of the respective baseline values, irrespective of the taking of oral baclofen. FR threshold area after placebo at the left and right legs measured on average $71 \%$ and $121 \%$ of the respective baseline values for the children not taking oral baclofen, whereas it measured $181 \%$ and $204 \%$ respectively, for those taking oral baclofen.

After the administration of ITB, the FR threshold did not change significantly from baseline for both legs (Table 2.4A). In relative terms, FR threshold after ITB at the left and right legs measured on average $100 \%$ and $158 \%$ of the respective baseline values. Compared to baseline, the FR threshold area after ITB decreased significantly in both legs, but only for those children who did not take oral baclofen (Table 2.4B). For those children who took oral baclofen, the FR threshold area after ITB bilaterally remained the same (Table 2.4C). In relative terms, FR threshold area after ITB at the left and right legs measured on average $24 \%$ and $44 \%$ of the respective baseline values for the children not taking oral baclofen, whereas it measured $163 \%$ and $74 \%$ respectively, for the children taking oral baclofen. 
Table 2.4 Mean FR threshold (FRth) and FR threshold area (FRa) values with standard deviations at baseline and after administration of placebo and the effective baclofen dose

A Mean FR threshold (FRth) values in milliamperes (mA) for all children, irrespective of the taking of oral baclofen

\begin{tabular}{lrcccrrrr}
\hline Legs & $\mathrm{n}$ & $\begin{array}{c}\text { Baseline } \\
\text { mean FRth }\end{array}$ & $\begin{array}{c}\text { Placebo } \\
\text { mean FRth }\end{array}$ & $\begin{array}{c}\text { Baclofen } \\
\text { mean FRth }\end{array}$ & $\begin{array}{c}\text { Difference in } \\
\text { mean FRth }\end{array}$ & $95 \% \mathrm{Cl}$ & $p$ & $\begin{array}{c}\text { Corrected } \\
p\end{array}$ \\
\hline All & 18 & $7.0 \pm 2.9$ & $6.8 \pm 3.3$ & & $0.2 \pm 2.8$ & $-1.2-1.6$ & 0.757 & 0.757 \\
& 18 & $7.0 \pm 2.9$ & & $8.3 \pm 3.6$ & $-1.2 \pm 3.2$ & $-2.8-0.4$ & 0.124 & 0.620 \\
Left & 9 & $7.0 \pm 2.7$ & $5.9 \pm 1.8$ & & $1.2 \pm 2.8$ & $-1.0-3.4$ & 0.247 & 0.757 \\
& 9 & $7.0 \pm 2.7$ & & $6.7 \pm 1.8$ & $0.3 \pm 1.5$ & $-0.9-1.5$ & 0.565 & 0.757 \\
Right & 9 & $7.0 \pm 3.3$ & $7.8 \pm 4.2$ & & $-0.8 \pm 2.5$ & $-2.7-1.2$ & 0.385 & 0.757 \\
& 9 & $7.0 \pm 3.3$ & & $9.8 \pm 4.4$ & $-2.8 \pm 3.8$ & $-5.7-0.2$ & 0.061 & 0.366 \\
\hline
\end{tabular}

B Mean FR threshold area (FRa) values in millivolt milliseconds ( $\mathrm{mVms}$ ) for children not taking oral baclofen

\begin{tabular}{lrcccrrrr}
\hline Legs & $\mathrm{n}$ & $\begin{array}{c}\text { Baseline } \\
\text { mean FRa }\end{array}$ & $\begin{array}{c}\text { Placebo } \\
\text { mean FRa }\end{array}$ & $\begin{array}{c}\text { Baclofen } \\
\text { mean FRa }\end{array}$ & $\begin{array}{c}\text { Difference in } \\
\text { mean FRa }\end{array}$ & $95 \% \mathrm{Cl}$ & \multicolumn{2}{c}{$\begin{array}{c}\text { Corrected } \\
p\end{array}$} \\
\hline All & 13 & $152 \pm 66$ & $128 \pm 56$ & & $24 \pm 77$ & $-23-71$ & 0.289 & 0.578 \\
& 13 & $152 \pm 66$ & & $55 \pm 50$ & $97 \pm 39$ & $73-120$ & 0.000 & 0.000 \\
Left & 6 & $146 \pm 53$ & $100 \pm 66$ & & $46 \pm 77$ & $-35-127$ & 0.202 & 0.606 \\
& 6 & $146 \pm 53$ & & $41 \pm 54$ & $105 \pm 29$ & $74-136$ & 0.000 & 0.000 \\
Right & 7 & $156 \pm 80$ & $151 \pm 36$ & & $5 \pm 78$ & $-67-77$ & 0.879 & 0.879 \\
& 7 & $156 \pm 80$ & & $66 \pm 48$ & $90 \pm 47$ & $47-133$ & 0.002 & 0.008 \\
\hline
\end{tabular}

C Mean FR threshold area (FRa) values in millivolt milliseconds ( $\mathrm{mVms}$ ) for children taking oral baclofen

\begin{tabular}{|c|c|c|c|c|c|c|c|c|}
\hline Legs & $\mathrm{n}$ & $\begin{array}{l}\text { Baseline } \\
\text { mean FRa }\end{array}$ & $\begin{array}{c}\text { Placebo } \\
\text { mean FRa }\end{array}$ & $\begin{array}{l}\text { Baclofen } \\
\text { mean FRa }\end{array}$ & $\begin{array}{l}\text { Difference in } \\
\text { mean FRa }\end{array}$ & $95 \% \mathrm{Cl}$ & $p$ & $\begin{array}{c}\text { Corrected } \\
p\end{array}$ \\
\hline \multirow[t]{2}{*}{ All } & 5 & $26 \pm 16$ & $60 \pm 79$ & & $-34 \pm 65$ & $-115-47$ & 0.308 & 0.540 \\
\hline & 5 & $26 \pm 16$ & & $51 \pm 94$ & $-26 \pm 79$ & $-124-73$ & 0.511 & 0.540 \\
\hline \multirow[t]{2}{*}{ Left } & 3 & $34 \pm 16$ & $79 \pm 104$ & & $-46 \pm 88$ & $-264-172$ & 0.462 & 0.540 \\
\hline & 3 & $34 \pm 16$ & & $78 \pm 122$ & $-45 \pm 106$ & $-308-218$ & 0.540 & 0.540 \\
\hline \multirow[t]{2}{*}{ Right } & 2 & $14 \pm 3$ & $30 \pm 26$ & & $-16 \pm 24$ & $-229-196$ & 0.506 & 0.540 \\
\hline & 2 & $14 \pm 3$ & & $11 \pm$ & $3 \pm 3$ & $-23-29$ & 0.359 & 0.540 \\
\hline
\end{tabular}

Differences between the FR threshold values are shown with the 95\% confidence intervals $(\mathrm{Cl})$ and corresponding $p$-values

The FR elicited with supramaximal stimulation at baseline was tolerated by two children in both legs and by two children in one leg. Feasibility of the FR with supramaximal stimulation was $7 \%$, as only one of the 14 children tolerated these higher stimulus intensities at both ankles during all different test moments. Therefore, we did not carry out any statistical analyses on the FR, elicited with supramaximal stimulation. 


\section{DISCUSSION}

This is the first randomised, double-blind, placebo-controlled dose-escalation study demonstrating the H-reflex as a feasible, useful and objective test to quantify the decreasing motoneuron excitability in response to ITB bolus administration in a relatively large group of spastic children. The mean $H_{\max }$ and $H / M$ ratio values decreased significantly after ITB bolus administration and there was no placebo effect. In concordance with the knowledge that mental retardation is seen in $60 \%$ to $65 \%$ of children with a tetraplegia due to $\mathrm{CP}$, cooperation was limited in our study group with children suffering from intractable spasticity due to $\mathrm{CP} .{ }^{37}$ Nevertheless, in our study the H-reflex was feasible in $93 \%$ of the children. We therefore consider the H-reflex as a widely applicable neurophysiological test.

The primary aim of an ITB test treatment is to find out whether the patient will benefit from pump implantation for the continuous delivery of intrathecal baclofen. This decision should be primarily based on a positive clinical response to ITB bolus administration as experienced by the patient or as observed by the caregivers in case of children or adults who are not able to give their opinion. Reducing spasticity is not a treatment goal in itself, as spasticity can be functional, enabling the patient to stand in spite of any limb weakness. ${ }^{38}$ Spasticity is only treated when it leads to clinical symptoms or signs that are considered disabling. For each patient, individual goals of treatment are set. Improving (self) care and abolishing pain were main treatment goals in our study population and any improvement in these goals could be closely observed during the ITB bolus test treatment. In adjunct to this clinical evaluation, $H_{\max }$ as well as the $H / M$ ratio proved to be sensitive parameters in assessing the baclofen induced decrease in motoneuron excitability. It is considered that the use of the $H / M$ ratio is better, as it includes a normalisation procedure controlling for differences in skin impedance and location of the electrodes. ${ }^{21,39}$ Nevertheless, a few of the $H / M$ ratios found in our study were larger than 1.0. These aberrant results could be explained by suboptimal positioning of the stimulation electrodes. The supine position of the children and knee flexion deformities could have interfered with the stimulation of the posterior tibial nerve in the popliteal fossa. In case nerve stimulation would be suboptimal, $H_{\max }$ would still be recorded well, whereas $M_{\max }$ would possibly not have been attained.

Our findings correspond with the results of Dachy and Dan who carried out a non-placebo-controlled study in which they studied changes in the $H / M$ ratio and the FR after intrathecal bolus injection of baclofen in five children with severe spasticity of mixed aetiology. ${ }^{40}$ Two hours after administration of a $50 \mu \mathrm{g}$ ITB dose, the H-reflex had disappeared in four children and the $H / M$ ratio was reduced by $56 \%$ in the fifth child. Yablon and Stokic have reviewed several nonplacebo-controlled studies which have addressed changes in $H / M$ ratio after ITB 
bolus delivery in a total of 101 adults. ${ }^{11}$ The $H / M$ ratio typically decreased or the H-reflex disappeared after ITB bolus injection, in a dose-dependent manner. ${ }^{25,26,41,42}$ Stokic et al. demonstrated the $H / M$ ratio to be more sensitive than the Ashworth score in detecting a physiological response to ITB bolus delivery. ${ }^{13}$

There are several useful applications for the H-reflex during different phases of ITB treatment. ${ }^{11}$ If a patient for example does not respond to increasing ITB doses, it may be questioned whether the baclofen has been delivered at all and whether spinal cord neurons have responded yet. In that case $\mathrm{H}$-reflex values can be useful by confirming or negating successful ITB delivery. ${ }^{11}$ Recording an individual $\mathrm{H}$-reflex profile can also be useful during ITB dose titration and for early indicating pump or catheter related complications. ${ }^{43}$ The definite intrathecal drug delivery system is composed of a programmable infusion pump implanted in the abdominal wall and a connecting catheter, which is inserted in the intrathecal space in the spine. Sudden or gradual increases in the $H / M$ ratio should give rise to suspicion on a low pump reservoir baclofen volume or a catheter or pump related complication. ${ }^{43}$ It is very important to detect these complications in an early stage, as abrupt interruption of ITB delivery can lead to the potentially life threatening ITB withdrawal syndrome. ${ }^{44,45}$

We will now discuss our results with regard to the FR parameters. Unlike the $H_{\text {max }}$ the $H / M$ ratio and the FR threshold, the average FR threshold area was significantly lower in children who took oral baclofen in comparison with children who did not take oral baclofen. This difference was observed during the measurements at baseline and after the administration of, respectively, placebo and baclofen. Apparently, due to oral baclofen the excitability of the FR spinal interneuron system had already decreased, whereas the excitability of the neurons associated with the H-reflex had not yet changed. Baclofen is a GABA-B receptor agonist. In the mammalian spinal cord, GABA is highest concentrated in the dorsal grey matter, followed by the ventral grey matter with only minimal amounts in the white matter. ${ }^{46}$ In the dorsal horn, GABA-B is predominantly found in laminae I-III in interneurons, which are presynaptic to dendrites, cell bodies and other axon terminals. ${ }^{46}$ It is postulated that the presynaptic inhibition and other gating mechanisms related to pain and flexor spasms take place in the dorsal horn. ${ }^{18}$ On the other hand, the muscle relaxant effect of baclofen takes place in the ventral horn, where GABA is localised in interneurons presynaptic to motoneuron cell bodies and small and large dendrites. ${ }^{46}$ Thus, our finding that oral baclofen only had an inhibitory effect on the FR threshold area may be explained by the higher concentrations of GABA in the dorsal horn where the connections of the FR interneuronal network are localised.

In our study, the taking of oral baclofen had already resulted in such a decrease in mean FR threshold area that a floor effect seemed to have appeared and no further decrease could be observed after ITB administration. However, in the 
children who did not take oral baclofen, FR threshold area in both legs decreased significantly with ITB. In conclusion, our findings imply that only in children who do not take oral baclofen, the FR threshold area can also be a useful measure to evaluate the effect of ITB administration. Nevertheless, even recording the FR threshold and concordant FR threshold area by stimulation with lowest intensities was tolerated in only $63 \%$ of children. This lower tolerance is probably due to the painful stimuli required to activate the small-diameter, high-threshold nociceptive A-delta fibers. ${ }^{33}$ Moreover, during the FR the sudden withdrawal of the legs would often result in a generalised startle response and sometimes in pain.

Dachy and Dan described an increase in FR threshold and a decrease in FR threshold area after ITB bolus administration in six spastic children. ${ }^{40}$ Parise et al. reported an increase of biceps femoris FR threshold and a decrease of FR area in 17 spastic adults who were treated with continuous ITB delivery. ${ }^{12}$ FR area values were obtained with high stimulus intensities, which were required to obtain a maximal response prior to baclofen treatment. In our study population, increasing stimulation intensities to determine the maximum FR was rarely tolerated. We therefore advise against the use of the FR, elicited with supramaximal stimulation, in spastic children.

\section{CONCLUSIONS}

Irrespective of the taking of oral baclofen, the soleus H-reflex is a feasible and useful objective measure to quantify the decreasing motoneuron excitability in response to ITB bolus administration. Being tolerated by children with severe spastic type $\mathrm{CP}$, we consider the H-reflex as a widely feasible electrophysiological test. In children who do not take oral baclofen, the FR threshold area can also be used as an objective outcome measure in ITB treatment. However, the H-reflex had a better feasibility than the FR in our study population. We suggest introducing the H-reflex as the electrophysiological gold standard for the evaluation of the effect of ITB in spastic children. 


\section{REFERENCES}

1. Kuban KC, Leviton A. Cerebral palsy. N Engl J Med 1994;330:188-195.

2. Miller G. Cerebral palsies: an overview. In: Miller G, Clark GD, eds. The cerebral palsies. Boston: Butterworth-Heineman, 1998;1-36.

3. Lance JW. The control of muscle tone, reflexes, and movement: Robert Wartenberg Lecture. Neurology 1980;30:1303-1313.

4. Gilmartin R, Bruce D, Storrs BB, Abbott R, Krach L, Ward J, Bloom K, Brooks WH, Johnson DL, Madsen JR, McLaughlin JF, Nadell J. Intrathecal baclofen for management of spastic cerebral palsy: multicenter trial. J Child Neurol 2000;15:71-77.

5. Albright AL, Gilmartin R, Swift D, Krach LE, Ivanhoe CB, McLaughlin JF. Long-term intrathecal baclofen therapy for severe spasticity of cerebral origin. J Neurosurg 2003;98: 291-295.

6. Campbell WM, Ferrel A, McLaughlin JF, Grant GA, Loeser JD, Graubert C, Bjornson K. Longterm safety and efficacy of continuous intrathecal baclofen. Dev Med Child Neurol 2002; 44:660-665.

7. Damiano DL, Quinlivan JM, Owen BF, Payne P, Nelson KC, Abel MF. What does the Ashworth scale really measure and are instrumented measures more valid and precise? Dev Med Child Neurol 2002;44:112-118.

8. Ashworth B. Preliminary trial of carisoprodol in multiple sclerosis. Practitioner 1964;192: 540-542.

9. Levin MF. On the nature and measurement of spasticity. Clin Neurophysiol 2005;116: 1754-1755.

10. Bowery NG, Pratt GD. GABAB receptors as targets for drug action. Arzneimittelforschung 1992; 42:215-223.

11. Yablon SA, Stokic DS. Neurophysiologic evaluation of spastic hypertonia: implications for management of the patient with the intrathecal baclofen pump. Am J Phys Med Rehabil 2004;83(10 Suppl):S10-18.

12. Parise M, Garcia-Larrea L, Mertens P, Sindou M, Mauguiere F. Clinical use of polysynaptic flexion reflexes in the management of spasticity with intrathecal baclofen. Electroencephalogr Clin Neurophysiol 1997;105:141-148.

13. Stokic DS, Yablon SA, Hayes A. Comparison of clinical and neurophysiologic responses to intrathecal baclofen bolus administration in moderate-to-severe spasticity after acquired brain injury. Arch Phys Med Rehabil 2005;86:1801-1806.

14. Fisher MA, Shahani BT, Young RR. Electrophysiologic analysis of the motor system after stroke: the flexor reflex. Arch Phys Med Rehabil 1979;60:7-11.

15. Hallett M, Berardelli A, Delwaide P, Freund HJ, Kimura J, Lucking C, Rothwell JC, Shahani BT, Yanagisawa N. Central EMG and tests of motor control. Report of an IFCN committee. Electroencephalogr Clin Neurophysiol 1994;90:404-432.

16. Shahani BT, Young RR. Human flexor reflexes. J Neurol Neurosurg Psychiatry 1971;34: 616-27.

17. Milanov IG. Flexor reflex for assessment of common interneurone activity in spasticity. Electromyogr Clin Neurophysiol 1992;32:621-629.

18. Shahani BT, Young RR. Human flexor spasms. In: Desmedt JE, ed. New developments in electromyography and clinical neurophysiology. Vol. 3. Basel: Karger, 1973;734-743.

19. Misiaszek JE. The H-reflex as a tool in neurophysiology: its limitations and uses in understanding nervous system function. Muscle Nerve 2003;28:144-160.

20. Schieppati $M$. The Hoffmann reflex: a means of assessing spinal reflex excitability and its descending control in man. Prog Neurobiol 1987;28:345-376.

21. Zehr PE. Considerations for use of the Hoffmann reflex in exercise studies. Eur J Appl Physiol 2002;86:455-468.

22. Fisher MA. $\mathrm{H}$ reflexes and $\mathrm{F}$ waves. Fundamentals, normal and abnormal patterns. Neurol Clin 2002;20:339-360, vi.

23. Angel RW, Hofmann WW. The $\mathrm{H}$ reflex in normal, spastic, and rigid subjects. Arch Neurol 1963;44:591-596. 
24. Matthews WB. Ratio of maximum $\mathrm{H}$ reflex to maximum $\mathrm{M}$ response as a measure of spasticity. J Neurol Neurosurg Psychiatry 1966;29:201-204.

25. Orsnes G, Crone C, Krarup C, Petersen N, Nielsen J. The effect of baclofen on the transmission in spinal pathways in spastic multiple sclerosis patients. Clin Neurophysiol 2000;111: 1372-1379.

26. Macdonell RA, Talalla A, Swash M, Grundy D. Intrathecal baclofen and the H-reflex. J Neurol Neurosurg Psychiatry 1989;52:1110-1112.

27. Levin MF, Hui-Chan $\mathrm{C}$. Are $\mathrm{H}$ and stretch reflexes in hemiparesis reproducible and correlated with spasticity? J Neurol 1993;240:63-71.

28. Katz RT, Rovai GP, Brait C, Rymer WZ. Objective quantification of spastic hypertonia: correlation with clinical findings. Arch Phys Med Rehabil 1992;73:339-347.

29. Bakheit AM, Maynard VA, Curnow J, Hudson N, Kodapala S. The relation between Ashworth scale scores and the excitability of the alpha motor neurones in patients with post-stroke muscle spasticity. J Neurol Neurosurg Psychiatry 2003;74:646-648.

30. Pisano F, Miscio G, Del Conte C, Pianca D, Candeloro E, Colombo R. Quantitative measures of spasticity in post-stroke patients. Clin Neurophysiol 2000;111:1015-1022.

31. Delwaide PJ. Human reflex studies for understanding the motor system. Phys Med Rehabil Clin N Am 1993;4:669-686.

32. Stokic DS, Hayes A, Yablon SA. The utility of H-reflex for monitoring the delivery of continuous intrathecal baclofen (ITB) in patients with dysfunctional spasticity: 1. Repeatability and doseresponse relationship. Neurorehabil Neural Repair 2001;15:327.

33. Sandrini G, Serrao M, Rossi P, Romaniello A, Cruccu G, Willer JC. The lower limb flexion reflex in humans. Prog Neurobiol 2005;77:353-395.

34. Hochberg Y. A sharper Bonferroni procedure for multiple tests of significance. Biometrika 1988;75:800-802.

35. Palisano R, Rosenbaum P, Walter S, Russell D, Wood E, Galuppi B. Development and reliability of a system to classify gross motor function in children with cerebral palsy. Dev Med Child Neurol 1997;39:214-223.

36. Gorter JW, Rosenbaum PL, Hanna SE, Palisano RJ, Bartlett DJ, Russell DJ, Walter SD, Raina P, Galuppi BE, Wood E. Limb distribution, motor impairment, and functional classification of cerebral palsy. Dev Med Child Neurol 2004;46:461-467.

37. Dabney KW, Lipton GE, Miller F. Cerebral palsy. Curr Opin Pediatr 1997;9:81-88.

38. Ward AB. A summary of spasticity management--a treatment algorithm. Eur J Neurol 2002;9 Suppl 1:48-52; dicussion 53-61.

39. Tucker KJ, Tuncer M, Turker KS. A review of the H-reflex and $M$-wave in the human triceps surae. Hum Mov Sci 2005;24:667-688.

40. Dachy B, Dan B. Electrophysiological assessment of the effect of intrathecal baclofen in spastic children. Clin Neurophysiol 2002;113:336-340.

41. Lazorthes Y, Sallerin-Caute B, Verdie JC, Bastide R, Carillo JP. Chronic intrathecal baclofen administration for control of severe spasticity. J Neurosurg 1990;72:393-402.

42. Azouvi P, Roby-Brami A, Biraben A, Thiebaut JB, Thurel C, Bussel B. Effect of intrathecal baclofen on the monosynaptic reflex in humans: evidence for a postsynaptic action. J Neurol Neurosurg Psychiatry 1993;56:515-519.

43. Yablon SA, Hayes A, Stokic DS. The utility of H-reflex for monitoring the delivery of continuous intrathecal baclofen (CITB) in patients with dysfunctional spasticity: 2. Dose adjustment and troubleshooting. Neurorehabil Neural Repair 2001;15:328.

44. Coffey RJ, Edgar TS, Francisco GE, Graziani V, Meythaler JM, Ridgely PM, Sadiq SA, Turner MS. Abrupt withdrawal from intrathecal baclofen: recognition and management of a potentially lifethreatening syndrome. Arch Phys Med Rehabil 2002;83:735-741.

45. Zuckerbraun NS, Ferson SS, Albright AL, Vogeley E. Intrathecal baclofen withdrawal: emergent recognition and management. Pediatr Emerg Care 2004;20:759-764.

46. Malcangio M, Bowery NG. GABA and its receptors in the spinal cord. Trends Pharmacol Sci 1996; 17:457-462. 



\section{CHAPTER 3}

Intrathecal baclofen in children with spastic cerebral palsy: a double-blind, randomised, placebo-controlled, dose-finding study

MA Hoving, EPM van Raak, GHJJ Spincemaille, LJ Palmans, FAM Sleypen, JSH Vles, on behalf of the Dutch Study Group on Child Spasticity

Dev Med Child Neurol 2007;49:654-659 


\begin{abstract}
Intrathecal baclofen therapy can be very effective in the treatment of intractable spasticity, but its effectiveness and safety have not yet been thoroughly studied in children with cerebral palsy. The aims of this double-blind, randomised, placebo-controlled, dosefinding study were to select children eligible for continuous intrathecal baclofen infusion, to assess the effective intrathecal baclofen bolus dose and evaluate the effects, side effects and complications. Outcome measures included the original Ashworth scale and the visual analogue scale for individually formulated problems. We included nine girls and eight boys, aged between 7 and 16 years (mean $13 y 2 \mathrm{~m} \pm 2 \mathrm{y} 9 \mathrm{~m}$ ). Twelve children had spastic cerebral palsy and five spastic-dyskinetic cerebral palsy. One child was classified on the Gross Motor Function Classification System at level III, two at level IV and 14 at level $\mathrm{V}$. The test treatment was successful in all 17 children with an effective intrathecal baclofen bolus dose of $12.5 \mu \mathrm{g}$ in one, $20 \mu \mathrm{g}$ in another, $25 \mu \mathrm{g}$ in ten and $50 \mu \mathrm{g}$ in five children. Intrathecal baclofen significantly reduced muscle tone, diminished pain and facilitated ease of care. Placebo did not have these effects. Nine side effects of intrathecal baclofen were registered, including slight lethargy in seven children. Fourteen children had symptoms of lowered cerebrospinal fluid pressure. This complication did not occur in three children in whom the neurosurgeon had tunnelled the catheter subcutaneously. We conclude that intrathecal baclofen bolus administration is effective and safe for carefully selected children with intractable spastic cerebral palsy.
\end{abstract}




\section{INTRODUCTION}

Spasticity accounts for 70 to $91 \%$ of the motor disorders associated with cerebral palsy (CP). ${ }^{1}$ In severely affected children (Gross Motor Function Classification System (GMFCS) levels IV and V), it can cause pain, sleeping disorders, increased energy requirements, and interference with positioning, transfers, dressing, and body hygiene. Secondary phenomena such as contractures and pressure sores can add to the treatment problems. A substantial group of children with severe spastic type CP does not respond to regular treatments, such as physical therapy, orthopaedic surgery, or oral medication. An effective treatment option for intractable spasticity is continuous infusion of intrathecal baclofen (CITB) ${ }^{2-4}$ Baclofen acts as a gamma-aminobutyric acid (GABA-B) agonist, which is a major inhibitory neurotransmitter predominantly found in laminae I to III of the spinal cord dorsal horn. ${ }^{5}$ Baclofen passes the blood-brain barrier poorly; as a result, taking oral baclofen leads to high blood levels and virtually undetectable levels in the cerebrospinal fluid (CSF). Conversely, administration of a hundredth part of the oral baclofen dose intrathecally can relieve spasticity without the side effects often encountered with high baclofen doses taken orally. ${ }^{6}$ Intrathecal baclofen (ITB) can be delivered continuously by a programmable infusion pump implanted in an abdominal subcutaneous or subfascial pocket, and a connecting catheter, which is inserted in the intrathecal space. Before pump implantation, patients will usually have an ITB test treatment to evaluate whether ITB gives the desired effect without unacceptable side effects.

In 1985, Penn and Kroin established the effectiveness of CITB in patients with spasticity of spinal origin. ${ }^{7}$ In the same year, Dralle et al. reported on the beneficial effect of ITB in a child with spasticity of cerebral origin. ${ }^{8}$ In 2000, the American Academy for Cerebral Palsy and Developmental Medicine (AACPDM) published a systematic review on the degree of evidence about ITB treatment for spasticity in individuals with CP. ${ }^{9}$ They concluded that except for two case reports, none of the studies solely concerned children. They underlined the need for further prospective, randomised trials that use valid and reliable outcome measures, in well-described and homogeneous patient groups.

In 2002, we started the Dutch national study on the efficacy and safety of CITB for intractable spasticity in children with CP. The study included the selection, test treatment, pump implantation, and follow-up phases. In the present article we report on the double-blind, randomised, placebo-controlled, dose-finding ITB test treatment. The aims were: 1) to select children eligible for CITB treatment, 2) assess the effective ITB bolus dose, and 3) evaluate the effects, side effects, complications and procedures. 


\section{METHODS}

\section{Participants and general study design}

Medical specialists referred children from all parts of the Netherlands to the University Hospital Maastricht for possible participation in the Dutch national ITB study. In Maastricht, where all phases of this national study took place, a multidisciplinary team decided whether the child met the eligibility criteria (Table 3.1). We planned a test treatment for eligible children. After admission, the neurosurgeon inserted under general anaesthesia an external lumbar catheter (Perifix $^{\circledR} 300$ Mini Set; B Braun, Melsungen, Germany). Postoperatively and during the test days, the children stayed on the paediatric medium care unit, where vital signs were monitored. The morning after catheter insertion, the first study medication bolus was administered intrathecally via the catheter. During the first two test days the bolus randomly contained baclofen $25 \mu \mathrm{g}$ or placebo. On each of the subsequent six test days the bolus contained baclofen $50 \mu \mathrm{g}$ or placebo, then baclofen $75 \mu \mathrm{g}$ or placebo, and, finally, baclofen $100 \mu \mathrm{g}$ or placebo. Thus, in a given two-day treatment period, patients received baclofen and placebo in random order. An independent statistician generated the randomisation lists, permitting a balanced distribution of study medication sequences within the same child as well as between the children. The pharmacist prepared and numbered the study medication in accordance with these randomisation lists. All other involved people were blinded to the contents of the study medication boluses.

\section{Table $3.1 \quad$ Eligibility criteria for participants}

\section{Inclusion criteria}

1) Age between 4 and 16 years

2) Spastic diplegia or tetraplegia as part of cerebral palsy

3) Insufficient response to oral spasticity-reducing medication

4) In a mixed cerebral palsy syndrome, spasticity is the most prominent sign

5) Spasticity results in a decrease in the quality of life of the child and/or its caregivers

6) Sufficient motivation for study participation including availability for follow-up

7) Magnetic resonance imaging of the brain rules out progressive diseases

8) Minimal weight of $20 \mathrm{~kg}$ (valid until January 1st 2004)

9) Wheelchair bound without ability to creep or sit unsupported (valid until January 1st 2004)

10) Child is able to understand and carry out instructions (valid until January 1st 2004)

\section{Exclusion criteria}

1) Hypersensitivity to baclofen

2) Contraindications for general anaesthesia

3) Insufficient general health

4) Intractable epileptic seizures

5) Infection of the lumbar skin

6) Systemic infection 
In consultation with the child and the caregivers, we formulated three individual problems. The treatment goals were to improve these individually formulated problems. During test days, caregivers took notes about the treatment goals, other effects, and any side effects, including the time of occurrence. An experienced paediatric physiotherapist measured Ashworth scores every day before bolus administration (baseline) and 2, 4 and 6 hours afterwards. ${ }^{10}$ Ashworth scores were bilaterally assessed in seven lower-extremity muscle groups (hip adductors, flexors, and extensors; knee flexors and extensors; and ankle plantarflexors and dorsiflexors). Before catheter insertion, we selected the hip, knee, and anklerelated muscle group with highest tone on both sides, in total identifying six muscle groups per child. We defined the clinical effect as positive only if the following two criteria were met: 1) a satisfying improvement in the individual treatment goals as experienced by the child and/or the caregivers, and 2) at least a one-point reduction on the Ashworth scale compared with the baseline score of that specific day, in at least three of the six individually selected muscle groups. Furthermore, this one-point reduction had to last for two successive measurements on the same day. ${ }^{2,10,11}$ On the day that a positive clinical response was observed, the test treatment ended and the study medication code was broken. Only if this positive clinical response was observed at the first test day did the child and caregivers have the opportunity to experience the results of the second test day before the test treatment was ended. We offered this opportunity, because the decision on pump implantation should be well based. Having noticed a positive clinical response on the first test day, children and parents might have a need for confirmation by observing a lack of effect on the second test day. If the code break proved that the child had responded to baclofen, he or she was considered eligible for further treatment with CITB. If after eight test days no positive clinical effect had been observed, the child was not eligible for pump implantation.

\section{Outcome measures}

We used the original Ashworth scale ${ }^{12}$ and the visual analogue scale (VAS) for individually formulated problems as outcome measures. In daily clinical practice, there is as yet no objective outcome measure available to evaluate the effect of ITB bolus administration in children with spastic CP. Therefore, in spite of its limitations, the standard clinical scale for measuring spasticity is the Ashworth scale. ${ }^{12,13}$ It is a score for grading muscle tone and does not exclusively quantify spasticity. It lacks sensitivity for the detection of small changes in muscle tone. The strengths of the Ashworth scale are that it quickly provides information on muscle tone and it can be easily measured several times a day. ${ }^{13}$ Children were examined in supine position with a cushion under their knees. The environment was kept as quiet as possible. For each child, the Ashworth scores were always 
rated by the same paediatric physical therapist. ${ }^{14}$ Before muscle tone was graded, the particular limb was passively stretched an average of three times. ${ }^{14}$ In most previous studies, Ashworth scores of different muscles had been added up to produce a summed Ashworth score. ${ }^{2,10,11}$ This is methodologically incorrect, because the Ashworth score is an ordinal level measure. ${ }^{14}$

The VAS is a valid and reliable measure in rating pain intensity in adults and children over six years of age. ${ }^{15-17}$ It has also been used for measuring satisfaction, ${ }^{18}$ feelings,${ }^{19}$ quality of sleep, ${ }^{19}$ dyspnoea, ${ }^{20,21}$ emotional function, ${ }^{20,21}$ and fatigue, ${ }^{20,21}$ and seemed to be responsive ${ }^{19-21}$ and valid. ${ }^{21}$ Because the children in our study had different problems, we used the VAS for measuring the severity of the individually formulated problems. The VAS for pain is a straight 10 centimetre horizontal line with anchor points of 'no pain' (score 0) and 'unbearable pain' (score 10). ${ }^{16}$ We changed the anchor points in 'very dissatisfied' (score 0) and 'very satisfied' (score 10) to permit the uniform use of the VAS for the defined individual problems. Depending on both the ability to understand the test and to draw a vertical line, the VAS was rated by the child or by a parent. Each VAS was rated once before the test treatment would start (baseline) and at the end of each test day, reviewing the observations of that day. During VAS rating, the children and parents did not know the Ashworth scores for that day.

\section{Side effects and complications}

We registered side effects and complications on standardised forms. The form for side effects was filled out twice every test day: before bolus administration and at the end of the test day, reviewing the observations of that day. In this way we could identify better any study medication related side effects.

\section{Statistical analysis}

The statistical package SPSS for Windows, Release 11.0.1., was used for statistical analyses. We applied non-parametric methods, because of the small sample size. In small samples, it is not possible to be sure that a variable is normally distributed. The Wilcoxon Signed Rank Test was used to compare the Ashworth scale and VAS-scores at baseline and after intrathecal administration of placebo and the effective baclofen dose. The Mann-Whitney $U$ test was used to analyse whether children who required an ITB dose $\geq 50 \mu \mathrm{g}$ differed in age, weight, sex, GMFCS level, CP type, or the use of oral baclofen from children requiring an ITB dose $<50 \mu \mathrm{g}$. Results with $p \leq 0.05$ were considered statistically significant. 


\section{Ethical approval and consent}

The study was approved by the medical ethical committee of the University Hospital Maastricht. In accordance with local legislation, we obtained written informed consent from the parents, and also from the children, if they were aged 12 years or older and capable of understanding the nature and impact of the study.

\section{RESULTS}

\section{Participants}

Thirty-eight children, 23 boys and 15 girls, were referred as possible candidates for the Dutch national ITB study. The main reasons for referral were 'having pain' and problems with 'ease of care'. From January 2002 to December 2003 many children who wished to participate were not included because they did not meet the weight, mobility, and/or the cognition criteria. We therefore decided to widen the eligibility criteria by omitting inclusion criteria 8, 9 and 10 from January 2004 (Table 3.1). Seventeen children, among them nine girls and eight boys, aged between 7 and 16 years (mean $13 y 2 \mathrm{~m} \pm 2 \mathrm{y} 9 \mathrm{~m}$ ), were included. The characteristics of the included children are summarised in Table 3.2. Seven children still used oral baclofen and they continued this use during the test treatment.

Table 3.2 Characteristics of the participants

\begin{tabular}{rlrlllll}
\hline Case & $\begin{array}{c}\text { Age } \\
\text { and } \\
\text { sex }\end{array}$ & $\begin{array}{c}\text { Weight } \\
(\mathrm{kg})\end{array}$ & $\begin{array}{c}\text { Cerebral palsy } \\
\text { type }\end{array}$ & $\begin{array}{c}\text { Diplegia/ } \\
\text { tetraplegia }\end{array}$ & $\begin{array}{c}\text { GMFCS } \\
\text { level }\end{array}$ & $\begin{array}{c}\text { Oral baclofen Associated problems } \\
\text { dose } \\
\text { (mg/kg) }\end{array}$ & \\
\hline 1 & $15 \mathrm{~F}$ & 34 & spastic/dyskinetic & tetra & $\mathrm{V}$ & - & con, uro \\
2 & $11 \mathrm{M}$ & 26 & spastic & tetra & $\mathrm{V}$ & - & spe, dro, con, uro, brp \\
3 & $14 \mathrm{M}$ & 30 & spastic & tetra & $\mathrm{V}$ & - & spe, dro, con, uro, epi, brp \\
4 & $12 \mathrm{~F}$ & 40 & spastic/dyskinetic & tetra & $\mathrm{V}$ & - & spe, dro, vis \\
5 & $16 \mathrm{M}$ & 84 & spastic & di & $\mathrm{IV}$ & - & slp \\
6 & $13 \mathrm{~F}$ & 60 & spastic/dyskinetic & tetra & $\mathrm{V}$ & 1.00 & spe, uro, slp, vis \\
7 & $9 \mathrm{~F}$ & 22 & spastic/dyskinetic & tetra & $\mathrm{V}$ & 1.36 & spe, dro, con, uro, slp, epi, aud \\
8 & $16 \mathrm{M}$ & 51 & spastic & tetra & $\mathrm{V}$ & - & spe, dro, con, epi \\
9 & $16 \mathrm{~F}$ & 35 & spastic & tetra & $\mathrm{V}$ & - & spe, dro, con, uro, slp, vis, epi, brp \\
10 & $7 \mathrm{M}$ & 24 & spastic & tetra & $\mathrm{V}$ & 1.35 & spe, dro, uro, slp, epi \\
11 & $14 \mathrm{M}$ & 17 & spastic & tetra & $\mathrm{V}$ & 0.59 & spe, dro, con, uro, slp, vis, epi, brp \\
12 & $12 \mathrm{~F}$ & 33 & spastic & tetra & $\mathrm{V}$ & - & spe, dro, uro, vis \\
13 & $16 \mathrm{M}$ & 70 & spastic & di & $\mathrm{III}$ & 0.86 & - \\
14 & $16 \mathrm{~F}$ & 48 & spastic & di & $\mathrm{IV}$ & - & con, uro \\
15 & $15 \mathrm{~F}$ & 33 & spastic/dyskinetic & tetra & $\mathrm{V}$ & - & spe, dro, con, uro \\
16 & $10 \mathrm{~F}$ & 27 & spastic & tetra & $\mathrm{V}$ & 1.11 & spe, dro, con, vis \\
17 & $12 \mathrm{M}$ & 21 & spastic & tetra & $\mathrm{V}$ & 1.43 & spe, dro, con, slp \\
\hline
\end{tabular}

${ }^{a}$ GMFCS, Gross Motor Function Classification System; ${ }^{b}$ spe = speech problem; dro = drooling; con = constipation; uro = urological problem; slp = sleeping disorder; vis = visual impairment; epi = epilepsy; brp = bronchopulmonary problem; aud = auditory problem 


\section{Effects}

All 17 children showed a positive clinical effect in response to an ITB bolus dose. Table 3.3 shows the number of test days, the study medication randomisation sequences, and the effective ITB dose per child. The effective ITB dose was 12.5 $\mu \mathrm{g}$ in one child, $20 \mu \mathrm{g}$ in another, $25 \mu \mathrm{g}$ in ten and $50 \mu \mathrm{g}$ in five children. For the child who already responded to ITB $12.5 \mu \mathrm{g}$, we deviated from the protocol by starting with this lower dose. This child was known to experience side effects easily in response to different oral medications. The child who responded to ITB $20 \mu \mathrm{g}$ had two separate test treatments. During the first day of the first test treatment he experienced apathy and, in upright position, nausea and vomiting. His vital signs were normal. We broke the test treatment off, because his condition impeded the observation of effects and side effects. During a second admission, we did an open-label test treatment administering ITB $20 \mu \mathrm{g}$ by lumbar puncture. This resulted in a positive clinical response and slight lethargy as side effect. We excluded the test results of this boy from statistical analyses because the test treatment had not been carried out double-blind.

The five children who required ITB $50 \mu \mathrm{g}$ were significantly older $(p=0.037)$ and weighed more $(p=0.007)$ than the 12 children who responded to a lower dose of ITB. No significant difference was found for sex, GMFCS, CP type or the use of oral baclofen. The caregivers noted effects from about 1.5 to 9.5 hours after administration of the effective ITB dose, with a maximum effect after 4.5 hours. The Ashworth scores, assessed 2, 4, and 6 hours after administration of the effective ITB dose, significantly decreased in comparison with baseline for all muscle groups $(0.001 \leq p \leq 0.040)$, except for the left hip flexors 2 hours after ITB administration $(p=0.080)$. The Ashworth score after placebo administration did not change significantly in any muscle group at any test moment $(0.083 \leq p \leq 1.000)$. In the three children who had two placebo days, the results of the first placebo day were used for the Ashworth and VAS analyses. 
Table 3.3 Study medication randomisation sequence, effective intrathecal baclofen (ITB) dose, side effects and complications

\begin{tabular}{|c|c|c|c|c|c|c|}
\hline \multirow[t]{2}{*}{ Case } & \multirow{2}{*}{$\begin{array}{l}\text { Study medication } \\
\text { sequence } \\
(\mathrm{P}=\text { placebo }) \\
(\mathrm{B}=\text { baclofen }) \\
\end{array}$} & \multirow{2}{*}{$\begin{array}{l}\text { Effective } \\
\text { ITB dose } \\
(\mu \mathrm{g})\end{array}$} & \multirow[t]{2}{*}{ Side effects ITB } & \multirow{2}{*}{$\begin{array}{l}\text { Catheter } \\
\text { in situ } \\
\text { (days) }\end{array}$} & \multicolumn{2}{|c|}{ Complications } \\
\hline & & & & & $\begin{array}{c}\text { Symptoms of } \\
\text { lowered CSF } \\
\text { pressure }\end{array}$ & $\begin{array}{l}\text { Other } \\
\text { complications }\end{array}$ \\
\hline 1 & P-B & 25 & No & 4 & No & $\begin{array}{l}\text { Defective } \\
\text { connection } \\
\text { catheter cap }\end{array}$ \\
\hline 2 & P-B & 25 & No & 3 & No & \\
\hline 3 & B & $20^{\mathrm{a}}$ & Lethargy & 2 & Yes & \\
\hline 4 & P-B & 12.5 & No & 3 & Yes & \\
\hline 5 & P-B-B & 50 & No & 4 & Yes & \\
\hline 6 & B-P-P-B & 50 & Lethargy & 5 & Yes & \\
\hline 7 & P-B & 25 & Lethargy & 4 & Yes & $\begin{array}{l}\text { Disconnection } \\
\text { catheter cap }\end{array}$ \\
\hline 8 & P-B-B & 50 & Lethargy & 4 & Yes & \\
\hline 9 & B-P & 25 & No & 3 & Yes & \\
\hline 10 & B & 25 & $\begin{array}{l}\text { Lethargy } \\
\text { Excessive hypotonia }\end{array}$ & 3 & Yes & \\
\hline 11 & B-P & 25 & Lethargy & 3 & Yes & $\begin{array}{l}\text { Disconnection } \\
\text { catheter cap }\end{array}$ \\
\hline 12 & P-B & 25 & Lethargy & 3 & Yes & \\
\hline 13 & B-P-P-B & 50 & No & 5 & No & Radiculopathy \\
\hline 14 & B-P & 25 & No & 3 & Yes & Gastroenteritis \\
\hline 15 & P-B-P-B & 50 & No & 5 & Yes & \\
\hline 16 & B-P & 25 & $\begin{array}{l}\text { Perspiration of } \\
\text { hands and feet }\end{array}$ & 3 & Yes & \\
\hline 17 & B-P & 25 & No & 3 & Yes & \\
\hline
\end{tabular}

CSF = cerebrospinal fluid; ${ }^{a}$ positive clinical effect during a second, open-label test treatment by lumbar puncture

The VAS scores were rated by the caregivers for 15 children; two children rated the VAS scores themselves (cases 13 and 14). Table 3.4 shows that both the VAS for pain and the VAS for ease of care significantly improved after administration of the effective ITB dose without placebo effect. Fourteen of the 17 children were bed-bound because they had symptoms of lowered CSF pressure. Consequently, certain individually formulated problems could not be evaluated during the test treatment. In individual cases, improvements were noted concerning transfers, voiding, startle responses, operating the electric wheelchair, and arm function. One boy (case 13) underwent the test treatment because of deteriorating gait in spite of multilevel treatment with botulinum toxin. He saw his goals fulfilled as with ITB $50 \mu \mathrm{g}$ the pain in his hamstrings disappeared and walking took less energy. 
Table 3.4 Mean visual analogue scale (VAS) scores for ease of care and for pain, at baseline, and after intrathecal administration of placebo and effective baclofen dose

\begin{tabular}{llccccc}
\hline Scale & Treatment & $\mathrm{n}$ & \multicolumn{2}{c}{ VAS-score } & Difference & $p$ \\
\cline { 4 - 5 } & & & Baseline & $\begin{array}{c}\text { After bolus } \\
\text { administration }\end{array}$ & & \\
\hline Ease of care & Placebo & 13 & $2.4 \pm 1.4$ & $3.3 \pm 2.0$ & $0.9 \pm 1.7$ & 0.093 \\
& Baclofen & 14 & $2.3 \pm 1.4$ & $7.4 \pm 2.2$ & $5.1 \pm 2.1$ & 0.001 \\
Pain & Placebo & 10 & $3.2 \pm 2.1$ & $4.3 \pm 2.6$ & $1.1 \pm 3.5$ & 0.262 \\
& Baclofen & 11 & $3.2 \pm 2.0$ & $6.5 \pm 3.1$ & $3.3 \pm 2.9$ & 0.010 \\
\hline
\end{tabular}

Scores are shown as mean $\pm \mathrm{SD}$

\section{Side effects and complications}

Table 3.3 shows the side effects and complications for each child. Nine side effects of ITB were registered in eight children. Seven children became slightly lethargic, including a child who also suffered from transient excessive hypotonia. The main complication, which occurred in 14 of the 17 children, consisted of one or more symptoms that could fit in with the diagnosis of lowered CSF pressure. These symptoms included lethargy, decreased appetite, dry mouth, dizziness, perspiration, pallor, nausea, vomiting and headache. The last four symptoms appeared or increased only in an upright position. In three children, CSF leaked from the catheter connection. In one of these, the catheter connection was defective, so a new catheter had to be inserted; in the other two, reconnection of the cap solved the problem. We did not observe symptoms of lowered CSF pressure in three children in whom the neurosurgeon had tunnelled the catheter subcutaneously for a few centimetres. Fourteen children preventively received one to four doses of cefazoline perioperatively. One child had radicular pain in his right leg postoperatively. The pain was completely resolved by retracting the catheter for $5 \mathrm{~cm}$. Another child first had abdominal cramps due to constipation, developing gastroenteritis later on. At that time, more children on the ward had gastroenteritis.

Overall, none of the children required respiratory support or admission to intensive care. None of the children developed meningitis.

\section{DISCUSSION}

The test treatment was successful in all 17 children, and all went on to the randomised, open-label pump implantation phase. Intrathecal bolus administration of baclofen reduced muscle tone, diminished pain and facilitated care. Placebo did not have these effects. In individual cases, gait, transfers, voiding, operating the electric wheelchair and arm control improved, while startle responses decreased. A satisfying clinical effect was achieved with ITB 
bolus doses of between $12.5 \mu \mathrm{g}$ and $50 \mu \mathrm{g}$. The older and heavier children more often required ITB $50 \mu \mathrm{g}$. Side effects included slight lethargy in seven of 17 children, and transient excessive hypotonia in one child. We would expect fewer side effects during CITB treatment, being able to titrate the baclofen dose with the programmable infusion pump. The main complication concerned symptoms of lowered CSF pressure in 14 of 17 children, caused by CSF loss during the operation or CSF leaking alongside or from the catheter. Children with CP may be more susceptible to lowered CSF pressure symptoms, owing to decreased compliance of the CSF compartment. ${ }^{22,23}$ Albright et al. postulated that the increased incidence of CSF leaking during ITB therapy in children with CP might be caused by occult hydrocephalus. ${ }^{24}$ They performed lumbar punctures in 24 children with CP and asymptomatic ventriculomegaly, resulting in abnormal high opening pressures in 23 children. However, lumbar punctures were performed under general anaesthesia, which can increase CSF pressure. ${ }^{24,25}$ They found no correlation between the opening pressures and the extent of ventriculomegaly. ${ }^{24}$ We did not measure opening pressures, because the children did neither have clinical symptoms nor magnetic resonance imaging signs of increased intracranial pressure. In the three children with a tunnelled catheter we observed no symptoms of lowered CSF pressure. The counterpressure created probably caused any CSF leaking along the catheter to cease. In three other children, CSF leaking was related to the catheter connection. These problems probably belong to the past because the firm of B-Braun has replaced the former, vulnerable connector of the Perifix ${ }^{\circledR} 300$ mini set with a solid click system.

Since the review of the American Academy for Cerebral Palsy and Developmental Medicine, a few reports about ITB treatment including children with $\mathrm{CP}$ have been published. ${ }^{4,9,26-30}$ We cannot compare or contrast our results with these reports, because none was placebo-controlled. Moreover, all studies focused on the pump implantation and follow-up without much attention on the preceding test treatment. Apart from Vloeberghs et al. ${ }^{28}$, who used an ITB $30 \mu \mathrm{g}$ bolus in the smallest children, test treatments started with an adult $50 \mu \mathrm{g}$ ITB bolus. ${ }^{4,27,29}$ We would expect many side effects with this high starting dose, as we and others noted side effects in response to ITB bolus doses as low as 20 and 10 $\mu g$, respectively. ${ }^{31}$ However, information on the children's weight and the incidence of side effects and complications was either limited or absent. ${ }^{4,26-30}$ Not all studies had a $100 \%$ success rate of the test treatment. ${ }^{26,28}$ After 83 test treatments, Vloeberghs et al. reported five non-responders and six children with a response not fulfilling the expectations of the caregivers. ${ }^{28}$ It is unclear whether they tried only one ITB bolus per child or also higher doses in non-responders. We would encourage our colleagues to report more comprehensively on the design, results and complications of ITB test treatments in children.

On the basis of our experience, we put forward some ideas to optimise the design of the test treatment and to decrease the incidence of catheter-related 
complications. From now on, we shall no longer use placebo. However, because a placebo-effect has been reported, outcome measures are important for sustaining a clinically observed positive effect. ${ }^{2,11}$ We suggest using the original Ashworth scale and the soleus H-reflex for this goal. The Ashworth scale has its limitations ${ }^{14,32}$, but it quickly provides information on muscle tone and can be easily measured several times a day. The soleus H-reflex is an objective measure to quantify the decreasing motoneuron excitability in response to ITB bolus administration and is feasible in children with severe CP. ${ }^{32}$ We believe that the effective ITB dose can be fairly predicted considering the child's age, weight, CP type and individual treatment goals. Because most children will require only one ITB test dose, bolus administration by lumbar puncture may be considered in children who understand the procedure and are able to cooperate. In case ITB administration by an external catheter is required, we would suggest tunnelling the catheter subcutaneously. General anaesthesia is often required in that case. Summarising, we believe that the design of each test treatment should be tailored to the characteristics and treatment goals of the individual child. More studies are needed to optimise ITB care for children. These studies should also address children with posture and movement disorders due to traumatic brain injury, near-drowning, hereditary spastic paraparesis, and spinal cord lesions.

\section{CONCLUSION}

ITB bolus administration is effective and safe for carefully selected children with intractable spastic type CP. Most children responded to ITB $25 \mu \mathrm{g}$, which is half the usual starting bolus dose for adults. The children who required ITB $50 \mu \mathrm{g}$ were significantly older and weighed more. Symptoms of lowered cerebrospinal fluid pressure frequently complicated the test treatment. Given these experiences, we have put forward ideas to optimise future ITB test treatments. The results of the randomised, open-label pump implantation phase and follow-up of the Dutch national ITB study in children with spastic type CP are forthcoming (Chapters 4 and 5 of this thesis). 


\section{REFERENCES}

1. Surman G, Bonellie S, Chalmers J, Colver A, Dolk H, Hemming K, King A, Kurinczuk JJ, Parkes J, Platt MJ. UKCP: a collaborative network of cerebral palsy registers in the United Kingdom. J Public Health (Oxf) 2006;28:148-156.

2. Gilmartin R, Bruce D, Storrs BB, Abbott R, Krach L, Ward J, Bloom K, Brooks WH, Johnson DL, Madsen JR, McLaughlin JF, Nadell J. Intrathecal baclofen for management of spastic cerebral palsy: multicenter trial. J Child Neurol 2000;15:71-77.

3. Albright AL, Gilmartin R, Swift D, Krach LE, Ivanhoe CB, McLaughlin JF. Long-term intrathecal baclofen therapy for severe spasticity of cerebral origin. J Neurosurg 2003;98: 291-295.

4. Campbell WM, Ferrel A, McLaughlin JF, Grant GA, Loeser JD, Graubert C, Bjornson K. Longterm safety and efficacy of continuous intrathecal baclofen. Dev Med Child Neurol 2002;44:660-665.

5. Malcangio M, Bowery NG. GABA and its receptors in the spinal cord. Trends Pharmacol Sci 1996; 17:457-462.

6. Kroin JS. Intrathecal drug administration. Present use and future trends. Clin Pharmacokinet 1992;22:319-326.

7. Penn RD, Kroin JS. Continuous intrathecal baclofen for severe spasticity. Lancet 1985;2: 125-127.

8. Dralle D, Muller H, Zierski J, Klug N. Intrathecal baclofen for spasticity. Lancet 1985;2:1003.

9. Butler C, Campbell S. Evidence of the effects of intrathecal baclofen for spastic and dystonic cerebral palsy. AACPDM Treatment Outcomes Committee Review Panel. Dev Med Child Neurol 2000;42:634-645.

10. Albright AL. Intrathecal baclofen in cerebral palsy movement disorders. J Child Neurol 1996;11 Suppl 1:S29-35.

11. Van Schaeybroeck P, Nuttin B, Lagae L, Schrijvers E, Borghgraef C, Feys P. Intrathecal baclofen for intractable cerebral spasticity: a prospective placebo-controlled, double-blind study. Neurosurgery 2000;46:603-9; discussion 609-612.

12. Ashworth B. Preliminary trial of carisoprodol in multiple sclerosis. Practitioner 1964;192: 540-542.

13. Damiano DL, Quinlivan JM, Owen BF, Payne P, Nelson KC, Abel MF. What does the Ashworth scale really measure and are instrumented measures more valid and precise? Dev Med Child Neurol 2002;44:112-118.

14. Pandyan $\mathrm{AD}$, Johnson $\mathrm{GR}$, Price $\mathrm{Cl}$, Curless $\mathrm{RH}$, Barnes MP, Rodgers $\mathrm{H}$. A review of the properties and limitations of the Ashworth and modified Ashworth Scales as measures of spasticity. Clin Rehabil 1999;13:373-383.

15. Chapman CR, Casey KL, Dubner R, Foley KM, Gracely RH, Reading AE. Pain measurement: an overview. Pain 1985;22:1-31.

16. Wallenstein SL, Heidrich G, 3rd, Kaiko R, Houde RW. Clinical evaluation of mild analgesics: the measurement of clinical pain. Br J Clin Pharmacol 1980;10 Suppl 2:319S-327S.

17. Tyler DC, Tu A, Douthit J, Chapman CR. Toward validation of pain measurement tools for children: a pilot study. Pain 1993;52:301-309.

18. Singer AJ, Thode HC. Determination of the minimal clinically significant difference on a patient visual analog satisfaction scale. Acad Emerg Med 1998;1998:1007-1011.

19. Aitken RC. Measurement of feelings using visual analogue scales. Proc R Soc Med 1969;62: 989-993.

20. Guyatt G, Townsend M, Berman B, Keller JL. A comparison of Likert and visual analogue scales for measuring change in function. J Chronic Dis 1987;40:1129-1133.

21. Jaeschke R, Singer J, Guyatt G. A comparison of seven-point and visual analogue scales. Control Clin Trials 1990;11:43-51.

22. Bergsneider M. Evolving concepts of cerebrospinal fluid physiology. Neurosurg Clin N Am 2001;12:631-638, vii. 
23. Portella G, Cormio M, Citerio G, Contant C, Kiening K, Enblad P, Piper I. Continuous cerebral compliance monitoring in severe head injury: its relationship with intracranial pressure and cerebral perfusion pressure. Acta Neurochir (Wien) 2005;147:707-713.

24. Albright AL, Ferson S, Carlos S. Occult hydrocephalus in children with cerebral palsy. Neurosurgery 2005;56:93-6; discussion 96-97.

25. Sponheim S, Skraastad O, Helseth E, Due-Tonnesen B, Aamodt G, Breivik H. Effects of 0.5 and 1.0 MAC isoflurane, sevoflurane and desflurane on intracranial and cerebral perfusion pressures in children. Acta Anaesthesiol Scand 2003;47:932-938.

26. Murphy NA, Irwin MC, Hoff C. Intrathecal baclofen therapy in children with cerebral palsy: efficacy and complications. Arch Phys Med Rehabil 2002;83:1721-1725.

27. Awaad Y, Tayem H, Munoz S, Ham S, Michon AM, Awaad R. Functional assessment following intrathecal baclofen therapy in children with spastic cerebral palsy. J Child Neurol 2003;18: 26-34.

28. Vloeberghs M, Keetley R, Morton R. Intrathecal baclofen in the management of spasticity due to cerebral palsy. Pediatr Rehabil 2005;8:172-179.

29. Scheinberg A, O'Flaherty S, Chaseling R, Dexter M. Continuous intrathecal baclofen infusion for children with cerebral palsy: a pilot study. J Paediatr Child Health 2001;37:283-288.

30. Albright AL, Awaad Y, Muhonen M, Boydston WR, Gilmartin R, Krach LE, Turner M, Zidek KA, Wright E, Swift D, Bloom K. Performance and complications associated with the synchromed 10-ml infusion pump for intrathecal baclofen administration in children. J Neurosurg 2004;101(1 Suppl):64-68.

31. Armstrong RW, Steinbok P, Cochrane DD, Kube SD, Fife SE, Farrell K. Intrathecally administered baclofen for treatment of children with spasticity of cerebral origin. J Neurosurg 1997;87:409-414.

32. Hoving MA, van Kranen-Mastenbroek VH, van Raak EP, Spincemaille GH, Hardy EL, Vles JS, On Behalf Of The Dutch Study Group On Child S. Placebo controlled utility and feasibility study of the H-reflex and flexor reflex in spastic children treated with intrathecal baclofen. Clin Neurophysiol 2006;117:1508-17 (Chapter 2 of this thesis). 



\section{CHAPTER 4}

Efficacy of intrathecal baclofen therapy in children with intractable spastic cerebral palsy:

a randomised controlled trial

MA Hoving, EPM van Raak, GHJJ Spincemaille, LJ Palmans, JG Becher, JSH Vles, on behalf of the Dutch Study Group on Child Spasticity

Submitted 


\section{ABSTRACT}

\section{Background}

Intractable spasticity can be treated effectively with continuous infusion of intrathecal baclofen. Because evidence for its use in the treatment of children with spastic cerebral palsy is lacking, we conducted a randomised controlled trial.

\section{Aims}

To test whether continuous infusion of intrathecal baclofen is effective in comparison with standard treatment only.

\section{Methods}

Seventeen children, aged $13.2 \pm 2.8$ years, with intractable spastic cerebral palsy were randomised to receive a Synchromed pump for continuous infusion of intrathecal baclofen after either one month (CITB group) or six months (Control group). Primary outcomes were the 6-month-change scores on the 0-10 visual analogue scale for individually formulated problems and the Caregiver Assistance scale of the Pediatric Evaluation of Disability Inventory self-care domain. One of the secondary outcome measures was health related quality of life as measured with the Child Health Questionnaire-PF50.

\section{Results}

Nine children were randomly assigned to the CITB group and eight to the Control group. The visual analogue scale for individual problems improved with $4.0 \pm 1.7$ in the CITB group and changed with $-0.2 \pm 1.3$ in the Control group $(p=0.001)$. Pediatric Evaluation of Disability Inventory scores did not change significantly. The Child Health Questionnaire-PF50 6-month-change score significantly differed in favour of the CITB group for the domains of bodily pain/discomfort $(p=0.014)$, mental health $(p=0.045)$, psychosocial status $(p=0.027)$ and parents' personal time limitation $(p=0.043)$.

\section{Conclusion}

The results of this randomised controlled trial establish continuous infusion of intrathecal baclofen to be effective in carefully selected children with problems caused by intractable spastic cerebral palsy. 


\section{INTRODUCTION}

With a prevalence of about 2 per 1000 live births in Western countries, cerebral palsy (CP) is the most common cause of severe physical disability in childhood. ${ }^{1}$ Spasticity accounts for 70 to $91 \%$ of the motor disorders associated with CP and is intractable in a substantial group of children. ${ }^{2}$ Intractable spasticity can cause pain, sleeping disorders, increased energy requirements, and interference with positioning, transfers, dressing, and body hygiene. Secondary phenomena such as contractures and pressure sores can add to the treatment problems. Continuous infusion of intrathecal baclofen (CITB) can be very effective in the treatment of intractable spasticity. ${ }^{3}$

In 2000, the American Academy for Cerebral Palsy and Developmental Medicine published a systematic review on the degree of evidence about CITB for spasticity in individuals with CP. ${ }^{4}$ They concluded that except for two case reports, none of the studies solely concerned children. They underlined the need for prospective, randomised trials that use valid and reliable outcome measures, in well-described and homogeneous patient groups. Therefore, we started a prospective Dutch national study on the efficacy and safety of CITB for intractable spasticity in children with CP in 2002..$^{5-8}$ The study included the selection, test treatment, pump implantation, and follow-up phase. Recently, we reported on the doubleblind, randomised, placebo-controlled, dose-finding test treatment. ${ }^{5}$ Bolus administration of intrathecal baclofen (ITB) significantly reduced muscle tone, diminished pain, and facilitated ease of care. Placebo did not have these effects. ${ }^{5}$ Our present article addresses the pump implantation phase. The aim of this randomised controlled trial (RCT) was to study the efficacy of CITB in the treatment of children with problems caused by intractable spastic CP.

\section{METHODS}

\section{Participants and study design}

Seventeen children, nine girls and eight boys, aged between 7 and 16 years (mean age $13.2 \pm 2.8$ years), participated in the Dutch ITB study. The eligibility criteria of this study are shown in Table 4.1. ${ }^{5}$ After a successful test treatment, the children were randomised to receive a programmable Synchromed infusion pump (Medtronic, Inc., Minneapolis, MN) after either 1 month (CITB group) or 6 months (Control group; Figure 4.1). In both groups, standard treatment was continued, including any physiotherapy, speech therapy and occupational therapy. Before the start of the Dutch ITB study, an independent statistician generated the allocation schedule with an unpredictable sequence of assignments. The investigator who enrolled the children had no entry to this list 
and was, at the time of each enrolment, not aware of the next assignment in the sequence. For assignment, the investigator called the independent statistician who consulted the allocation list. After randomisation, the treatment was openlabel and non-blinded. An experienced neurosurgeon inserted the pumps under general anaesthesia in the lateral abdomen. All children participated in the 3-monthly follow-up visits. All pump implantations and follow-up visits took place at the University Hospital Maastricht in the Netherlands. The main investigator was present during all admissions and follow-up visits of the children.

Table 4.1 Eligibility criteria for the Dutch ITB study

\section{Inclusion criteria}

1) Age between 4 and 16 years

2) Spastic diplegia or tetraplegia as part of cerebral palsy

3) Insufficient response to oral spasticity-reducing medication

4) In a mixed cerebral palsy syndrome, spasticity is the most prominent sign

5) Spasticity results in a decrease in the quality of life of the child and/or its caregivers

6) Sufficient motivation for study participation including availability for follow-up

7) Magnetic resonance imaging of the brain rules out progressive diseases

8) Minimal weight of $20 \mathrm{~kg}$ (valid until January 1st 2004)

9) Wheelchair bound without ability to creep or sit unsupported (valid until January 1st 2004)

10) Child is able to understand and carry out instructions (valid until January 1st 2004)

\section{Exclusion criteria}

1) Hypersensitivity to baclofen

2) Contraindications for general anaesthesia

3) Insufficient general health

4) Intractable epileptic seizures

5) Infection of the lumbar skin

6) Systemic infection

\section{Outcome measures}

We used the International Classification of Functioning, Disability and Health (ICF) for the selection of a broad choice of outcome measures (Figure 4.2). ${ }^{9}$ For all outcome measures, we compared the 6-month-change scores between the CITB group and the Control group. The two primary outcome measures included the Caregiver Assistance scale of the self-care domain of the Pediatric Evaluation of Disability Inventory (PEDI) and the visual analogue scale (VAS) for individually formulated problems. 


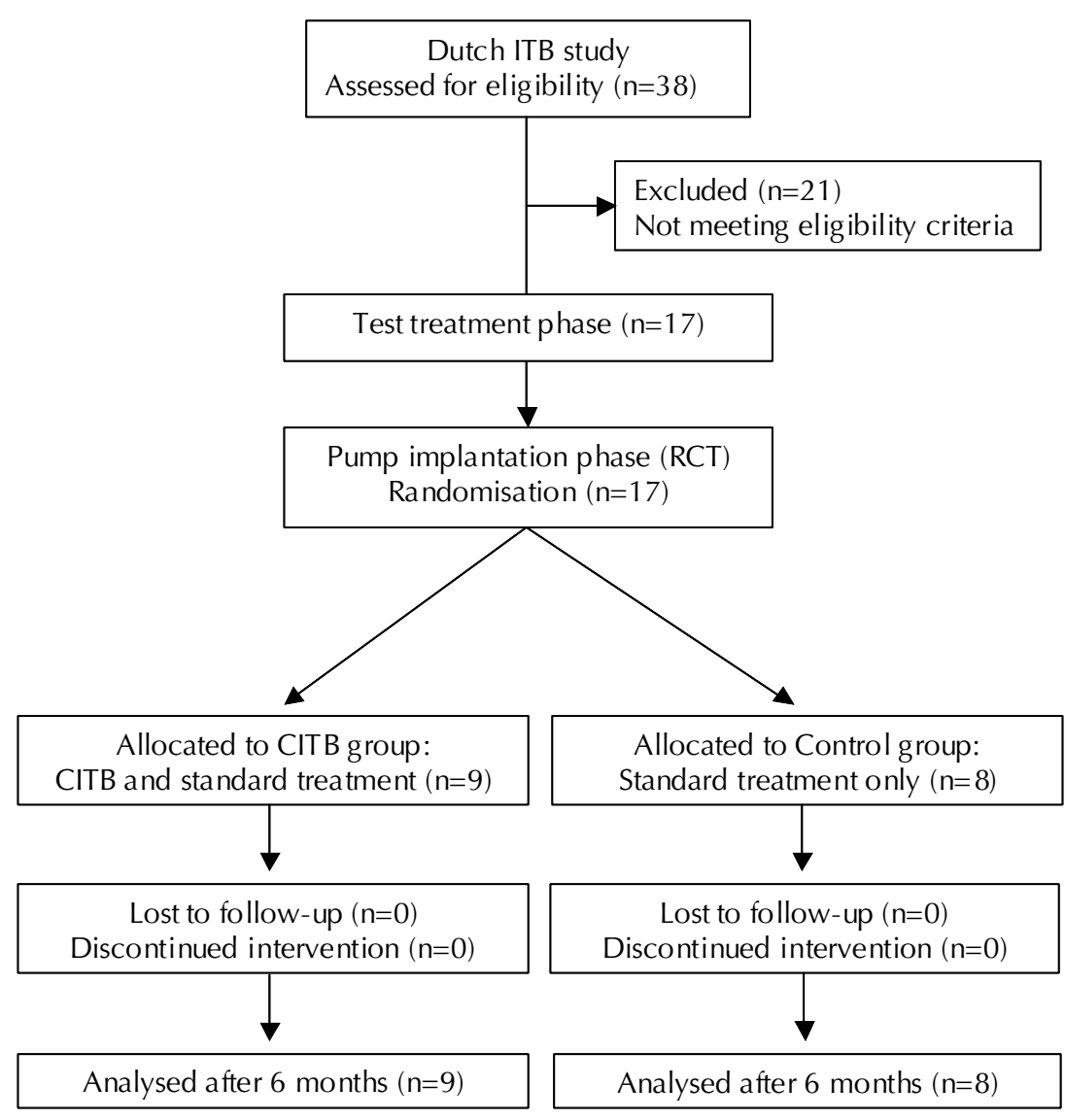

Figure 4.1 CONSORT flow diagram for the first three phases of the Dutch ITB study

The VAS is a valid and reliable measure for rating pain intensity in children over six, and has also been used to measure anxiety, sadness, anger, worry, happiness and fatigue. ${ }^{10-12}$ The VAS showed preliminary reliability and validity for both child self-report and parent-proxy report. ${ }^{10}$ When clinicians rated the VAS, the VAS validly identified the minimal clinically important difference on the PEDI. ${ }^{13}$ Since the children in our study had different problems, we used a separate VAS for three individually formulated problems per child. We used the average of these three VAS scores for statistical analysis. ${ }^{10}$ Since ease of care and pain were the most frequently reported problems, we also analysed these VASs separately. The VAS is a straight 10-cm horizontal line with anchor points 'very dissatisfied' (score 0 ) and 'very satisfied' (score 10). ${ }^{5}$ Depending on both the ability to 
understand the test and to draw a vertical line, the VAS was rated by the child or by a parent. Two children and 15 parents rated the VASs.

The study included several secondary outcome measures. In the ICF domain of body functions and structures, we used the original Ashworth scale. ${ }^{5}$ Ashworth scores were bilaterally assessed by the same experienced paediatric physical therapist in four upper extremity muscle groups (elbow and wrist flexors and extensors) and seven lower extremity muscle groups (hip adductors, flexors and extensors; knee flexors and extensors; and ankle plantarflexors and dorsiflexors). ${ }^{14}$ Since the Ashworth scale is an ordinal scale, we separately analysed the scores of the 22 muscle groups.

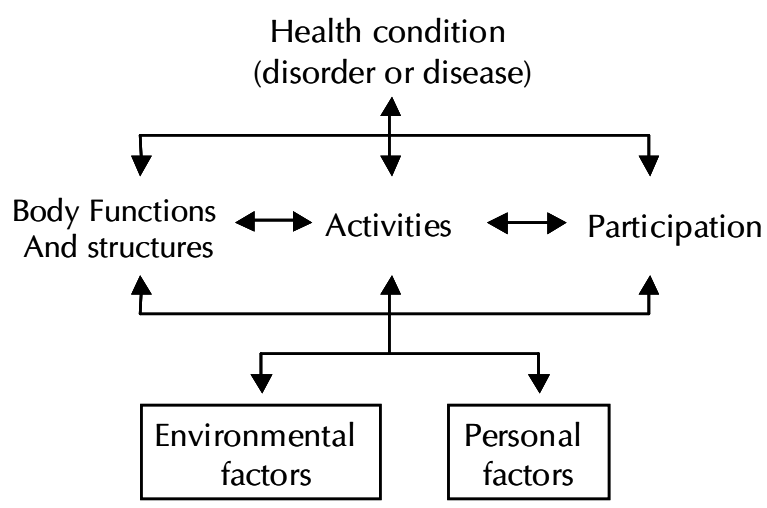

Figure 4.2 International Classification of Functioning, Disability and Health (ICF) model of Disability

In the ICF domains of activities and participation, we used the Dutch versions of the PEDI and the Gross Motor Function Measure (GMFM), both valid and reliable measures. ${ }^{15}$ Within the self-care domain, we used the Functional Skills scale, which measures capability, and the Caregiver Assistance scale, which measures performance. ${ }^{16}$ The GMFM is a criterion-referenced observational measure for addressing change in gross motor function for children with CP. The 88 items of the GMFM are scored on a 4-point ordinal scale and grouped into five dimensions: 1) lying and rolling, 2) sitting, 3) crawling and kneeling, 4) standing, and 5) walking, running and jumping. Five-year-old children without motor delays are usually able to accomplish all GMFM items. We used the GMFM-88 in two ways. First, we addressed the scores per dimension, expressed as a percentage of the maximum score for that dimension. Second, we defined any goal dimensions per child. In case we selected more than one goal dimension, the percentage scores of the chosen dimensions were averaged. In addition to the 
GMFM-88, we used the 66-item version of the GMFM, which is based on interval scaling and has good psychometric properties. ${ }^{17}$

Since CP specific health related quality of life (HRQL) measures were lacking, we used the Dutch version of the Child Health Questionnaire-Parent Form 50 (CHQPF50). ${ }^{18}$ The CHQ-PF50 is a generic child health instrument designed to measure the physical and psychosocial well-being of children aged 5 years and older. ${ }^{18}$ The $\mathrm{CHQ}$ comprises several domains that are scaled from 0 to 100 . Higher scores reflect a better HRQL. Physical and psychosocial summary scores were calculated using normative data from North American children. ${ }^{18}$

\section{Statistical analysis}

We used SPSS for Windows statistical package, Release 11.0.1. for statistical analyses. Because of the small sample size, we used the non-parametric MannWhitney $U$ Test to compare the change in outcome measures between baseline and follow-up at 6 months in the CITB and the Control group. Results with $p \leq 0.05$ were considered statistically significant. The Mann-Whitney $U$ Test only supplies $p$-values without information on effect sizes and their confidence intervals. To gain insight in the effect sizes, we calculated medians with ranges for ordinal measures and means with standard deviations for interval and ratio measures.

\section{Power calculation}

We based the power calculation on the results of a study about children with spastic CP, who were treated with selective dorsal rhizotomy. ${ }^{19}$ In this study, Caregiver Assistance scaled scores of the PEDI self-care domain at baseline and 12-month follow-up were compared. After 12 months, PEDI scores had significantly improved with $4.42 \pm 1.32$ points. We assumed that in our study, the children would not have reached maximum improvement after 6 months yet. Therefore, we set the clinically significant difference worth to detect in our study, at three points with an estimated standard deviation of 1.82 points. With a significance level of 0.05 and a power of $90 \%$, the number of patients needed per group $=\left(2 \sigma^{2} / \delta^{2}\right) *(\alpha+\beta)^{2}=7.7=8$. In total 16 children were needed. Allowing for a drop out of $10 \%$, a maximum of 18 children would be included.

\section{Ethical aspects}

The study was approved by the medical ethical committee of the University Hospital Maastricht and the Maastricht University. In accordance with local legislation, we obtained written informed consent from the parents, and also from the children if they were aged 12 years or older and capable of understanding the nature and impact of the study. 


\section{RESULTS}

\section{Participants and procedures}

Nine children were assigned to the CITB group and eight children to the Control group (Figure 4.1). Table 4.2 shows the baseline characteristics. Children were randomised from July 2002 until January 2005. The last follow-up visit for this phase of the Dutch ITB study was attended in October 2005. In the CITB group, the mean time between the test treatment and pump implantation was $46 \pm 19$ days; the mean time between the pump implantation and the 6-month follow-up visit was $181 \pm 27$ days. In the Control group, the mean time between the test treatment and the 6-month follow-up visit was $183 \pm 26$ days. The neurosurgeon placed the catheter tip under fluoroscopic guidance between T5-T7 in all children. In the CITB group, the mean daily CITB dose was $67 \pm 25 \mu \mathrm{g}$ right after pump implantation and $176 \pm 118 \mu \mathrm{g} 6$ months later. Three children in the CITB group and four in the Control group used oral baclofen. The children in the CITB group gradually discontinued this use, all during the first 10 postoperative days.

Table 4.2 Baseline characteristics per group

\begin{tabular}{|c|c|c|c|c|c|c|c|c|c|c|c|c|}
\hline \multirow[t]{2}{*}{ Group } & \multirow[t]{2}{*}{$\mathrm{n}$} & \multicolumn{2}{|c|}{$\begin{array}{l}\text { Age } \\
(y)\end{array}$} & \multirow{2}{*}{$\begin{array}{l}\text { Sex } \\
\text { M/F }\end{array}$} & \multirow{2}{*}{$\begin{array}{c}\begin{array}{c}\text { Weight } \\
(\mathrm{kg})\end{array} \\
\text { Mean } \pm \text { SD }\end{array}$} & \multirow{2}{*}{$\begin{array}{c}\text { Oral } \\
\text { baclofen } \\
\text { (n) }\end{array}$} & \multicolumn{3}{|c|}{$\begin{array}{l}\text { GMFCS } \\
\text { level (n) }\end{array}$} & \multirow{2}{*}{$\begin{array}{c}\text { Spasticity } \\
\text { type (n) } \\
\text { Diplegia/ } \\
\text { Tetraplegia }\end{array}$} & \multicolumn{2}{|c|}{$\begin{array}{c}\text { CP type } \\
(\mathrm{n})\end{array}$} \\
\hline & & Mean \pm SD & $\begin{array}{l}\text { Median } \\
\text { (range) }\end{array}$ & & & & III & IV & V & & Spastic & $\begin{array}{c}\text { Spastic- } \\
\text { dyskinetic }\end{array}$ \\
\hline CITB & 9 & $13.9 \pm 2.3$ & $15.0(10-16)$ & $5 / 4$ & $36.4 \pm 20.3$ & 3 & 0 & 1 & 8 & $1 / 8$ & 7 & 2 \\
\hline Control & 8 & $12.4 \pm 3.2$ & $12.5 \quad(7-16)$ & $3 / 5$ & $40.9 \pm 17.3$ & 4 & 1 & 1 & 6 & $2 / 6$ & 5 & 3 \\
\hline
\end{tabular}

GMFCS $=$ Gross Motor Function Classification System

\section{Effects}

Table 4.3 shows the effects for all outcome measures, except for the original Ashworth scale (too many data). Table 4.4 shows the distribution of the 51 individually formulated problems among both trial groups. The VAS for individual problems improved with $4.0 \pm 1.7$ in the CITB group and changed with $-0.2 \pm 1.3$ in the Control group ( $p=0.001$; Figure 4.3). The 6-month-change score of the PEDI Caregiver Assistance scale of the self-care domain did not significantly differ between both trial groups $(p=0.720)$. 


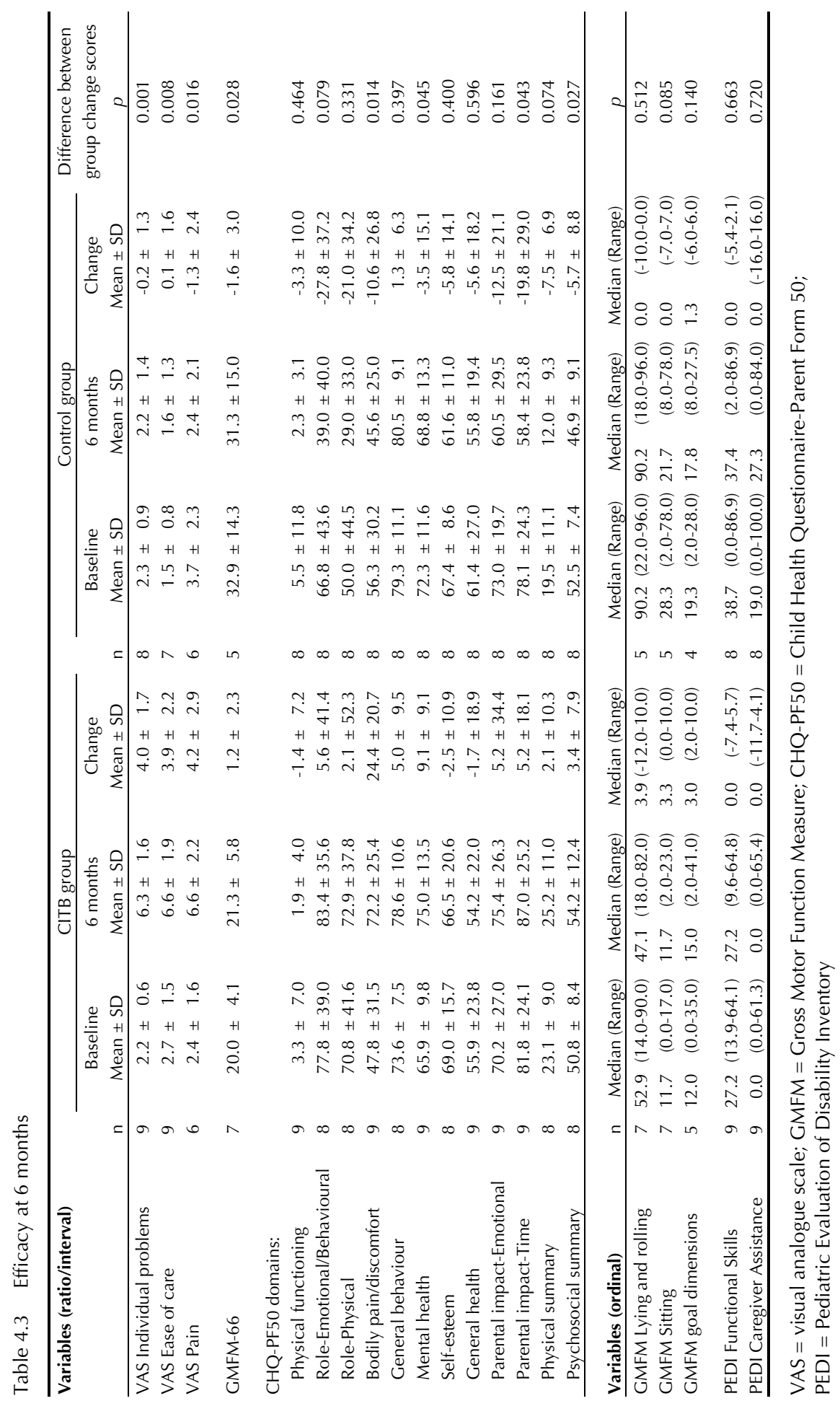


Table 4.4 Distribution of the individually formulated problems per group

\begin{tabular}{|c|c|c|c|c|c|c|c|c|c|}
\hline Group & $\mathrm{n}$ & $\begin{array}{c}\text { Ease of } \\
\text { care } \\
(\mathrm{n})\end{array}$ & $\begin{array}{l}\text { Pain } \\
\text { (n) }\end{array}$ & $\begin{array}{l}\text { Transfers } \\
\text { (n) }\end{array}$ & $\begin{array}{c}\text { Sitting } \\
\text { position } \\
(\mathrm{n})\end{array}$ & $\begin{array}{c}\text { Use of } \\
\text { wheelchair } \\
\text { (n) }\end{array}$ & $\begin{array}{l}\text { Startle } \\
\text { response } \\
(\mathrm{n})\end{array}$ & $\begin{array}{l}\text { Urinating } \\
\text { (n) }\end{array}$ & $\begin{array}{l}\text { Miscellaneous } \\
(\text { all } n=1) \\
\end{array}$ \\
\hline CITB & 9 & 9 & 6 & 3 & 3 & 1 & 0 & 1 & $\begin{array}{l}\text { Pushing head backwards } \\
\text { Absent hand function } \\
\text { Sleep } \\
\text { Tense body feeling }\end{array}$ \\
\hline Control & 8 & 7 & 6 & 2 & 0 & 2 & 2 & 1 & $\begin{array}{l}\text { Right arm function } \\
\text { Extreme excitement during eating } \\
\text { Walking distance } \\
\text { Energy use during walking }\end{array}$ \\
\hline
\end{tabular}

In the ICF domain of body functions and structures, the 6-month-change Ashworth score between both trial groups significantly differed in favour of the CITB group for the right wrist flexors $(p=0.038)$, the left hip adductors $(p=0.025)$ and both hip flexors (right $p=0.022$, left $p=0.043$ ). The VAS for ease of care improved with $3.9 \pm 2.2$ in the CITB group and with $0.1 \pm 1.6$ in the Control group ( $p=0.008$; Figure 4.4). The VAS for pain improved with $4.2 \pm 2.9$ in the CITB group and worsened with $-1.3 \pm 2.4$ in the Control group $(p=0.016$; Figure 4.5).

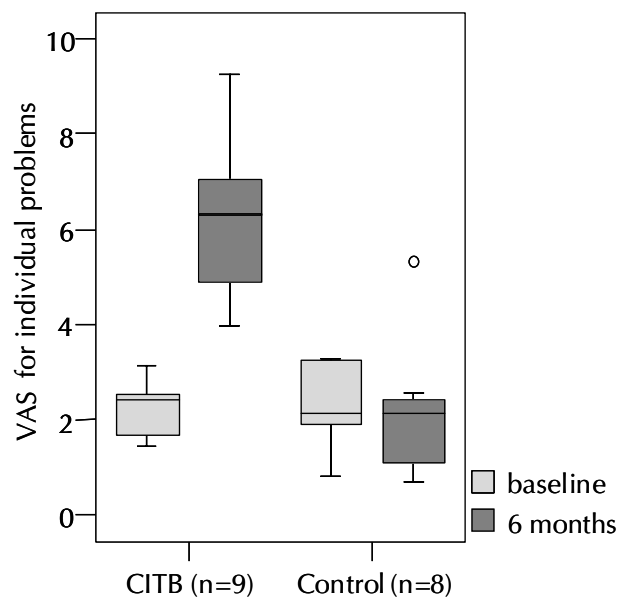

Figure 4.3 Change in the 0-10 VAS for individual problems per group. A higher VAS score represents less problems 


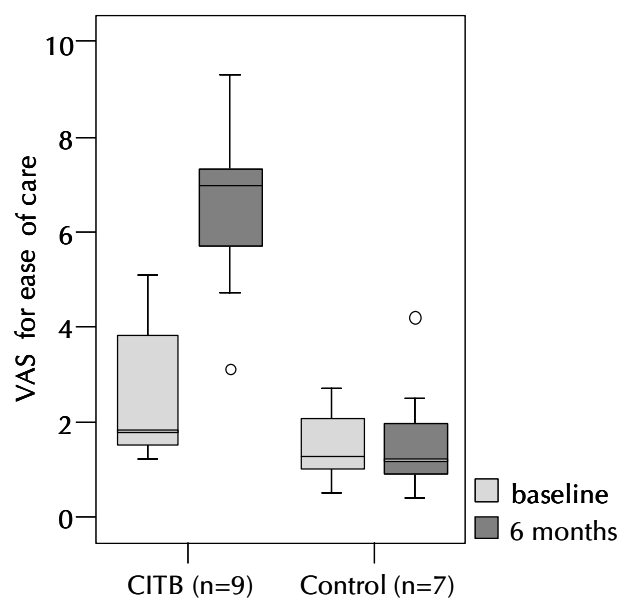

Figure 4.4 Change in the 0-10 VAS for ease of care per group. A higher VAS score represents improved ease of care

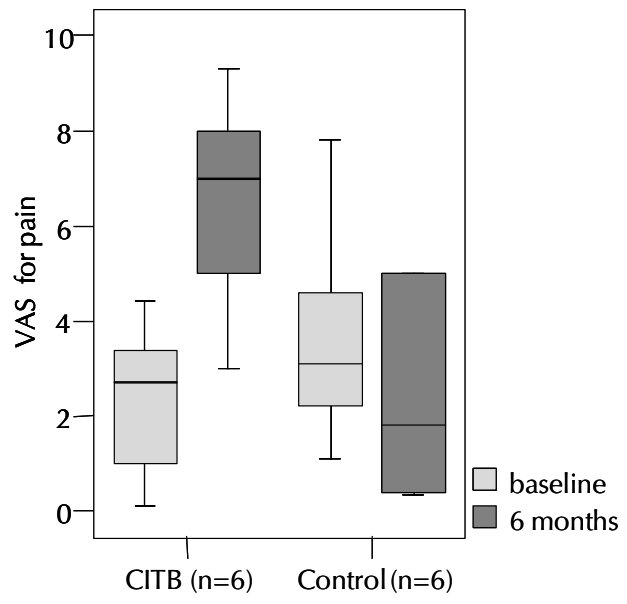

Figure 4.5 Change in the 0-10 VAS for pain per group. A higher VAS score represents less pain

In the ICF domains of activities and participation, the GMFM-66 improved with $1.2 \pm 2.3$ points in the CITB group and worsened with $-1.6 \pm 3.0$ points in the Control group $(p=0.028)$. The GMFM-88 sitting dimension improved with 3.3 points (range 0.0 to 10.0) in the CITB group and remained unchanged in the Control group (median 0.0 points, range -7.0 to $7.0 ; p=0.085$ ). Table 4.5 shows the distribution of the nine GMFM goal dimensions among both trial groups. The 
GMFM goal dimension score improved with 3.0 points (range 2.0 to 10.0) in the CITB group and with 1.3 points (range -6.0 to 6.0 ) in the Control group $(p=0.140)$. The 6 -month-change score of the PEDI Functional Skills scale of the self-care domain did not significantly differ between both groups ( $p=0.663$ ).

Table 4.5 Distribution of Gross Motor Function Measure (GMFM) goal dimensions per group

\begin{tabular}{|c|c|c|c|c|c|c|c|c|c|c|}
\hline \multirow[t]{2}{*}{ Group } & \multirow[t]{2}{*}{$n$} & \multirow{2}{*}{$\begin{array}{c}\text { Age } \\
(y) \\
\text { Mean } \pm \text { SD }\end{array}$} & \multirow{2}{*}{$\begin{array}{l}\text { Sex } \\
M / F\end{array}$} & \multirow{2}{*}{$\begin{array}{c}\text { Spasticity type } \\
\text { (n) } \\
\text { Diplegia/ } \\
\text { Tetraplegia }\end{array}$} & \multicolumn{2}{|c|}{$\begin{array}{l}\text { CP type } \\
(\mathrm{n})\end{array}$} & \multirow{2}{*}{$\begin{array}{l}\text { GMFCS } \\
\text { level (n) } \\
\text { III IV V }\end{array}$} & \multicolumn{3}{|c|}{$\begin{array}{l}\text { GMFM goal dimensions } \\
(\mathrm{n})\end{array}$} \\
\hline & & & & & Spastic & $\begin{array}{c}\text { Spastic- } \\
\text { dyskinetic }\end{array}$ & & $\begin{array}{l}\text { Lying/ } \\
\text { rolling }\end{array}$ & Sitting & $\begin{array}{l}\text { Standing/ } \\
\text { walking }\end{array}$ \\
\hline CITB & 5 & $13.4 \pm 2.7$ & $3 / 2$ & $1 / 4$ & 3 & 2 & $\begin{array}{lll}0 & 1 & 4\end{array}$ & 1 & 4 & 0 \\
\hline Control & 4 & $14.5 \pm 1.9$ & $2 / 2$ & $2 / 2$ & 3 & 1 & $\begin{array}{lll}1 & 1 & 2\end{array}$ & 0 & 2 & 2 \\
\hline
\end{tabular}

The CHQ-PF50 domain score of bodily pain/discomfort improved with $24.4 \pm 20.7$ points in the CITB group and worsened with $-10.6 \pm 26.8$ points in the Control group $(p=0.014)$. This also counted for the domains of mental health (CITB group $9.1 \pm 9.1$ points versus Control group $-3.5 \pm 15.1$ points; $p=0.045$ ), parental impact-time (CITB group $5.2 \pm 18.1$ points versus Control group $19.8 \pm 29.0$ points; $p=0.043$ ) and the psychosocial summary score (CITB group $3.4 \pm 7.9$ points versus Control group $-5.7 \pm 8.8$ points; $p=0.027$ ).

\section{DISCUSSION}

This is the first RCT addressing the efficacy of CITB in children with intractable spastic CP. Because of the varying nature of the children and the numerous outcomes of primary interest, others have considered a RCT practically impossible or inappropriate for evaluating treatment in children with $\mathrm{CP} .{ }^{20}$ In our present RCT, CITB reduced individually formulated problems, it relieved pain, and it improved both ease of care and gross motor functioning, significantly. Moreover, the HRQL significantly improved for the domains of bodily pain/discomfort, mental health (the extent of anxiety, depression and positive affect), psychosocial status, and parents' personal time limitation.

Since the review of the American Academy for Cerebral Palsy and Developmental Medicine, a few reports about ITB treatment including children with $\mathrm{CP}$, have been published. ${ }^{21-27}$ Though we cannot directly compare or contrast our results with these non-randomised studies, our findings are in keeping with previous reports. In our study, the main indications for CITB were pain and problems with ease of care. CITB attenuates spasticity associated pain, but also exerts direct antinociceptive effects. ${ }^{28,29}$ Contrary to the significant improvement on the VAS for ease of care, the two PEDI self-care domain scores 
did not improve. This means that the facilitation in ease of care did not comprise that the children could take better care of themselves, nor that they needed less assistance. According to the caregivers, the decrease in muscle tone and pain both facilitated ease of care and made care less time consuming. Nine children in our study had one or more functional goals. In comparison with standard treatment only, the GMFM-66 score improved significantly, while the GMFM goal dimension score improved non-significantly. We believe CITB accounted for the improved gross motor functioning, since mean GMFM scores of children with serious CP (Gross Motor Function Classification System (GMFCS) levels III-V) without specific treatment (ITB, botulinum toxin, selective dorsal rhizotomy) reach a plateau by 7 years of age. ${ }^{30}$ The efficacy of CITB was also manifested in an improved HRQL. Although HRQL measurement has a high priority in current $\mathrm{CP}$ research, previous reports on CITB in children with spastic CP did not include HRQL measures.

Our present study has a few limitations. The first concerns the inability to blind the participants and investigators for group assignment. Secondly, the generalisability of the results is confined to relatively older children with intractable spastic CP who rely on wheeled mobility (GMFCS levels IV and V). However, in clinical practice CITB is mostly indicated for children with GMFCS levels IV and $\mathrm{V}^{27}$

We conclude that CITB is effective in the treatment of carefully selected children with problems caused by intractable spastic CP. The safety and 1-year efficacy of CITB will be addressed in our article on the follow-up phase of the Dutch ITB study (Chapter 5 of this thesis). 


\section{REFERENCES}

1. Kuban KC, Leviton A. Cerebral palsy. N Engl J Med 1994;330:188-195.

2. Surman G, Bonellie S, Chalmers J, Colver A, Dolk H, Hemming K, King A, Kurinczuk JJ, Parkes J, Platt MJ. UKCP: a collaborative network of cerebral palsy registers in the United Kingdom. J Public Health (Oxf) 2006;28:148-156.

3. Albright AL, Ferson SS. Intrathecal baclofen therapy in children. Neurosurg Focus 2006;21: 1-6.

4. Butler C, Campbell S. Evidence of the effects of intrathecal baclofen for spastic and dystonic cerebral palsy. AACPDM Treatment Outcomes Committee Review Panel. Dev Med Child Neurol 2000;42:634-645.

5. Hoving MA, van Raak EPM, Spincemaille GHJJ, Palmans LJ, Sleypen FAM, Vles JSH, on behalf of the Dutch Study Group on Child Spasticity. Intrathecal baclofen in children with spastic cerebral palsy: a double-blind, randomized, placebo-controlled, dose-finding study. Dev Med Child Neurol 2007;49:654-659 (Chapter 3 of this thesis).

6. Hoving MA, Evers SMAA, Ament AJHA, van Raak EPM, Vles JSH, on behalf of the Dutch Study Group on Child Spasticity. Intractable spastic cerebral palsy in children: a Dutch cost of illness study. Dev Med Child Neurol 2007;49:397-398 (Chapter 7 of this thesis).

7. Hoving MA, Smulders NM, Abdul Fatah B, van Kroonenburgh MJ, van Raak EPM, Spincemaille GHJJ, Vles JSH, on behalf of the Dutch Study Group on Child Spasticity. The use of an Indium111 DTPA flow study in the evaluation of a lumbar swelling in a girl with a baclofen pump. Neuropediatrics 2006;37:99-101 (Chapter 6 of this thesis).

8. Hoving MA, van Kranen-Mastenbroek VHJM, van Raak EPM, Spincemaille GHJJ, Hardy ELM, Vles JSH, on behalf of the Dutch Study Group on Child Spasticity. Placebo controlled utility and feasibility study of the H-reflex and flexor reflex in spastic children treated with intrathecal baclofen. Clin Neurophysiol 2006;117:1508-1517 (Chapter 2 of this thesis).

9. International Classification of Functioning, Disability and Health. World Health Organization. Geneva, 2002.

10. Sherman SA, Eisen S, Burwinkle TM, Varni JW. The PedsQL Present Functioning Visual Analogue Scales: preliminary reliability and validity. Health Qual Life Outcomes 2006;4:75.

11. Hunt O, Burden D, Hepper P, Stevenson M, Johnston C. Parent reports of the psychosocial functioning of children with cleft lip and/or palate. Cleft Palate Craniofac J 2007;44:304-311.

12. Stinson JN, Kavanagh T, Yamada J, Gill N, Stevens B. Systematic review of the psychometric properties, interpretability and feasibility of self-report pain intensity measures for use in clinical trials in children and adolescents. Pain 2006;125:143-157.

13. Iyer LV, Haley SM, Watkins MP, Dumas HM. Establishing minimal clinically important differences for scores on the pediatric evaluation of disability inventory for inpatient rehabilitation. Phys Ther 2003;83:888-898.

14. Ashworth B. Preliminary trial of carisoprodol in multiple sclerosis. Practitioner 1964;192: 540-2.

15. Ketelaar $M$, Vermeer $A$, Helders PJ. Functional motor abilities of children with cerebral palsy: a systematic literature review of assessment measures. Clin Rehabil 1998;12:369-380.

16. Ostensjo S, Bjorbaekmo W, Carlberg EB, Vollestad NK. Assessment of everyday functioning in young children with disabilities: an ICF-based analysis of concepts and content of the Pediatric Evaluation of Disability Inventory (PEDI). Disabil Rehabil 2006;28:489-504.

17. Russell DJ, Avery LM, Rosenbaum PL, Raina PS, Walter SD, Palisano RJ. Improved scaling of the gross motor function measure for children with cerebral palsy: evidence of reliability and validity. Phys Ther 2000;80:873-885.

18. Landgraf JM, Abetz L, Ware JE. The CHQ user's manual. Boston: The Health Institute, New England Medical Center, 1996.

19. van Schie PEM, Vermeulen RJ, van Ouwerkerk WJR, Kwakkel G, Becher JG. Selective dorsal rhizotomy in cerebral palsy to improve functional abilities: evaluation of criteria for selection. Child Nerv Syst 2005;21:451-457.

20. Stanley F, Blair E, Alberman E. Epidemiological issues in evaluating the management of cerebral palsy. In: Bax MCO, ed. Cerebral palsies: epidemiology and causal pathways. Vol. 151. London: Mac Keith Press, 2000;176-194. 
21. Campbell WM, Ferrel A, McLaughlin JF, Grant GA, Loeser JD, Graubert C, Bjornson K. Longterm safety and efficacy of continuous intrathecal baclofen. Dev Med Child Neurol 2002;44:660-665.

22. Murphy NA, Irwin MC, Hoff C. Intrathecal baclofen therapy in children with cerebral palsy: efficacy and complications. Arch Phys Med Rehabil 2002;83:1721-1725.

23. Awaad Y, Tayem H, Munoz S, Ham S, Michon AM, Awaad R. Functional assessment following intrathecal baclofen therapy in children with spastic cerebral palsy. J Child Neurol 2003;18: 26-34.

24. Vloeberghs M, Keetley R, Morton R. Intrathecal baclofen in the management of spasticity due to cerebral palsy. Pediatr Rehabil 2005;8:172-179.

25. Scheinberg A, O'Flaherty S, Chaseling R, Dexter M. Continuous intrathecal baclofen infusion for children with cerebral palsy: a pilot study. J Paediatr Child Health 2001;37:283-288.

26. Albright AL, Awaad Y, Muhonen M, Boydston WR, Gilmartin R, Krach LE, Turner M, Zidek KA, Wright E, Swift D, Bloom K. Performance and complications associated with the synchromed 10-ml infusion pump for intrathecal baclofen administration in children. J Neurosurg 2004;101(1 Suppl):64-68.

27. Motta F, Buonaguro V, Stignani C. The use of intrathecal baclofen pump implants in children and adolescents: safety and complications in 200 consecutive cases. J Neurosurg 2007;107(1 Suppl):32-35.

28. Malcangio M, Bowery NG. GABA and its receptors in the spinal cord. Trends Pharmacol Sci 1996;17:457-462.

29. Bowery NG. GABAB receptor: a site of therapeutic benefit. Curr Opin Pharmacol 2006;6: 37-43.

30. Rosenbaum PL, Walter SD, Hanna SE, Palisano RJ, Russell DJ, Raina P, Wood E, Bartlett DJ, Galuppi BE. Prognosis for gross motor function in cerebral palsy: creation of motor development curves. JAMA 2002;288:1357-1363. 



\section{CHAPTER 5}

Safety and one-year efficacy of intrathecal

baclofen therapy in children with intractable

spastic cerebral palsy

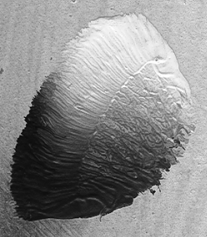

MA Hoving, EPM van Raak, GHJJ Spincemaille, VHJM van Kranen-Mastenbroek, M van Kleef, JW Gorter, JSH Vles, on behalf of the Dutch Study Group on Child Spasticity

Submitted 


\section{ABSTRACT}

\section{Background}

Prospective studies that address both efficacy and safety of continuous infusion of intrathecal baclofen in children with spastic cerebral palsy, and that use outcome measures beyond muscle tone, are lacking.

\section{Aims}

To study the efficacy at 12 months and safety up to 24 months after start of continuous infusion of intrathecal baclofen in children with intractable spastic cerebral palsy.

\section{Methods}

Nine girls and eight boys, aged $13.7 \pm 2.9$ years, received a Synchromed pump for continuous infusion of intrathecal baclofen. We prospectively recorded effects and adverse events at regular follow-up visits up to 24 months. Outcome measures included the 0-10 visual analogue scale for individual problems, Gross Motor Function Measure and health related quality of life as measured with the Child Health Questionnaire-PF50.

\section{Results}

Continuous infusion of intrathecal baclofen for 12 months significantly improved the visual analogue scale for individual problems with $4.7 \pm 2.0(p=0.000)$, visual analogue scale for ease of care with $5.2 \pm 2.1(p=0.000)$, visual analogue scale for pain with $5.4 \pm 2.7(p=0.002)$; Gross Motor Function Measure sitting dimension with 3.3 points (range -4.0 to 22.0; $p=0.022$ ), Gross Motor Function Measure goal dimension with 4.0 points (range 0.0 to 26.0; $p=0.007$ ); and Child Health Questionnaire-PF50 domains of bodily pain/discomfort with $25.6 \pm 35.9$ points $(p=0.016)$ and mental health with $9.8 \pm 11.3$ points $(p=0.007)$. During a mean follow-up of 18.4 months (range 12 to 24 ), we recorded 80 adverse events. Eight adverse events were serious, but not life-threatening.

\section{Conclusions}

Continuous infusion of intrathecal baclofen was effective at 12 months and safe up to 24 months for carefully selected children with intractable spastic cerebral palsy. Continuous infusion of intrathecal baclofen relieved pain, facilitated ease of care and improved mental health. The majority of children could extend their activities and participation. 


\section{INTRODUCTION}

Continuous intrathecal baclofen infusion (CITB) can be very effective in the treatment of intractable spasticity. ${ }^{1}$ However, in 2000 the American Academy for Cerebral Palsy and Developmental Medicine stated that evidence for the use of CITB in children with cerebral palsy (CP) is lacking. ${ }^{2}$ Since then, a few studies about CITB that included children with spastic CP have been published. ${ }^{3-7}$ In a consecutive case series, Murphy et al. retrospectively studied the efficacy and complications of CITB in 23 children with CP. ${ }^{3}$ Side effects were not addressed. Another limitation of this study was the use of the Ashworth scale as single outcome measure. ${ }^{3}$ Campbell et al. reviewed the long-term safety and efficacy of CITB in the treatment of 21 children and adolescents. ${ }^{4}$ It mainly was a retrospective study, that included patients with spastic $\mathrm{CP}$, mixed type $\mathrm{CP}$, and patients with other causes of cerebral spasticity. ${ }^{4}$ Awaad et al. prospectively studied the efficacy of CITB in 29 patients with spastic CP, focussing on impairments, functional limitations and disability. ${ }^{5}$ They did not only include children, but also adults, whereas safety of CITB was not structurally addressed. ${ }^{5}$ Albright et al. prospectively evaluated the complications associated with CITB via a Synchromed EL 10-ml pump in 100 children of whom 90 were diagnosed with CP. ${ }^{6}$ Their study did not address efficacy and possible side effects of CITB. ${ }^{6}$ Motta et al. retrospectively studied the incidence of three common complications of CITB in 200 children (175 with CP) without addressing other safety aspects. ${ }^{7}$ We conclude that there still is a lack of prospective studies that address efficacy and safety of CITB in a homogeneous group of children with spastic CP, using outcome measures beyond the Ashworth scale.

In 2002, we started a Dutch national study on the efficacy and safety of CITB in children with intractable spastic CP. ${ }^{8-11}$ This study included a randomised controlled trial, which showed that CITB was effective in comparison with standard treatment only (Chapter 4 of this thesis). CITB for 6 months significantly relieved pain, and significantly improved individually formulated problems, ease of care, gross motor functioning and health related quality of life (HRQL) for the domains of bodily pain/discomfort, mental health, psychosocial status and parents' personal time limitation. Our present article describes the prospective continuation of the RCT. It addresses the one-year efficacy of CITB and its safety from pump implantation up to 24 months of follow-up. We discuss the efficacy of CITB both in terms of HRQL and in terms of body functions, activities and participation as defined in the International Classification of Functioning, Disability and Health (ICF). ${ }^{12}$ 


\section{METHODS}

Seventeen children, nine girls and eight boys, participated in the Dutch ITB study. We refer to our prior article for the eligibility criteria of this study. ${ }^{8}$ The children were aged $13.7 \pm 2.9$ years (range 7 to 17 ) at time of pump implantation. An experienced neurosurgeon inserted a programmable Synchromed infusion pump (Medtronic, Inc., Minneapolis, Minnesota) under general anaesthesia subcutaneously or, in children with little subcutaneous fat, subfascially in the lateral abdomen. All children received prophylactic antibiotics peroperative and during the first postoperative day. We programmed the pumps to infuse intrathecal baclofen in a simple continuous mode directly following implantation. We usually started with a daily CITB dose of twice the effective intrathecal baclofen test treatment bolus dose. ${ }^{8}$ We then optimised the CITB dose during hospitalisation and after discharge. After pump implantation, the children participated in the 3-monthly follow-up visits at the University Hospital Maastricht in the Netherlands for at least one year. The main investigator was present during all admissions and follow-up visits of the children.

\section{Outcome measures}

Figure 5.1 shows which outcome measures we used to evaluate efficacy during the first follow-up year. For details of the applied outcome measures, we refer to prior articles and our RCT (Chapter 4 of this thesis)., ${ }^{8,11}$ In addition, we always asked for changes in common $\mathrm{CP}$ associated problems, including speech, swallowing, bowel movements, urological problems, sleep, drooling, epileptic seizures and changes in transfers and in operating the wheelchair. Regarding their overall satisfaction with CITB we asked during the last follow-up visit, whether the children and their caregivers would participate in the test treatment and implantation procedures again.

\section{Adverse events}

We structurally recorded adverse events on standardised forms. We defined an adverse event as any undesirable experience occurring to a participant during the study, whether or not considered related to CITB. Adverse events included aggravation of symptoms or signs, which were present before CITB started. A serious adverse event was defined as any untoward medical occurrence or effect that: 1) resulted in death, 2) was life-threatening, 3) required hospitalisation or prolongation of existing hospitalisation, or 4) resulted in persistent or significant disability or incapacity. We subdivided the recorded adverse events in procedure and device related events and non-procedure and device related events. We also noted whether the event was temporary or enduring at time of the child's last 
follow-up visit. We related the total number of events to the number of follow-up patient-months.

\section{Statistical analysis}

We used SPSS for Windows statistical package, Release 11.0.1., for statistical analyses. We used the non-parametric Wilcoxon Signed Rank Test to compare the results of the outcome measures at the 6-month and 12-month follow-up visit with those at baseline. Baseline measurements were carried out before pump implantation (Figure 5.1). Results with $p \leq 0.05$ were considered statistically significant. The Wilcoxon Signed Rank Test only supplies $p$-values without information on effect sizes and their confidence intervals. To gain insight in the effect sizes, we calculated medians with ranges for ordinal measures, and means with standard deviations for interval and ratio measures.

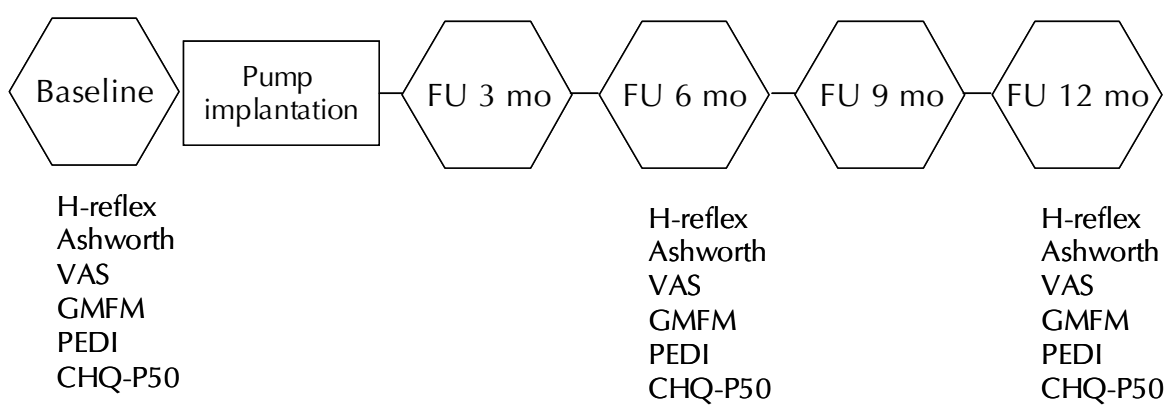

Figure 5.1 Outcome measures for measuring efficacy

$\mathrm{FU}=$ follow-up; $\mathrm{H}$-reflex = soleus $\mathrm{H}$-reflex; Ashworth = original Ashworth scale; VAS = visual analogue scale; GMFM = Gross Motor Function Measure; PEDI = Pediatric Evaluation of Disability Inventory; CHQ-PF50 = Child Health Questionnaire-Parent Form 50

\section{Ethical approval and consent}

The study was approved by the medical ethical committee of the University Hospital Maastricht and the Maastricht University. In accordance with local legislation, we obtained written informed consent from the parents, and also from the children if they were aged 12 years or older and capable of understanding the nature and impact of the study. 


\section{RESULTS}

\section{Participants}

Table 5.1 shows the clinical characteristics of the 17 participating children at time of pump implantation. One neurosurgeon implanted all pumps between September 2002 and April 2005. Table 5.2 summarises the pump implantation details per child. The neurosurgeon placed the catheter tip under fluoroscopic guidance between T5-T7 in all children. The mean CITB daily dose was $61 \pm 27$ $\mu \mathrm{g}$ directly after pump implantation, $189 \pm 132 \mu \mathrm{g}$ after 6 months and $233 \pm 170$ $\mu \mathrm{g}$ after 12 months. Seven children took oral baclofen at time of the pump implantation. It was gradually discontinued during the first 10 postoperative days in six children. In one child the dose was largely reduced (case 10). The last follow-up visit was attended in May 2006.

Table 5.1 Children's clinical characteristics at time of pump implantation

\begin{tabular}{|c|c|c|c|c|c|c|c|}
\hline$\overline{\text { Case }}$ & $\begin{array}{l}\text { Age } \\
\text { and } \\
\text { sex }\end{array}$ & $\begin{array}{c}\text { Weigh } \\
(\mathrm{kg})\end{array}$ & $\begin{array}{l}\text { Cerebral palsy } \\
\text { type }\end{array}$ & $\begin{array}{l}\text { Diplegia/ } \\
\text { tetraplegia }\end{array}$ & $\begin{array}{l}\text { GMFCS }^{a} \\
\text { level }\end{array}$ & $\begin{array}{c}\text { Oral } \\
\text { baclofen } \\
\text { dose }(\mathrm{mg} / \mathrm{kg})\end{array}$ & $\mathrm{CP}$ associated problems ${ }^{\mathrm{b}}$ \\
\hline 1 & $15 \mathrm{~F}$ & 36 & spastic/dyskinetic & tetra & V & - & con, uro \\
\hline 2 & $11 \mathrm{M}$ & 25 & spastic & tetra & V & - & spe, dro, con, uro, swa, brp \\
\hline 3 & $14 \mathrm{M}$ & 31 & spastic & tetra & $\mathrm{V}$ & - & spe, dro, con, uro, epi, brp \\
\hline 4 & $13 \mathrm{~F}$ & 40 & spastic/dyskinetic & tetra & V & - & spe, dro, con, swa, vis \\
\hline 5 & $16 \mathrm{M}$ & 84 & spastic & di & IV & - & con, slp \\
\hline 6 & $14 \mathrm{~F}$ & 63 & spastic/dyskinetic & tetra & V & 0.95 & spe, uro, slp, vis \\
\hline 7 & $9 \mathrm{~F}$ & 26 & spastic/dyskinetic & tetra & $\mathrm{V}$ & 1.15 & spe, dro, con, uro, swa, slp, epi, aud \\
\hline 8 & $17 \mathrm{M}$ & 53 & spastic & tetra & $\mathrm{V}$ & - & spe, dro, con, uro, epi \\
\hline 9 & $16 \mathrm{~F}$ & 35 & spastic & tetra & $\mathrm{V}$ & - & spe, dro, con, uro, swa, slp, vis, epi, brp \\
\hline 10 & $7 \mathrm{M}$ & 27 & spastic & tetra & $\mathrm{V}$ & 1.20 & spe, dro, uro, swa, slp, epi \\
\hline 11 & $14 \mathrm{M}$ & 18 & spastic & tetra & $\mathrm{V}$ & 0.56 & spe, dro, con, uro, swa, slp, vis, epi, brp \\
\hline 12 & $13 \mathrm{~F}$ & 33 & spastic & tetra & $\mathrm{V}$ & - & spe, dro, uro, vis \\
\hline 13 & $17 \mathrm{M}$ & 70 & spastic & di & III & 0.86 & con \\
\hline 14 & $17 \mathrm{~F}$ & 48 & spastic & di & IV & - & con, uro \\
\hline 15 & $16 \mathrm{~F}$ & 33 & spastic/dyskinetic & tetra & $\mathrm{V}$ & - & spe, dro, con, uro \\
\hline 16 & $11 \mathrm{~F}$ & 27 & spastic & tetra & V & 1.11 & spe, dro, con, uro, swa, vis \\
\hline 17 & $12 \mathrm{M}$ & 24 & spastic & tetra & $\mathrm{V}$ & 1.25 & spe, dro, con, swa, slp \\
\hline
\end{tabular}

${ }^{\mathrm{a}}$ GMFCS, Gross Motor Function Classification System; ${ }^{\mathrm{b}}$ spe = speech problem; dro = drooling; con = constipation; uro = urological problem; swa = difficulty swallowing; slp = sleeping disorder; vis = visual impairment; epi = epilepsy; brp = bronchopulmonary problem; aud = auditory problem

\section{Effects}

Table 5.3 shows the effects of CITB for all outcome measures, except for the original Ashworth scale (too many data). In the following sections we report the one-year efficacy of CITB. 
Table 5.2 Device, implantation and CITB dose ( $\mu \mathrm{g} /$ day) details per child

\begin{tabular}{llllrrc}
\hline Case & $\begin{array}{l}\text { SynchroMed } \\
\text { pump model }^{\mathrm{a}}\end{array}$ & $\begin{array}{l}\text { Position pump in } \\
\text { abdominal wall }^{\mathrm{b}}\end{array}$ & $\begin{array}{l}\text { Catheter } \\
\text { model }^{\mathrm{a}}\end{array}$ & $\begin{array}{r}\text { CITB starting } \\
\text { dose }\end{array}$ & $\begin{array}{r}\text { CITB dose at } \\
6 \text { months }\end{array}$ & $\begin{array}{c}\text { CITB dose at } \\
12 \text { months }\end{array}$ \\
\hline 1 & EL 8627-18 & Left SC & 8709 & 50 & 105 & 360 \\
2 & EL 8626L-10 & Left SC & 8709 & 50 & 200 & 215 \\
3 & EL 8626L-10 & Left SF & 8709 & 40 & 76 & 110 \\
4 & EL 8627-10 & Right SF & 8709 & 25 & 319 & 263 \\
5 & EL 8627-18 & Right SC & 8709 & 100 & 300 & 350 \\
6 & EL 8627L-18 & Left SC & 8731 & 100 & 530 & 740 \\
7 & II 8637-20 & Right SF & 8731 & 50 & 110 & 169 \\
8 & II 8637-20 & Left SC & 8731 & 100 & 415 & 456 \\
9 & II 8637-20 & Right SF & 8731 & 50 & 68 & 75 \\
10 & II 8637-20 & Left SC & 8731 & 25 & 120 & 132 \\
11 & II 8637-20 & Right SF/SC & 8731 & 50 & 88 & 106 \\
12 & II 8637-20 & Left SF & 8731 & 50 & 104 & 104 \\
13 & II 8637-20 & Left SC & 8731 & 100 & 143 & 142 \\
14 & II 8637-20 & Right SC & 8731 & 50 & 230 & 288 \\
15 & II 8637-20 & Right SF & 8731 & 100 & 210 & 210 \\
16 & II 8637-20 & Left SC & 8731 & 50 & 97 & 136 \\
17 & II 8637-20 & Left SF & 8731 & 50 & 101 & 101 \\
\hline
\end{tabular}

${ }^{a}$ Medtronic, Inc., Minneapolis, Minnesota; ${ }^{b}$ SC = subcutaneous; SF = subfascial

Table 5.4 lists the individually formulated problems of the children. The $0-10$ visual analogue scale (VAS) for individually formulated problems significantly improved with $4.7 \pm 2.0(p=0.000$; Figure 5.2). Because ease of care and pain were the most frequently reported problems, we also analysed these VASs separately. The VAS for ease of care significantly improved with $5.2 \pm 2.1$ $(p=0.000$; Figure 5.3). The VAS for pain significantly improved with $5.4 \pm 2.7$ $(p=0.002 ;$ Figure 5.4).

In the ICF domain of body functions and structures, the $\mathrm{H} / \mathrm{M}$ ratio at both legs decreased significantly $(p \leq 0.001)$. The Ashworth score decreased significantly in five out of eight upper extremity muscle groups $(0.008 \leq p \leq 0.046)$ and nine out of 14 lower extremity muscle groups $(0.002 \leq p \leq 0.046)$. As spasticity and pain decreased, children could extend their activities and participation in several ways. For instance, one boy (case 11) resumed swimming and 12 children could sit longer and/or more comfortably in their wheelchairs (cases 1-6 and cases 1015). The parents of one girl (case 4) could put the riding gloves on in two instead of the prior 20 minutes. Improved arm extension in another boy (case 8) meant he could grasp, move and push objects, which used to be out of reach. With CITB he became independent in operating the computer and entering and leaving the house. Four children resumed or improved supported standing, cycling and/or walking (cases 4, 13, 14, and 16). Moreover, seven families could more easily set off for visits and day trips (cases 3, 4, 6, 9-11, and 15). 


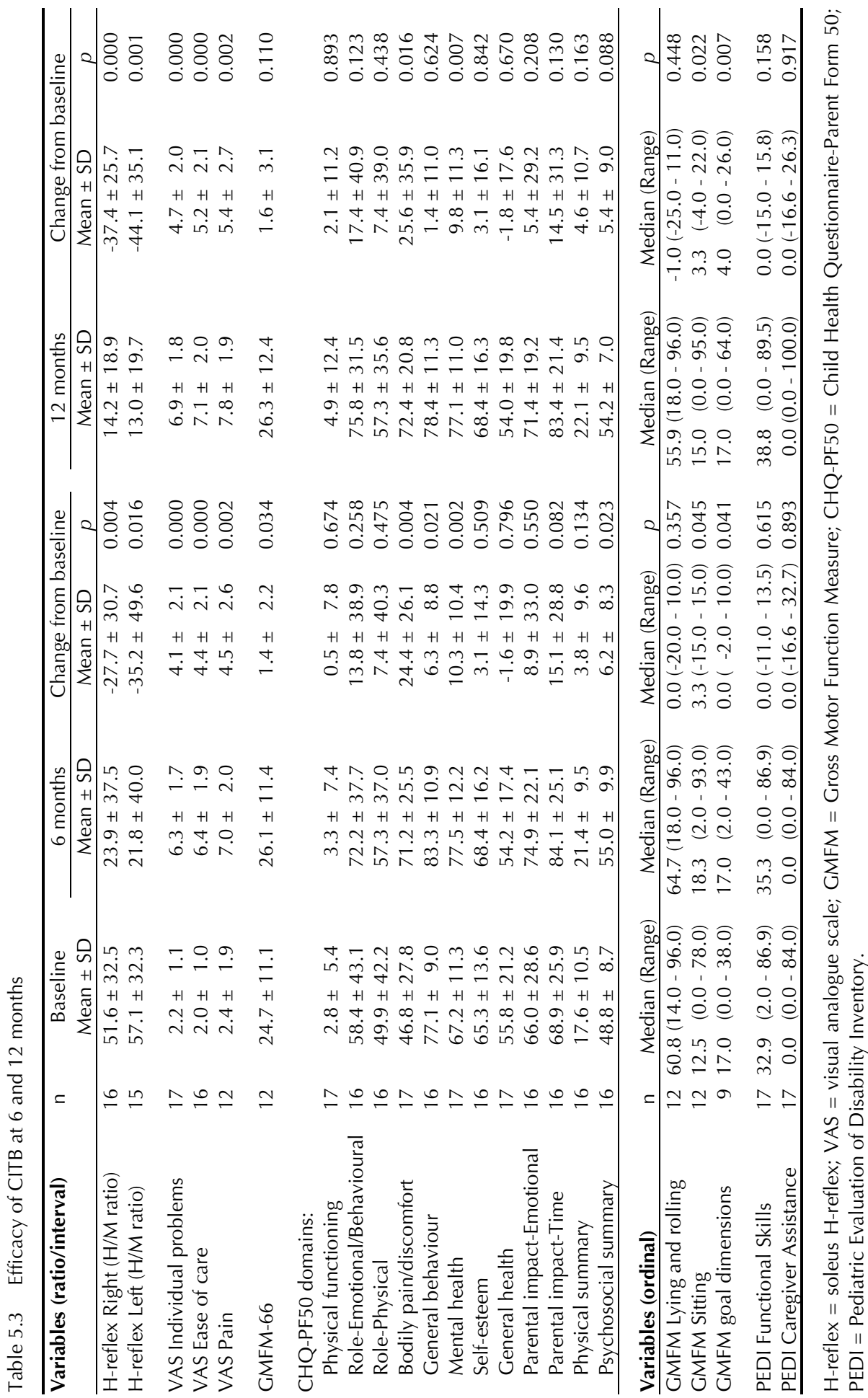


Table 5.4 Individually formulated problems (three per child)

\begin{tabular}{lr}
\hline Individual problem & $\mathrm{n}$ \\
\hline Ease of care & 16 \\
Pain & 12 \\
Transfers & 5 \\
Sitting position & 3 \\
Use of wheelchair & 3 \\
Startle response & 2 \\
Urinating & 2 \\
Pushing head backwards & 1 \\
Absent hand function & 1 \\
Sleep & 1 \\
Tense body feeling & 1 \\
Right arm function & 1 \\
Extreme excitement during eating & 1 \\
Walking distance & 1 \\
Energy use during walking & 1 \\
\hline Total & 51 \\
\hline
\end{tabular}

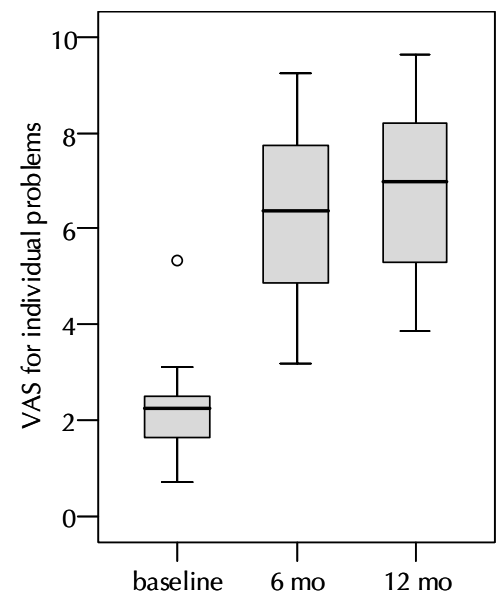

Figure 5.2 VAS (0-10) for individual problems at baseline and 6 and 12 months with CITB. A higher VAS score represents less problems 


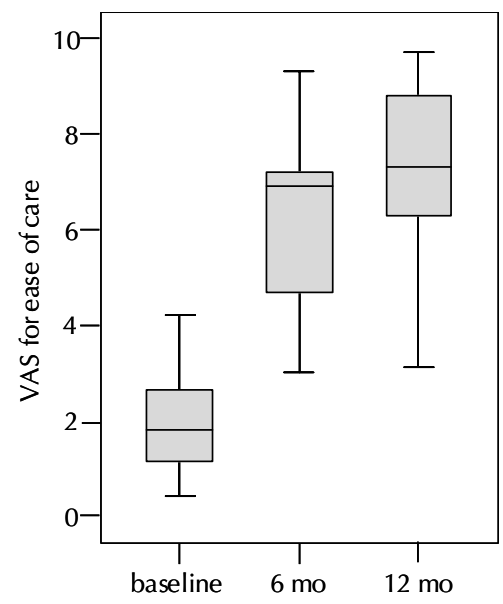

Figure 5.3 VAS (0-10) for ease of care at baseline and 6 and 12 months with CITB. A higher VAS score represents improved ease of care

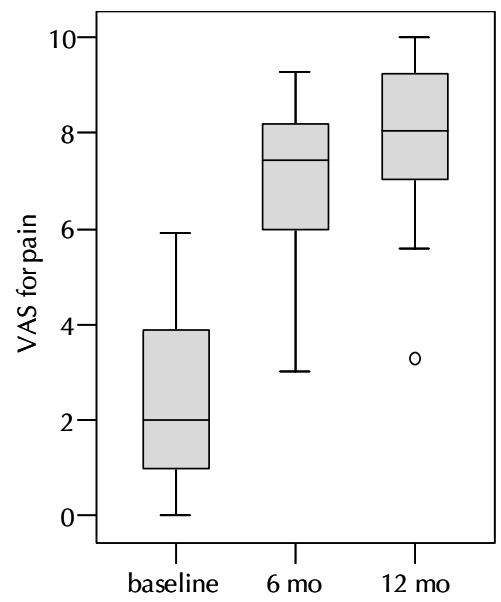

Figure 5.4 VAS (0-10) for pain at baseline and 6 and 12 months with CITB. A higher VAS score represents less pain

In the ICF domain of activities and participation, the GMFM sitting dimension score significantly improved with 3.3 points (range -4.0 to $22.0 ; p=0.022$ ). The GMFM goal dimension score significantly improved with 4.0 points (range 0.0 to 26.0; $p=0.007$ ). One boy who was classified at GMFCS level III (case 13), intended to improve his gait with CITB. Figure 5.5 shows his GMFM dimension scores over time. During the first 6 months with CITB he made progress within 
the GMFM sitting dimension after which he extended his standing and walking abilities. Within the self-care domain, PEDI Functional Skills and Caregiver Assistance scales did not improve with CITB.

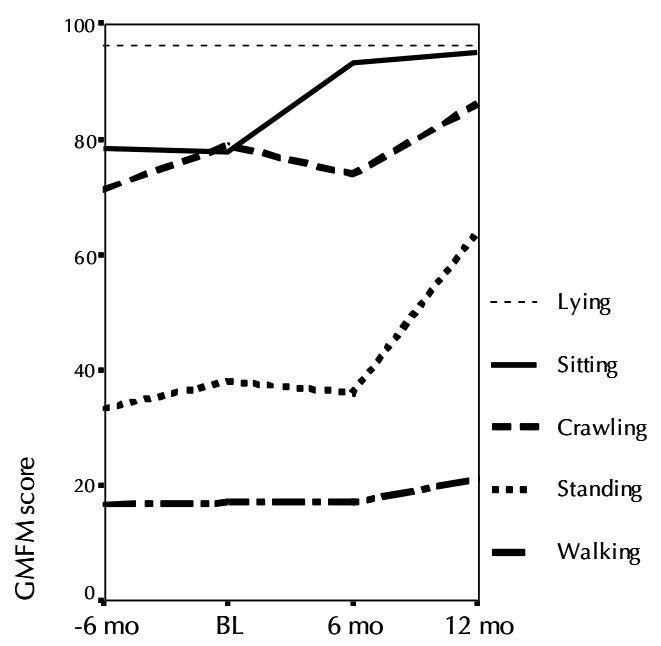

Figure 5.5 GMFM dimension scores of a boy (GMFCS level III) 6 months before pump implantation (-6 mo), at baseline (BL) and after 6 and 12 months with CITB

$\mathrm{HRQL}$, as measured on the 100-point child health questionnaire-parent form-50 scale, improved with $25.6 \pm 35.9$ points for bodily pain/discomfort $(p=0.016)$, with $9.8 \pm 11.3$ points for mental health $(p=0.007)$, and with $5.4 \pm 9.0$ points for the psychosocial status $(p=0.088)$. Table 5.5 summarises the effects on common $\mathrm{CP}$ associated problems at one year with CITB. Speech improved in three out of 13 children and swallowing in two out of eight children. In one child (case 3), both speaking and swallowing worsened along with the increasing CITB dose. Four out of five children could better operate their electric wheelchairs. One girl (case 4) used to suffer from extension spasms while riding. Moreover, in response to all kind of stimuli, her hand would lose contact with the joystick. With CITB she could safely and independently ride her electric wheelchair along a busy road, which resulted in an important increase in participation. Constipation improved in five out of 14 children. The bowel movements worsened in two out of 14 children due to problems pushing the faeces out of the rectum. In all children with constipation, the bowel movements could be well regulated with laxatives. CITB had a positive influence on sleep in five out of seven children due to a reduction in pain, spasms and, in one child (case 10), epileptic seizures. Transfers, all by carrying the child, improved in all four children. 
Table 5.5 Effects of CITB on common CP associated problems at 12 months

\begin{tabular}{|c|c|c|c|c|}
\hline \multirow[t]{2}{*}{ Problem } & \multirow{2}{*}{$\begin{array}{c}\text { Problem present } \\
\text { before CITB } \\
(\mathrm{n})\end{array}$} & \multicolumn{3}{|c|}{ Change with CITB } \\
\hline & & $\begin{array}{c}\text { Better } \\
(\mathrm{n})\end{array}$ & $\begin{array}{c}\text { No change } \\
(\mathrm{n})\end{array}$ & $\begin{array}{c}\text { Worse } \\
(\mathrm{n})\end{array}$ \\
\hline Constipation & 14 & 5 & 7 & 2 \\
\hline Urological problem & 13 & 0 & 12 & 1 \\
\hline Speech & 13 & 3 & 9 & 1 \\
\hline Drooling & 12 & 3 & 7 & 2 \\
\hline Swallowing & 8 & 2 & 5 & 1 \\
\hline Sleep & 7 & 5 & 2 & 0 \\
\hline Epilepsy & 6 & 2 & 4 & 0 \\
\hline Operating electric wheelchair & 5 & 4 & 1 & 0 \\
\hline Transfers & 4 & 4 & 0 & 0 \\
\hline
\end{tabular}

Before the start of CITB, six children had epilepsy of whom five used antiepileptic medications (Table 5.1). The child without medication (case 3) was known with 10-100 paroxysms of staring per week. With CITB this incidence clearly decreased. Another child (case 10) was diagnosed with symptomatic localisation bound epilepsy with on average three tonic seizures per month. With CITB, he became seizure free. One child kept being seizure free (case 7). Seizure activity did not change with CITB in two children (cases 9 and 11). One boy had been without seizures for years, when he experienced one tonic-clonic seizure 6 months after pump implantation (case 8). After the dose of his anticonvulsant was adjusted to his increased weight, he did not experience seizures anymore. One child (case 12) had three new-onset seizures in the first year with CITB. Two electroencephalograms, of which one after sleep deprivation, did not show epileptic discharges. We did not start antiepileptic medications, since the girl refused to take any.

\section{Adverse events}

We recorded adverse events for a mean duration of 18.4 months (range 12 to 24 months). Fourteen of the 17 children experienced a total of 51 non-procedure or device related adverse events during a follow-up of 312 patient-months (incidence 0.16 per patient-month [95\% Cl: 0.12-0.20]). Twenty-four different events were reported (Table 5.6). The most frequently observed event was lethargy, which occurred in eight children. In all children, the lethargy either disappeared spontaneously or after slightly reducing the CITB dose. Temporary pressure sores were noted in four children respectively at the toe, foot, hip and ear. Nausea, vomiting, excessive hypotonia and/or decreased appetite mainly occurred during the first postoperative days and seemed related to the taking of oral baclofen simultaneously with CITB. After we increased the CITB dose from $50 \mu \mathrm{g}$ to $58 \mu \mathrm{g}$, one boy (case 3) experienced relative hypotension and bradycardia, a headache, nausea and decreased appetite. These events 
disappeared by decreasing the dose and did not return during later dose increases. Five of the 51 non-procedure or device related adverse events were considered as serious, because they resulted in significant disability. None of the adverse events was life-threatening and no hospitalisation was necessary. The children with an excessive hypotonia all had a high tone of the extremities in combination with trunk hypotonia and a mediocre head balance.

Table 5.6 Non-procedure and device related adverse events (mean follow-up 18.4 months)

\begin{tabular}{|c|c|c|c|c|c|}
\hline \multirow[t]{2}{*}{ Adverse event } & \multirow{2}{*}{$\begin{array}{c}\text { Total } \\
(\mathrm{n})\end{array}$} & \multicolumn{2}{|c|}{ Adverse events (n) } & \multirow{2}{*}{$\begin{array}{c}\text { Number labelled } \\
\text { as serious }\end{array}$} & \multirow[t]{2}{*}{ Cases } \\
\hline & & Enduring & Temporary & & \\
\hline Constipation & 2 & & 2 & & 8,9 \\
\hline Sweating & 3 & 1 & 2 & & $1,2,4$ \\
\hline Dry mouth & 2 & & 2 & & 1,3 \\
\hline Lethargy & 8 & & 8 & & $1,2,3,4,6,7,13,16$ \\
\hline Drooling & 4 & 2 & 2 & & $1,4,16,17$ \\
\hline Hair loss & 1 & & 1 & & 1 \\
\hline Bradycardia & 1 & & 1 & & 3 \\
\hline Hypotension & 1 & & 1 & & 3 \\
\hline Nausea & 3 & & 3 & & $3,6,7$ \\
\hline Vomiting & 2 & & 2 & & 6,7 \\
\hline Decreased appetite & 2 & & 2 & & 3,7 \\
\hline Difficulty swallowing & 1 & 1 & & 1 & 3 \\
\hline Dyspnoea & 1 & & 1 & & 3 \\
\hline Dysarthria & 1 & 1 & & 1 & 3 \\
\hline Headache & 3 & & 3 & & $3,6,13$ \\
\hline Urinary incontinence & 1 & & 1 & & 5 \\
\hline Urinary hesitancy & 1 & 1 & & & 8 \\
\hline Faecal incontinence & 1 & & 1 & & 5 \\
\hline Pressure sore & 4 & & 4 & & $5,9,15,16$ \\
\hline Excessive hypotonia & 4 & 3 & 1 & 2 & $4,7,16,17$ \\
\hline Paroxysmal dizziness & 1 & & 1 & & 8 \\
\hline Paroxysmal paleness & 1 & & 1 & & 8 \\
\hline Urticaria & 1 & & 1 & & 17 \\
\hline Epileptic seizure & 2 & 1 & 1 & 1 & 8,12 \\
\hline Total & 51 & 10 & 41 & 5 & \\
\hline
\end{tabular}

Fourteen of the 17 children experienced a total of 29 procedure or device related adverse events during a follow-up of 312 patient-months (incidence 0.09 per patient-month [95\% Cl: 0.06-0.12]; Table 5.7). One third of these events concerned a swelling at the pump or catheter insertion site. Except for one swelling ${ }^{10}$, these always resolved either spontaneously or with a temporary pressure dressing. We considered three of the 29 events as serious, because these children required a second operation resulting in a prolonged hospital stay. None of the children had a wound infection or meningitis and none of the pumps had to be removed. 


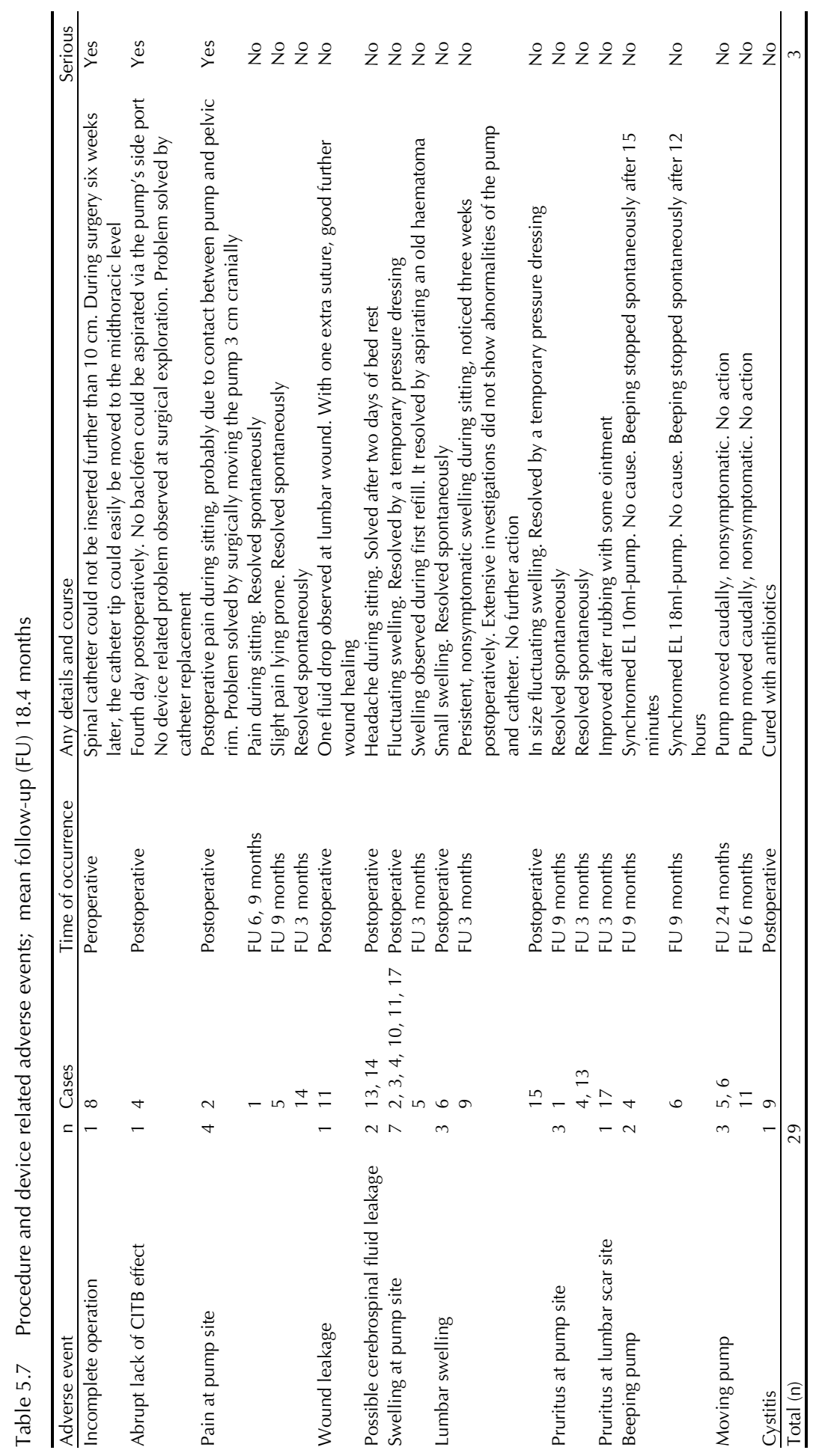




\section{Overall satisfaction}

Fifteen of the 17 children and/or their parents stated they would participate in all procedures again. Two parents were not sure, in spite of the achieved individual treatment goals for their children. The doubts in case 12 were based on both the new-onset seizures and the girl's stress during pump refills. The doubts in case 16 were based on a worsened trunk tone and head balance.

\section{DISCUSSION}

CITB was both effective at 12 months and safe up to 24 months for children with problems caused by intractable spastic CP. Early and great effects were a relief of pain and the facilitation of ease of care. CITB decreased both upper and lower extremity tone. With the control of pain and spasticity, most children were able to extend their activities and participation. HRQL improved for the domains of bodily pain/discomfort and mental health. Adverse events frequently occurred, but were for the greater part short-lasting and nonserious. Overall patient satisfaction was high.

The GMFM sitting and goal dimension scores kept improving beyond 6 months after pump implantation. One explanation for this ongoing improvement is that most children had not reached their optimal CITB dose after 6 months yet. Secondly, children need time to adapt to the altered tone, before they can show progress in gross motor abilities. We believe CITB accounted for the improved gross motor functioning, since mean GMFM scores of children with serious CP (GMFCS levels III-V) without specific treatment (intrathecal baclofen, botulinum toxin, selective dorsal rhizotomy) reach a plateau by 7 years of age. ${ }^{13}$ The GMFM results of the ambulant boy suggest children will first improve functional skills they already control before improving and gaining more difficult skills.

Most children experienced one or more non-procedure or device related adverse events. Lethargy occurred in almost half of the children and resolved either spontaneously or after slightly decreasing the CITB dose. Among the serious adverse events were new-onset seizures in one girl. However, in five of the six children who had epilepsy before pump implantation, seizure frequency remained stable or decreased. Epilepsy occurs in $15 \%$ to $60 \%$ of people with CP and its course tends to be severe. ${ }^{14}$ Buonaguro et al. retrospectively studied the relationship between epilepsy and CITB in 150 children with CP. ${ }^{15}$ Sixty of these children had epilepsy before CITB started. Seizure frequency decreased in eight children, worsened in two and one child had new-onset seizures. In conclusion, CITB does not seem to trigger or worsen seizure activity. Therefore, we do not consider intractable epilepsy as an absolute contraindication for CITB. 
During a follow-up of 312 patient-months, the incidence of procedure and device related adverse events (often called complications) was 0.09 per patientmonth (95\% Cl: 0.06-0.12). Three complications were serious, because they required surgical management and resulted in a prolonged hospital stay. Albright et al. reported 69 procedure and device related complications during a follow-up of 1178 patient-months (incidence 0.06 per patient-month [95\% $\mathrm{Cl}$ : 0.05-0.07]) in 100 spastic children with a SynchroMed EL 10-ml pump. ${ }^{6}$ Forty-seven of 69 complications were serious. They also found that the incidence of serious procedure related adverse events was significantly higher in children younger than 8 years. ${ }^{6}$ Murphy et al. reported 27 complications during a follow-up of 468 patient-months (incidence 0.06 per patient-month [95\% Cl: 0.04-0.08]) in 23 children with $\mathrm{CP}$, aged between 4.5 and 17.4 years (mean 8.8), weighing $23.7 \mathrm{~kg}$ on average. ${ }^{3}$ Eleven of the 25 implanted systems (44\%) had to be explanted. Eight of 11 pumps were removed due to wound infection or dehiscence. Lower age, height and weight were associated with higher explantation rates. ${ }^{3}$ Motta et al. studied the incidence of three common complications of CITB in 200 children (175 with $\mathrm{CP}$ ), aged $13.7 \pm 6.6$ years. $^{7}$ They recorded 75 complications during a follow-up of 10,142 patient-months (incidence 0.0075 per patient-month [95\% Cl: 0.0058-0.0092]). Twenty children (10\%) had an infection, 34 (17\%) leakage of cerebrospinal fluid (one pump removal) and 21 (10.5\%) catheter associated complications (15 pump removals). The incidence of infections decreased from $10 \%$ to $4.8 \%$ after adoption of the subfascial implantation technique and modification of the preoperative prophylaxis procedures. ${ }^{7}$

In our study, none of the children developed wound infections and none of the pumps had to be explanted. A possible explanation may be that the children in our study were relatively old (mean age 13.7) and heavy (mean weight $39.6 \mathrm{~kg}$ ). Secondly, regarding the importance of postoperative wound healing, we did not allow discharge before the wounds had healed well. Thirdly, we used the new SynchroMed II pump for the last 11 implantations. This pump is only $19.5 \mathrm{~mm}$ thick as opposed to the older SynchroMed EL 10-ml and 18-ml pumps which are $21.6 \mathrm{~mm}$ and $27.5 \mathrm{~mm}$ thick, respectively. The smaller SynchroMed II pump gives less skin and wound tension, which may result in less skin erosion, wound dehiscence and infections.

The complication incidences of the reported studies should be interpreted with caution. Studies with a relatively short follow-up may show a higher complication incidence, because the majority of complications occurs during the first postoperative months. Another bias concerns differences in the definition and inclusion of complications, e.g. Motta et al. only included three types of complications. $^{7}$ Although children are more prone to device or procedure related complications than adults, the complication incidence in children is decreasing due to the standard use of prophylactic antibiotic agents, improved surgical 
techniques and technological advances in the design of pumps and catheters. ${ }^{1,3,7,16}$

Now that we have established CITB to be effective and safe in the treatment of problems caused by intractable spasticity in children with $\mathrm{CP}$, we should aim to optimise its appliance. A future challenge regarding treatment with CITB is to select the right children at the right age. Currently, available pumps are sufficiently small so that there is no longer a need for any size or weight restrictions. ${ }^{17}$ However, younger, malnourished, and the most seriously affected spastic children seem to be more vulnerable to adverse events. ${ }^{3,6,7}$ On the other hand, early treatment with CITB can prevent contractures, dislocations and the subsequent need for orthopaedic procedures. ${ }^{18,19}$ Another challenge is to predict which catheter tip level is best for the individual child. We emphasise the role of multidisciplinary teams in specialised centres to make well considered, child centred treatment plans. Individual treatment goals should be clear, relevant and realistic. Outcome measures should include highly individualised, subjective measures such as the VAS or goal attainment scaling and more standardised measures, such as relevant GMFM dimensions, PEDI scales or HRQL domains. ${ }^{20-24}$ 


\section{REFERENCES}

1. Albright AL, Ferson SS. Intrathecal baclofen therapy in children. Neurosurg Focus 2006;21:1-6.

2. Butler C, Campbell S. Evidence of the effects of intrathecal baclofen for spastic and dystonic cerebral palsy. AACPDM Treatment Outcomes Committee Review Panel. Dev Med Child Neurol 2000;42:634-645.

3. Murphy NA, Irwin MC, Hoff C. Intrathecal baclofen therapy in children with cerebral palsy: efficacy and complications. Arch Phys Med Rehabil 2002;83:1721-1725.

4. Campbell WM, Ferrel A, McLaughlin JF, Grant GA, Loeser JD, Graubert C, Bjornson K. Longterm safety and efficacy of continuous intrathecal baclofen. Dev Med Child Neurol 2002;44:660-665.

5. Awaad Y, Tayem H, Munoz S, Ham S, Michon AM, Awaad R. Functional assessment following intrathecal baclofen therapy in children with spastic cerebral palsy. J Child Neurol 2003;18: 26-34.

6. Albright AL, Awaad Y, Muhonen M, Boydston WR, Gilmartin R, Krach LE, Turner M, Zidek KA, Wright E, Swift D, Bloom K. Performance and complications associated with the synchromed 10-ml infusion pump for intrathecal baclofen administration in children. J Neurosurg 2004;101(1 Suppl):64-68.

7. Motta F, Buonaguro V, Stignani C. The use of intrathecal baclofen pump implants in children and adolescents: safety and complications in 200 consecutive cases. J Neurosurg 2007;107(1 Suppl):32-35.

8. Hoving MA, van Raak EPM, Spincemaille GHJJ, Palmans LJ, Sleypen FAM, Vles JSH. Intrathecal baclofen in children with spastic cerebral palsy: a double-blind, randomized, placebocontrolled, dose-finding study. Dev Med Child Neurol 2007;49(9):654-659 (Chapter 3 of this thesis).

9. Hoving MA, Evers SMAA, Ament AJHA, van Raak EPM, Vles JSH, on behalf of the Dutch Study Group on Child Spasticity. Intractable spastic cerebral palsy in children: a Dutch cost of illness study. Dev Med Child Neurol 2007;49:397-398 (Chapter 7 of this thesis).

10. Hoving MA, Smulders NM, Abdul Fatah B, van Kroonenburgh MJ, van Raak EPM, Spincemaille GHJ, Vles JSH, on behalf of the Dutch Study Group on Child Spasticity. The use of an Indium111 DTPA flow study in the evaluation of a lumbar swelling in a girl with a baclofen pump. Neuropediatrics 2006;37:99-101 (Chapter 6 of this thesis).

11. Hoving MA, van Kranen-Mastenbroek VHJM, van Raak EPM, Spincemaille GHJJ, Hardy ELM, Vles JSH, on behalf of the Dutch Study Group on Child Spasticity. Placebo controlled utility and feasibility study of the H-reflex and flexor reflex in spastic children treated with intrathecal baclofen. Clin Neurophysiol 2006;117:1508-1517 (Chapter 2 of this thesis).

12. International Classification of Functioning, Disability and Health. World Health Organization. Geneva, 2002.

13. Rosenbaum PL, Walter SD, Hanna SE, Palisano RJ, Russell DJ, Raina P, Wood E, Bartlett DJ, Galuppi BE. Prognosis for gross motor function in cerebral palsy: creation of motor development curves. JAMA 2002;288:1357-1363.

14. Arzimanoglou A. Epilepsy as the presenting manifestation of structural brain lesions. In: Arzimanoglou A, Guerrini R, Aicardi J, eds. Aicardi's epilepsy in children. 3rd ed. Philadelphia: Lippincott Williams \& Wilkins, 2004;310.

15. Buonaguro V, Scelsa B, Curci D, Monforte S, luorno T, Motta F. Epilepsy and intrathecal baclofen therapy in children with cerebral palsy. Pediatr Neurol 2005;33:110-113.

16. Vender JR, Hester S, Waller JL, Rekito A, Lee MR. Identification and management of intrathecal baclofen pump complications: a comparison of pediatric and adult patients. J Neurosurg 2006;104(1 Suppl):9-15.

17. Albright AL. Intrathecal baclofen for childhood hypertonia. Childs Nerv Syst 2007;23(9):971-9.

18. Morton RE, Scott B, McClelland V, Henry A. Dislocation of the hips in children with bilateral spastic cerebral palsy, 1985-2000. Dev Med Child Neurol 2006;48:555-558.

19. Gerszten PC, Albright AL, Johnstone GF. Intrathecal baclofen infusion and subsequent orthopedic surgery in patients with spastic cerebral palsy. J Neurosurg 1998;88:1009-1013. 
20. Ostensjo S, Bjorbaekmo W, Carlberg EB, Vollestad NK. Assessment of everyday functioning in young children with disabilities: an ICF-based analysis of concepts and content of the Pediatric Evaluation of Disability Inventory (PEDI). Disabil Rehabil 2006;28:489-504.

21. Bjornson KF, McLaughlin JF. The measurement of health-related quality of life (HRQL) in children with cerebral palsy. Eur J Neurol 2001;8 Suppl 5:183-193.

22. Rosenbaum P, Stewart D. The World Health Organization International Classification of Functioning, Disability, and Health: a model to guide clinical thinking, practice and research in the field of cerebral palsy. Semin Pediatr Neurol 2004;11:5-10.

23. Engelen V, Ketelaar M, Gorter JW. Selecting the appropriate outcome in paediatric physical therapy; how individual treatment goals of children with cerebral palsy are reflected in GMFM88 and PEDI. J Rehabil Med 2007;39:225-231.

24. Steenbeek D, Ketelaar M, Galama K, Gorter JW. Goal attainment scaling in paediatric rehabilitation: a critical review of the literature. Dev Med Child Neurol 2007;49:550-556. 



\section{CHAPTER 6}

The use of an Indium ${ }^{111}$ DTPA flow study in the evaluation of a lumbar swelling in a girl with a baclofen pump

MA Hoving, NM Smulders, B Abdul Fatah, MJPG van Kroonenburgh, EPM van Raak, GHJJ Spincemaille, JSH Vles

Neuropediatrics 2006;37:99-101 


\section{ABSTRACT}

\section{Background}

The aim of this study was to introduce a useful diagnostic method to evaluate baclofen pump system-related complications without disturbing the continuous delivery of intrathecal baclofen.

\section{Methods}

We present a case report on the use of an indium" diethylenetriaminepentaacetic acid (DTPA) flow study in the evaluation of a lumbar swelling in a 16-year-old girl with spastic cerebral palsy, treated with continuous intrathecal baclofen.

\section{Results}

Disconnection or damage of the catheter leading to leakage of baclofen into the lumbar swelling could be ruled out by the use of an indium" DTPA flow study. This is the first report to illustrate the implementation of an indium" DTPA flow study without interrupting the infusion of continuous intrathecal baclofen.

\section{Conclusion}

An indium" DTPA flow study is a non-invasive, safe and patient friendly diagnostic method, which can be of great help in the evaluation of pump- or catheter-related complications and does not need to interfere with the delivery of continuous intrathecal baclofen. 


\section{INTRODUCTION}

Continuous intrathecal baclofen (CITB) infusion is a treatment option used to manage intractable spasticity. The intrathecal drug delivery system is composed of a programmable infusion pump implanted in an abdominal subcutaneous or subfascial pocket and a connecting catheter which is inserted in the intrathecal space in the spine, usually in the thoracic or lower cervical region. Children with severe spasticity of cerebral origin can benefit substantially from treatment with CITB in terms of pain and spasm relief, better sleep and improved ease of care. ${ }^{1}$ However, more than fifty percent of the patients experience side effects or complications of CITB therapy. ${ }^{2}$ The most commonly reported baclofen pump system-related problems are seromas, cerebrospinal fluid (CFS) leaks, and problems with the catheter, such as kinks, perforations or disconnections. CSF leaking along the intrathecal catheter may accumulate subcutaneously at the back or flow along the catheter to accumulate around the pump. A fluid collection at the back more often consists of CSF than serous fluid. Serous fluid will usually be absorbed in time, whereas CSF accumulation commonly requires therapy. ${ }^{2}$

Two diagnostic methods used in the evaluation of a pump- or catheter-related complication of CITB are a plain X-ray study to assess catheter continuity and a contrast study to evaluate catheter integrity. ${ }^{2}$ Contrast studies are only possible in pump models with a side port through which you need to inject the contrast medium directly into the catheter. This is a difficult procedure, which requires experience. Another disadvantage of this procedure is the disruption of CITB delivery, which can result in serious aggravation of spasticity.

We report on the implementation of an indium ${ }^{111}$ diethylenetriaminepentaacetic acid (DTPA) flow study as a useful and patient friendly diagnostic method in the evaluation of a lumbar swelling in a 16-year-old girl with spastic cerebral palsy, treated with CITB. Indium ${ }^{111}$ DTPA was used instead of technetium ${ }^{99}$ DTPA, because the European regulation states that only the former radiopharmacon may be used for intrathecal studies in Europe.

\section{CASE REPORT}

In a 16-year-old girl with a medical history of spastic quadriplegic cerebral palsy, epilepsy and profound cognitive impairments (Gross Motor Function Classification System level V), spasticity had increasingly led to pain and interference with care, restricting participation in social activities. After a successful intrathecal baclofen (ITB) bolus trial, treatment with CITB was started, 
delivered via a subfascially implanted SynchroMed II pump (Medtronic, Inc., Minneapolis, Minnesota, USA) and a two-piece connecting catheter (model 8731) entering the lumbar dural sac with the tip of the catheter located at the level of the fifth thoracic vertebra. Three weeks after pump implantation, the parents observed a lumbar swelling. In the mornings this lump was hardly visible, but during the day it would swell to a height of about $2 \mathrm{~cm}$. Although spasticity clearly decreased since CITB delivery, the child's general condition was mediocre. She was withdrawn into herself, lacked energy, fainted several times and she was pale. We could not rule out any headache or nausea, as the girl was not able to communicate verbally or non-verbally. During physical examination of the lumbar region, the connection of the two catheters was palpable within a fluctuating swelling of about three centimetres in average (Figure 6.1A). No swelling or abnormalities were found along the catheter or in the pump region at the abdomen. The differential diagnoses of this swelling were leakage of CSF along the catheter, leakage of baclofen from a tear or perforation in the catheter, a catheter disconnection or a seroma. We had no clear explanation for the poor condition of the girl and we could not rule out a catheter-related cause on clinical grounds. Moreover, the experience in this field was limited, so our multidisciplinary team decided to further elaborate on this problem. A plain X-ray showed an unchanged position of the pump and the catheter system in comparison with early postoperative films and did not reveal any kinks or a clear disconnection of the catheters (Figure 6.1C). A lumbar ultrasound showed an encapsulated cyst filled with clear fluid, sized $2.0 \times 3.6 \times 0.8 \mathrm{~cm}$, enclosing the catheter connector (Figure 6.1B). As we would rather not interrupt the continuous delivery of ITB, we decided to carry out an indium ${ }^{111}$ DTPA flow study on an out patient basis. We first emptied the drug reservoir of the pump. We then refilled it with exactly $5 \mathrm{ml}$ of baclofen in an unchanged ITB concentration of $500 \mu \mathrm{g} / \mathrm{ml}$ and $20.7 \mathrm{MBq}$ indium ${ }^{111}$ DTPA in $0.5 \mathrm{ml}$ of $0.9 \%$ saline solution. Adding the $0.9 \%$ saline solution, the ITB concentration was changed to $455 \mu \mathrm{g} / \mathrm{ml}$. We did not enter this change in concentration into the pump computer, nor did we program a compensatory change in ITB dose. As a result, the ITB dose was indirectly lowered with $9 \%$. In our patient, this did not result in an unacceptable increase in spasticity. We calculated that it would take the radiopharmaceutical 2.9 days to reach the tip of the catheter (ITB dose of $71.3 \mu \mathrm{g}$ per day divided by the ITB concentration 500 of $\mu \mathrm{g} / \mathrm{ml}$ is $0.14 \mathrm{ml}$ per day. Total volume of the catheters plus the dead space of the pump is $0.417 \mathrm{ml}$ divided by $0.14 \mathrm{ml} /$ day is 2.9 days). Static anterior and lateral images of the abdomen were obtained with a two-headed gamma camera (Multispect II, Siemens, Chicago, Illinois, USA) 5, 60 and 300 minutes and 1, 2, 3, 4, 7, 10 and 15 days post injection (p.i.) of the indium $^{111}$ DTPA into the pump reservoir. Consistent with our calculation, the images revealed radioactivity outside the pump in the proximal catheter system from the second day p.i. On days 4, 7 and 10 p.i., the complete catheter system 
was visible with a more intense focal accumulation of radioactivity in the area of the swelling. The exact edges of the lumbar swelling were marked on the skin using a cobalt ${ }^{57}$ marker. This revealed the size of the swelling to be clearly larger than the area of the focal accumulation of radioactivity (Figure 6.1D). The more intense focal accumulation was interpreted to be corresponding with the local loop of the catheter, visible on the X-ray (Figure 6.1C). At day 10 p.i., we emptied the pump again and refilled it with ITB $500 \mu \mathrm{g} / \mathrm{ml}$. At day 15 p.i. the images did not show radioactivity in the catheter anymore.

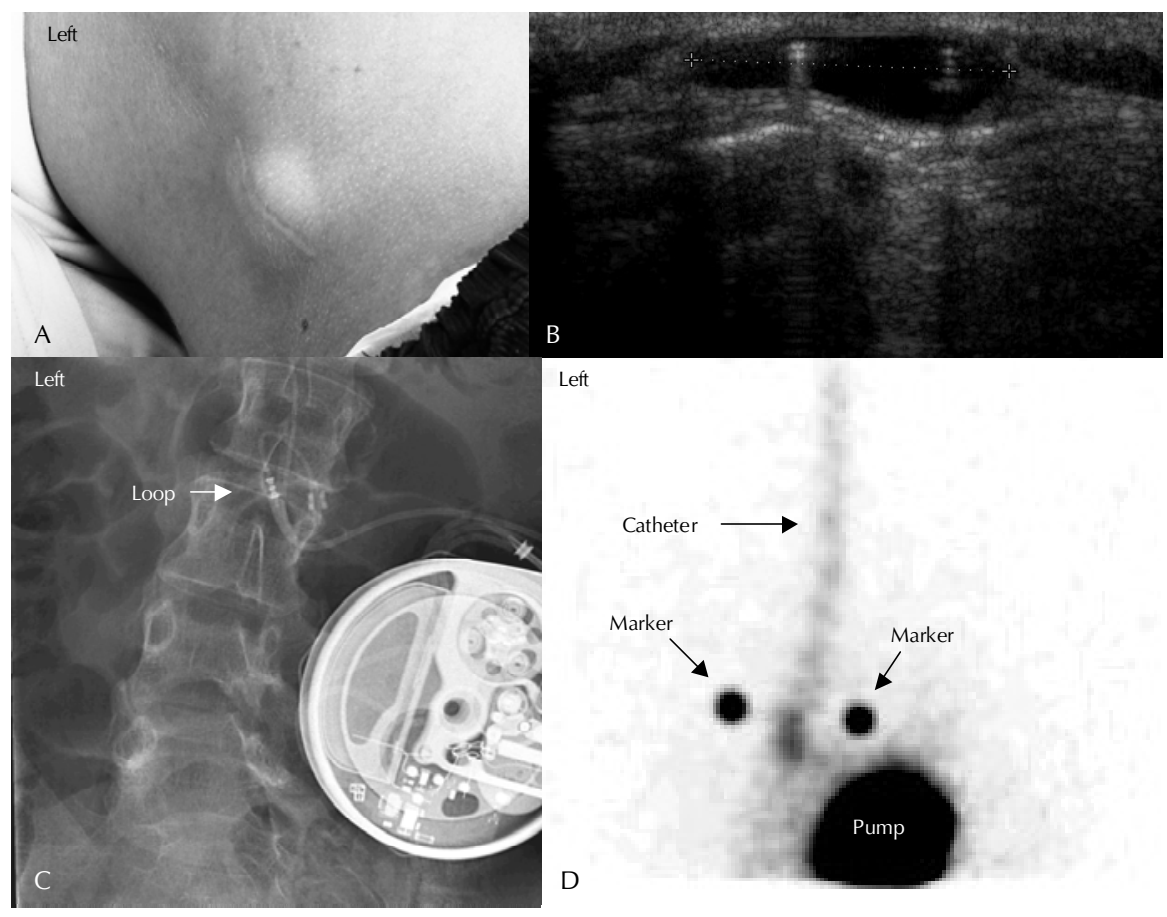

Figures 6.1 A The lumbar swelling in our patient

B Ultrasound of the swelling showing an encapsulated cyst

C Plain X-ray showing the pump and a part of the catheter system

D Image made on day 7 after injection of indium ${ }^{111}$ DTPA into the pump showing radioactivity in the catheter with a more focal accumulation in the area of the swelling. Marks at the edges of the swelling, using a cobalt ${ }^{57}$ marker on the skin, revealed the size of the swelling to be clearly larger than the area with the more intense focal accumulation of radioactivity which was interpreted as corresponding with the catheter loop, as shown on the plain X-ray film (C) 


\section{DISCUSSION}

In our patient, the lumbar swelling appeared while sitting at daytime and disappeared after having lain in bed at night. This pattern suggested leakage of CSF along the catheter into the swelling. However, in the case of a significant leakage of CSF, we would have expected a larger swelling as well as signs of an intracranial hypotension syndrome. A complete disconnection of the catheter was not very probable, as the girl kept responding successfully to CITB delivery. However, either an incomplete disconnection or damage of the catheter could have led to leakage from the catheter into the swelling. These complications could not be ruled out with an X-ray. The ultrasound showed an encapsulated cyst, but this could not provide us with information on possible leakage of fluid into the cyst.

Indium cisternography can be used to localise a tear in the dura mater leading to leakage of CSF. ${ }^{3,4}$ In our patient, the images of the indium ${ }^{111}$ DTPA flow study showed no radioactivity outside the pump and catheter system. On the basis of this finding we ruled out a disconnection and any perforations in the extradural catheter part. In our patient, $0.14 \mathrm{ml}$ of the indium ${ }^{111}$ DTPA solution per day entered the intrathecal space via the tip of the catheter. The indium ${ }^{111}$ DTPA solution was then diluted with roughly a factor 1000, as people have about 150 $\mathrm{ml}$ of CSF in total and the daily CSF production is about 150 to $500 \mathrm{ml}$. The question is whether the images would reveal such a small amount of radioactivity in the area of the swelling in case of leakage along the catheter. Considering the modest size of the swelling, we decided not to undertake any further action with respect to the cyst. One year after pump implantation, the cyst was still present and had not changed. In the meantime the general condition of the girl had improved along with an improving nutritional state and better adjustment of the CITB dose.

An indium ${ }^{111}$ DTPA flow study is a safe and reliable procedure in the evaluation of pump function and patency of an intrathecal, slow-flow infusion system. ${ }^{5-8}$ The refill procedure before and after the DTPA flow study is not different from other refills, so there is no reason to believe that there is an increased risk of adverse reactions. This is the first report to illustrate the implementation of an indium ${ }^{111}$ DTPA flow study without interrupting the delivery of CITB. The latter is possible as indium ${ }^{111}$ DTPA has a long half life of 2.8 days which allows delayed imaging. ${ }^{9}$ This is a great advantage for patients, as any interruption of the continuous delivery of ITB can result in severe rebound spasticity. We would like to highlight an indium ${ }^{111}$ DTPA flow study as a patient friendly, safe, and reliable diagnostic method in identifying or excluding pump- or catheter-related complications of CITB treatment. 


\section{REFERENCES}

1. Campbell WM, Ferrel A, McLaughlin JF, Grant GA, Loeser JD, Graubert C, Bjornson K. Longterm safety and efficacy of continuous intrathecal baclofen. Dev Med Child Neurol 2002;44:660-665.

2. Albright AL, Gilmartin R, Swift D, Krach LE, Ivanhoe CB, McLaughlin JF. Long-term intrathecal baclofen therapy for severe spasticity of cerebral origin. J Neurosurg 2003;98: 291-295.

3. Park $\mathrm{CH}$, Zhang J, Kim SM, Intenzo C, Lee JD. Cerebrospinal fluid leak from epidural spinal anesthesia detected by radionuclide cisternogram. Clin Nucl Med 1993;18:437-438.

4. Tijssen CC, van Gulik S, Sluzewski M. [Posture-dependent headache due to the spontaneous hypotension syndrome]. Ned Tijdschr Geneeskd 2005;149:996-1000.

5. Le Breton F, Daviet JC, Monteil J, Vidal J, Munoz M, Dudognon P, Salle JY. Radioisotopic control for baclofen pump catheter failure. Spinal Cord 2001;39:283-285.

6. O'Connell M, Wong TZ, Forkheim KE, Jain M, Shipes SW, Fuchs HE. Comparison of Tc99mDTPA and indium-111 DTPA studies of baclofen pump function. Clin Nucl Med 2004;29: 578-580.

7. Rosenson AS, Ali A, Fordham EW, Penn RD. Indium-111 DTPA flow study to evaluate surgically implanted drug pump delivery system. Clin Nucl Med 1990;15:154-156.

8. Schmidt E, Oates E. In-111 DTPA to evaluate the patency of an implanted intrathecal infusion pump. Clin Nucl Med 1997;22:768-770.

9. Goodwin DA, Song CH, Finston R, Matin P. Preparation, physiology, and dosimetry of 111 Inlabeled radiopharmaceuticals for cisternography. Radiology 1973;108:91-98. 



\section{CHAPTER 7}

Intractable spastic cerebral palsy in children:

a Dutch cost of illness study

MA Hoving, SMAA Evers, AJHA Ament, EPM van Raak, JSH Vles, on behalf of the Dutch Study Group on Child Spasticity

Dev Med Child Neurol 2007;49:397-398 (Published as a letter) 


\section{ABSTRACT}

\section{Background}

In a substantial group of children with spastic cerebral palsy, spasticity does not respond to regular therapies. New treatment options such as intrathecal baclofen therapy can be very effective, but cost a lot. Since escalating health care expenditures are a worldwide concern, economic evaluations become increasingly important in order to justify the introduction of expensive therapies. A cost of illness study defines the magnitude of an illness in monetary terms and can serve as a basis for any economic evaluation.

\section{Methods}

The aims of this Dutch cost of illness study were to estimate and categorise the expenditures for children with intractable spastic cerebral palsy by conducting a bottomup, disease specific, prevalence based cost of illness study from the societal perspective. Data were collected by a patient survey and by consulting files of health care institutions and local governments for a one-year period.

\section{Results}

We included eight girls and seven boys, aged between 7 and 16 years (mean $13.2 \pm 2.9$ years). From the societal perspective, mean annual costs were $€ 40,265$, which is more than eleven fold the mean expenditures on care per Dutch capita. Home care and guidance accounted for the highest expenditures $(€ 23,000 ; 57 \%)$, followed by special equipment and aids (€6927; 17\%), therapy and rehabilitation (€3262; 8\%), and transportation (€3101; 8\%). The expenditures for medical care were relatively small $(€ 1573 ; 4 \%)$.

\section{Conclusions}

The economic impact of intractable spastic cerebral palsy in children is relatively high and largely related to the motor impairments. Cost-effectiveness studies are needed to evaluate whether early and better treatment of spasticity might not only improve the children's quality of life, but also reduce the high associated costs. 


\section{INTRODUCTION}

Cerebral palsy (CP) is a term for a heterogeneous group of clinical syndromes that are characterised by abnormal motor actions and postural mechanisms, and that are due to non-progressive abnormalities of the developing brain. ${ }^{1} \mathrm{CP}$ is the most common cause of severe physical disability in childhood. ${ }^{2}$ The overall reported CP prevalence is 2.4 per 1000 children in developed countries. ${ }^{2,3}$ There is no cure, so treatment focuses on improving the quality of life of the child and its caregivers. Spasticity accounts for 70 to $91 \%$ of the motor disorders associated with $\mathrm{CP} ., 5$ Spasticity is a motor disorder characterised by a velocity-dependent increase in tonic stretch reflexes with exaggerated tendon jerks, resulting from hyperexcitability of the stretch reflex. ${ }^{6}$ Spasticity can cause pain, sleeping disorders, increased energy requirements, and interference with positioning, transfers, dressing, and body hygiene. Secondary phenomena such as contractures and pressure sores can add to the treatment problems. ${ }^{7}$ A substantial group of children with serious spastic $\mathrm{CP}$ does not respond to regular treatments, such as physical therapy, orthopaedic surgery or oral medication. An effective treatment option for intractable spasticity is continuous infusion of intrathecal baclofen. ${ }^{8-10}$ However, evidence for continuous infusion of intrathecal baclofen in the treatment of children with spastic CP is lacking. ${ }^{11}$ As a result, this promising therapy is not reimbursed for children in the Netherlands. Therefore, we started a Dutch national study on the efficacy and safety of continuous infusion of intrathecal baclofen for intractable spasticity in children with $\mathrm{CP}$ in 2002.

Throughout the world, spending on health care is outpacing economic growth. ${ }^{12}$ Policy makers and governmental officials agree that these rapidly escalating health expenditures must be controlled. This implies that in order to justify the introduction of any expensive medical treatment, it should go together with a cost analysis. For that reason, we embedded a cost of illness (COI) study and a cost-effectiveness analysis in the Dutch ITB study for children. A COI study defines the magnitude of a disease or injury in monetary terms. ${ }^{13}$ It can provide an economic framework for programme evaluation, assist in the allocation of research money, and it can serve as a basis for any economic evaluation, such as a cost-effectiveness, cost-benefit or cost-utility analysis. ${ }^{13-15}$ The aims of the present $\mathrm{COI}$ study were to estimate and categorise the expenditures for children with intractable $\mathrm{CP}$ from the societal perspective as well as the perspectives of the government, health insurers and families of the children. 


\section{METHODS}

This COI study was embedded in the Dutch ITB study on the efficacy and safety of continuous infusion of intrathecal baclofen in the treatment of intractable spasticity in children with $\mathrm{CP} .{ }^{16}$ We refer to our prior article for the eligibility criteria of this study. ${ }^{16}$ Medical specialists referred children from all parts of the Netherlands to the University Hospital Maastricht, where all phases of the study took place.

\section{Study design}

We conducted a bottom-up, disease specific, prevalence based COI study from the perspectives of society, the health insurers, the government and the families of the children. This means that we interviewed the parents about the costs of health care consumption and the use of other resources (bottom-up) for their child with spastic CP (disease-specific). In a prevalence based COI study, the costs within a given period of time are calculated for all the patients affected. ${ }^{15}$ We considered a one-year period. The perspective of a COI study indicates from which point of view the study is being considered. The chosen perspective determines which costs are included and thus which conclusions can be drawn from that particular COI study. The preferable, broadest perspective is the societal perspective, which provides an estimate of the economic impact of a disease to society. ${ }^{13}$ We left any production losses due to the illness out of consideration, as the study population consisted of children. ${ }^{14}$

\section{Data sources}

Data were collected by means of a questionnaire and a cost diary. Table 7.1 shows the various categories of resource use included in the questionnaire and diary. Parents completed the questionnaire, which covered the one-year period preceding the test treatment. The questionnaire also included questions on personal budgets and on resources with lifetimes longer than one year. A personal budget is a sum of money, allocated by the Dutch government, allowing parents to arrange and purchase any care, help and support the child needs. We validated and completed retrospectively collected data by retrieving information from records of the involved health care and governmental institutions. In addition to the retrospective questionnaire, the parents prospectively kept a cost diary during one month. The diary enclosed questions about weekly to monthly recurring consumption of different health care resources (Table 7.1). We extrapolated the data obtained from the diary over a one-year period. Both the questionnaire and the diary were completed before any intervention as part of the Dutch ITB study had taken place. 
Table 7.1 Categories of resource use included in questionnaire and diary

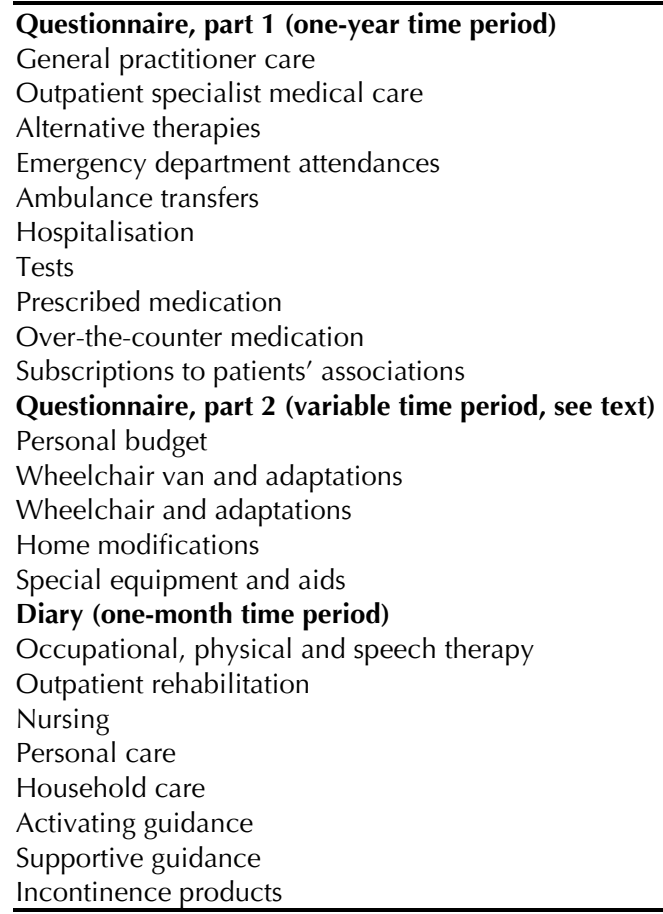

\section{Costs}

We valued the majority of costs using the Dutch guidelines for pharmacoeconomic research and real unit prices excluding taxes, as assigned by the University Hospital Maastricht (Table 7.2) ${ }^{17}$ Costs were estimated for the year 2003 in Euros. We discounted costs that were not available for the year 2003 with $4 \%$ per year according to the Dutch guidelines. ${ }^{17}$ Unit prices of medication were collected from the Pharmacotherapeutical Compass, a publication of the Dutch Health Care Insurance Board. We estimated unit costs of outpatient consultations of medical specialists by multiplying a baseline price with a weighing factor per speciality according to the Dutch guidelines for pharmacoeconomic research for university hospitals. ${ }^{17}$ For all resources with a lifetime longer than one year, a base lifetime was estimated for the calculation of the annual costs. Travelling expenses only concerned travelling to and from the hospital or to the therapist. We estimated the total costs for wheelchair vans differently per child, depending whether the van was only used for the child or also for other purposes. If a family had one or more cars plus the wheelchair van, we included the purchasing costs for the van, costs for maintenance, insurance and road tax in this category. Fixed annual rates for insurance, maintenance and road tax of respectively $€ 936, € 360$ and $€ 336$ were used (source: Dutch 
Consumer's Organisation Guide, August 2004). In case families also used the wheelchair van for general family purposes, the purchasing costs were lowered with those of a car in the medium-price range $(€ 5460$ per year; source: Dutch Consumer's Organisation Guide, August 2004). In the latter case, we did not take any costs for insurance, maintenance and road tax into account. Ultimately, we categorised the costs into eight main groups: 1) medical care, 2) therapy and rehabilitation, 3) special equipment and aids, 4) incontinence products, 5) transportation, 6) home care and guidance, 7) home modifications, and 8) out-ofpocket costs.

Table 7.2 Annual costs per resource unit in Euro

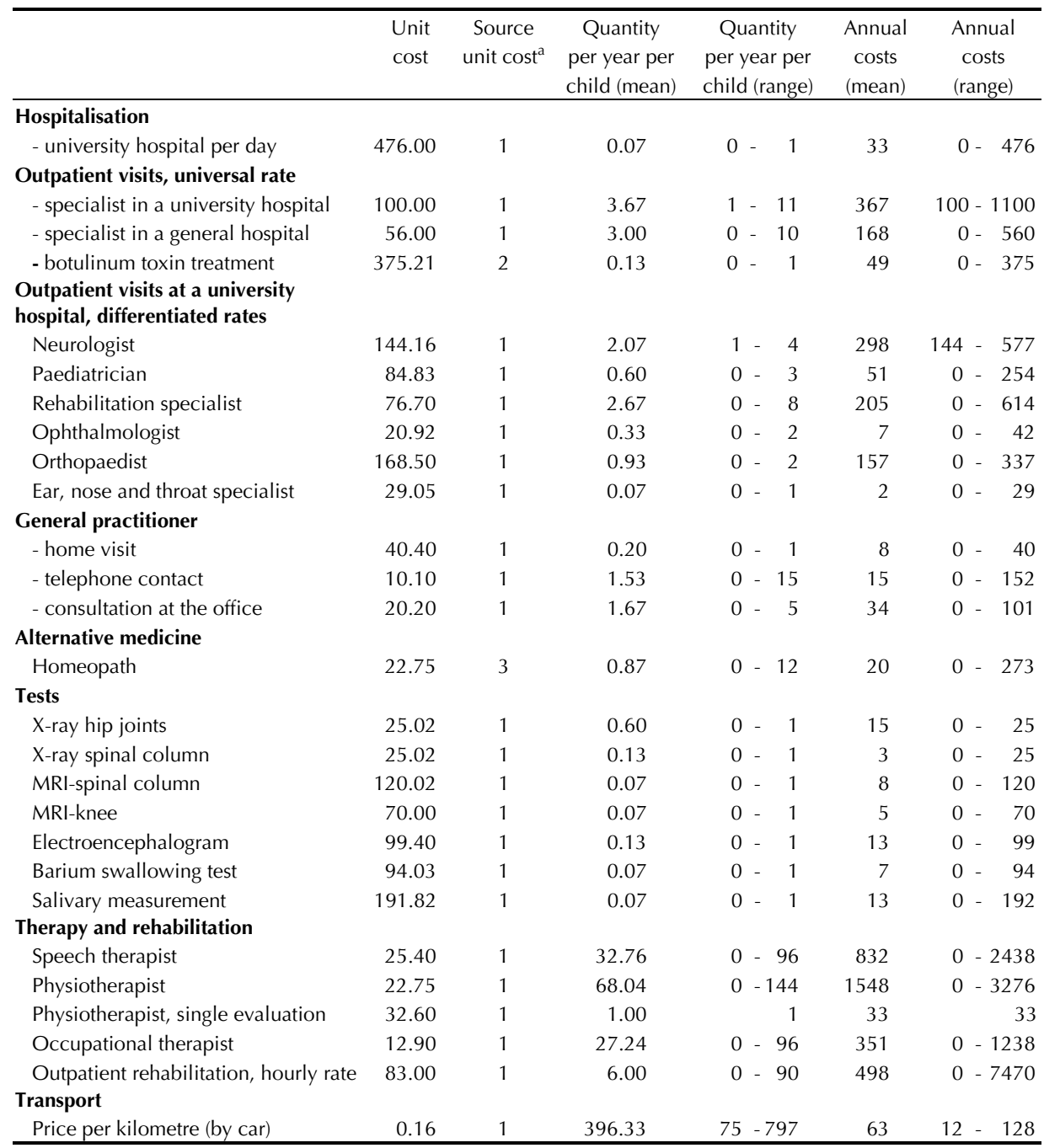

a Sources: 1 Dutch guideline for pharmacoeconomic research, 2 Data University Hospital Maastricht, 3 Patient questionnaire. 


\section{Sensitivity analysis}

Sensitivity analyses can be carried out to investigate the impact of certain assumptions on the study results. ${ }^{18}$ In this study we have applied different sensitivity analyses. First, we explored the sensitivity of results concerning variations in lifetimes of resources such as wheelchairs and wheelchair vans. Secondly, we recalculated the costs for consultations of medical specialists using a fixed rate for consulting specialists at university hospitals and a fixed rate for consulting specialists at general hospitals. Finally, we compared the amounts of allocated personal budgets of two consecutive years. We registered the personal budgets of two successive years, as the year of allocation of one personal budget often did not exactly parallel the year for which the questionnaire was completed.

\section{Ethical approval and consent}

The study was approved by the medical ethical committee of the University Hospital Maastricht. In accordance with local legislation, we obtained written informed consent from the parents, and also from the children if they were aged 12 years or older and capable of understanding the nature of the study. The informed consent also included permission for the retrieval of personal data.

\section{RESULTS}

We included eight girls and seven boys, aged between 7 and 16 years (mean $13.2 \pm 2.9$ years), in this COl study. One child was classified on the Gross Motor Function Classification System (GMFCS) at level III, two at level IV and 12 at level V. ${ }^{19}$ Children classified at GMFCS levels III and IV had a spastic diplegia and children classified at GMFCS level $\vee$ had a spastic tetraplegia. Two children were living in a home for children with a handicap during the week; all other children lived with their respective families. Both the one-year period covered by the first part of the questionnaire and the one-month period covered by the diary fell in all cases between January 2002 and February 2005. The response rate for the questionnaires as well as the diaries was $100 \%$.

\section{Costs from the societal perspective}

Table 7.2 shows the various resources, including their unit costs, quantities of use and the total annual costs per resource. Table 7.3 shows the annual societal costs as distributed among the eight main resource categories. From the societal perspective, the mean annual costs were $€ 40,265$. The highest costs fell under the categories of home care and guidance (€23,000; $57 \%)$, special equipment 
and aids (€6927; 17\%), therapy and rehabilitation (€3262; 8\%), and transportation (€3101; 8\%). The costs within the category of medical care were relatively low accounting for only $4 \%$ of total costs. Within the category of home care and guidance, four children did not have any consumption. One child got 348 hours of home care per year (hourly rate €40.40; in total €14,059), which was not paid from a personal budget. Ten children had a personal budget of $€ 33,094$ on average (range $€ 15,507$ to $€ 56,400$ ). Within the category of special equipment and aids, the purchase, adaptations and maintenance of wheelchairs accounted for $74 \%$ of the costs. All children had a non-electric wheelchair. Besides this, 13 of them also had an electric wheelchair. Within the category of therapy and rehabilitation, 13 children had physical therapy, nine had occupational therapy and seven had speech therapy on a regular basis. One child visited a rehabilitation centre once a week. Within the category of transportation costs, expenditures for wheelchair vans accounted for $97 \%$ of the costs.

Costs from the perspectives of the health insurers, government and families

The societal costs can be subdivided into costs of the health insurers, the government and the families (Table 7.4). From the perspective of the health insurers, mean annual costs per child were estimated at $€ 28,663$. The highest costs fell into the categories of home care and guidance $(€ 23,000 ; 80 \%)$. The expenditures for medical care accounted for only 5\% of costs. From the perspective of the government, mean annual costs were estimated at €9614 of which $€ 6607$ (69\%) for special equipment and aids. From the family perspective, mean annual costs were estimated at $€ 1988$ of which $€ 1471$ (74\%) for wheelchair vans.

\section{Sensitivity analyses}

Table 7.3 shows the results of the sensitivity analyses, conducted from the societal perspective. The most noticeable result was the increase in mean personal budget as allocated in two successive years. For three children the height of the personal budget did not change. For the other seven children, the allocated personal budgets increased from an average of $€ 33,094$ to $€ 46,436$ per child (mean increase 39\%; range 1\%-146\%). The maximum allocated personal budget was $€ 109,500$ a year. This rise is explained by a fundamental change in the regulation of personal budgets in the Netherlands since April 2003. The change from product to care function based budgeting has especially resulted in higher budgets for people with a mental handicap. The sensitivity analysis of the lifetimes of special equipment and aids showed a considerable range (€5660 to $€ 9885)$ in mean costs. The sensitivity analyses of wheelchair vans and home modifications showed somewhat smaller ranges in mean costs. Taking all 
sensitivity analyses into account, the estimated societal costs of $€ 40,265$ could in fact vary between $€ 37,659$ and $€ 53,141$ (Table 7.3 ). This range is mainly caused by the large increases in allocated personal budgets.

Table 7.3 Mean annual costs per resource category from the societal perspective (in Euro), including the results of the sensitivity analyses

\begin{tabular}{|c|c|c|c|c|c|c|}
\hline \multirow[t]{2}{*}{ Resource category } & \multicolumn{2}{|c|}{ Base } & \multicolumn{4}{|c|}{ Sensitivity analyses } \\
\hline & $\begin{array}{l}\text { Mean } \\
\text { costs }\end{array}$ & $\begin{array}{l}\% \text { of } \\
\text { total }\end{array}$ & $\begin{array}{l}\text { Mean } \\
\text { costs }\end{array}$ & $\begin{array}{l}\% \text { of } \\
\text { total }\end{array}$ & $\begin{array}{l}\text { Mean costs } \\
\text { including all } \\
\text { lowest costs }\end{array}$ & $\begin{array}{l}\text { Mean costs } \\
\text { including all } \\
\text { highest costs }\end{array}$ \\
\hline Medical care & 1573 & 3.91 & & & 1397 & 1573 \\
\hline Hospitalisation & 70 & 0.17 & & & & \\
\hline Emergency department care & 0 & 0.00 & & & & \\
\hline Specialist medical care & & & & & & \\
\hline - differentiated rates (base) & 760 & 1.89 & & & & \\
\hline - universal rates & & & 585 & 1.46 & & \\
\hline General practitioner care & 57 & 0.14 & & & & \\
\hline Tests & 64 & 0.16 & & & & \\
\hline Medication & 602 & 1.50 & & & & \\
\hline Alternative medicine & 20 & 0.05 & & & & \\
\hline Therapy and rehabilitation & 3262 & 8.10 & & & 3262 & 3262 \\
\hline Special equipment and aids & 6927 & 17.20 & & & 5660 & 9885 \\
\hline Wheelchairs & 5102 & 12.67 & & & & \\
\hline Other equipments and aids & 1825 & 4.53 & & & & \\
\hline - Depreciation 5 years (base) & 6927 & 17.20 & & & & \\
\hline - Depreciation 3 years & & & 9885 & 22.87 & & \\
\hline - Depreciation 7 years & & & 5660 & 14.51 & & \\
\hline Incontinence products & 547 & 1.36 & & & 547 & 547 \\
\hline Transportation & 3101 & 7.70 & & & 2531 & 4125 \\
\hline - Van depreciation 7 years (base) & 2997 & 7.44 & & & & \\
\hline - Van depreciation 5 years & & & 4021 & 9.74 & & \\
\hline - Van depreciation 9 years & & & 2427 & 6.11 & & \\
\hline Travelling expenses & 104 & 0.26 & & & & \\
\hline Home care and guidance & 23,000 & 57.12 & & & 23,000 & 31,894 \\
\hline - Personal budget year 1 (base) & 22,063 & 54.80 & & & & \\
\hline - Personal budget year 2 & & & 30,957 & 62.97 & & \\
\hline Home care (no personal budget) & 937 & 2.32 & & & & \\
\hline Home modification & 1812 & 4.50 & & & 1219 & 1812 \\
\hline - Depreciation 10 years (base) & 1812 & 4.50 & & & & \\
\hline - Depreciation 15 years & & & 1219 & 3.07 & & \\
\hline Out-of-pocket & 43 & 0.11 & & & 43 & 43 \\
\hline Total of mean annual costs & 40,265 & 100.00 & & & 37,659 & 53,141 \\
\hline
\end{tabular}


Table 7.4 Mean annual costs per resource category from the perspectives of the health insurers, the government and the families (in Euro)

\begin{tabular}{lrrrrrc}
\hline Resource category & \multicolumn{2}{c}{$\begin{array}{c}\text { Health insurer } \\
\text { perspective }\end{array}$} & \multicolumn{2}{c}{$\begin{array}{c}\text { Governmental } \\
\text { perspective }\end{array}$} & \multicolumn{2}{c}{$\begin{array}{c}\text { Family } \\
\text { perspective }\end{array}$} \\
\cline { 2 - 6 } & Mean costs & \% of total & Mean costs & $\%$ of total & Mean costs & $\%$ of total \\
\hline Medical care & $\mathbf{1 4 8 7}$ & $\mathbf{5 . 1 9}$ & $\mathbf{0}$ & $\mathbf{0}$ & $\mathbf{8 6}$ & $\mathbf{4 . 3 2}$ \\
Hospitalisation & 70 & 0.24 & 0 & 0 & 0 & 0 \\
Emergency department care & 0 & 0.00 & 0 & 0 & 0 & 0 \\
Specialist medical care & 760 & 2.65 & 0 & 0 & 0 & 0 \\
General practitioner care & 57 & 0.20 & 0 & 0 & 0 & 0 \\
Tests & 64 & 0.22 & 0 & 0 & 0 & 0 \\
Medication & 516 & 1.80 & 0 & 0 & 86 & 4.32 \\
Alternative medicine & 20 & 0.07 & 0 & 0 & 0 & 0 \\
Therapy and rehabilitation & $\mathbf{3 2 6 2}$ & $\mathbf{1 1 . 3 8}$ & $\mathbf{0}$ & $\mathbf{0}$ & $\mathbf{0}$ & $\mathbf{0}$ \\
Special equipment and aids & $\mathbf{3 0 4}$ & $\mathbf{1 . 0 6}$ & $\mathbf{6 6 0 7}$ & $\mathbf{6 8 . 7 2}$ & $\mathbf{1 6}$ & $\mathbf{0 . 8 0}$ \\
Wheelchairs & 18 & 0.06 & 5084 & 52.88 & 0 & 0 \\
Other equipments and aids & 286 & 1.00 & 1523 & 15.84 & 16 & 0.80 \\
Incontinence products & $\mathbf{5 4 7}$ & $\mathbf{1 . 9 1}$ & $\mathbf{0}$ & $\mathbf{0}$ & $\mathbf{0}$ & $\mathbf{0}$ \\
Transportation & $\mathbf{6 3}$ & $\mathbf{0 . 2 2}$ & $\mathbf{1 5 2 6}$ & $\mathbf{1 5 . 8 7}$ & $\mathbf{1 5 1 2}$ & $\mathbf{7 6 . 0 5}$ \\
Van & 0 & 0.00 & 1526 & 15.87 & 1471 & 74.01 \\
Travelling expenses & 63 & 0.22 & 0 & 0 & 40 & 2.03 \\
Home care and guidance & $\mathbf{2 3 , 0 0 0}$ & $\mathbf{8 0 . 2 4}$ & $\mathbf{0}$ & $\mathbf{0}$ & $\mathbf{0}$ & $\mathbf{0}$ \\
Personal budget & 22,063 & 76.97 & 0 & 0 & 0 & 0 \\
Home care (no personal budget) & 937 & 3.27 & 0 & 0 & 0 & 0 \\
Home modification & $\mathbf{0}$ & 0.00 & $\mathbf{1 4 8 1}$ & $\mathbf{1 5 . 4 0}$ & $\mathbf{3 3 1}$ & $\mathbf{1 6 . 6 7}$ \\
Out-of-pocket & $\mathbf{0}$ & 0.00 & 0 & 0 & $\mathbf{4 3}$ & $\mathbf{2 . 1 7}$ \\
\hline Total of mean annual costs & $\mathbf{2 8 , 6 6 3}$ & $\mathbf{1 0 0 . 0 0}$ & $\mathbf{9 6 1 4}$ & $\mathbf{1 0 0 . 0 0}$ & $\mathbf{1 9 8 8}$ & $\mathbf{1 0 0 . 0 0}$ \\
\hline
\end{tabular}

\section{DISCUSSION}

In this COI study we defined the magnitude of intractable spastic CP in children in monetary terms and we categorised the costs. We estimated the mean annual costs per child from the societal perspective at $€ 40,265$. This is more than eleven fold the mean expenditures on care per capita $(€ 3512)$ in the Netherlands in $2003 .{ }^{20}$ The societal costs were for $71 \%$ borne by the health insurers, for $24 \%$ by the government, and for $5 \%$ by the families.

Considering the division of expenditures, we found that $95 \%$ of costs fell outside the medical care sector. These costs mainly resulted from the motor impairments, which by definition characterise the CP syndromes. ${ }^{21}$ In spite of the high incidence of concomitant problems such as mental retardation, epilepsy, bladder and bowel dysfunction, the expenditures for medical care were relatively small $(4 \%)$. This may be explained by the aetiology of $\mathrm{CP}$, as it comprises a nonprogressive lesion of the brain. From the perspectives of society as well as the health insurers, by far the highest costs fell under the category of home care and guidance. These high expenditures are in agreement with the significantly greater care needs of children with severe disabilities in comparison with non-disabled 
children. ${ }^{22,23}$ In 2004, the Dutch government allocated an average personal budget of $€ 15,234$ per year to 69,500 people. The average annual personal budget allocated to the children included in our study increased to $€ 46,436$.

Ireys et al. studied the expenditures for care of children with one of eight selected chronic health conditions enrolled in the Washington State Medicaid Program. Medicaid claims data were analysed for 310,977 children of whom 950 children were diagnosed with CP. ${ }^{24}$ Mean expenditures for children with CP accompanied by tetraplegia were about two times higher than children with $\mathrm{CP}$ as a whole. This illustrates the general pattern in which relatively few children account for a disproportionate share of the expenditures. In comparison with the other seven chronic illnesses among which asthma, cystic fibrosis, spina bifida and diabetes, expenditures for $\mathrm{CP}$ were relatively lowest for inpatient care, highest for durable medical equipment and second highest for home health care services. These findings are in line with our results, illustrating that in CP the motor handicap accounts for the majority of costs.

Our study has underestimated the already high economic impact of intractable $\mathrm{CP}$ in children, as we left expenditures for special education and day-care out of consideration. The particular institutions could not provide us with these cost estimates. We think that expenditures for special education and day-care would not be influenced by therapeutic interventions for CP. Therefore, leaving these costs out will probably not have important consequences for future economic evaluations. Though we have obtained most data retrospectively, we believe we have been able to retrieve the great majority of data within the previously selected cost categories. The parents were all motivated to participate in this study, resulting in a $100 \%$ response rate for both the questionnaires and the cost diaries. Moreover, in case the parents doubted the completeness of their provided data, it was generally easy to obtain any additional information from Dutch health care institutions and local governments.

The results of this COI study can serve as a basis for any cost evaluation including children with intractable spastic CP. Our study showed that in these children the main economic burden was related to the motor impairments. The question arises whether early treatment of spasticity would not only improve the children's quality of life, but also would reduce the high associated costs. For example, early treatment of spasticity with continuous infusion of intrathecal baclofen can prevent contractures, dislocations and the subsequent need for orthopaedic procedures. ${ }^{25}$ Economic evaluations such as cost-effectiveness or cost-utility analyses are required to address this question. ${ }^{26}$ 


\section{REFERENCES}

1. Miller G. Cerebral palsies: an overview. In: Miller G, Clark GD, eds. The cerebral palsies. Boston: Butterworth-Heineman, 1998;1-36.

2. Kuban KC, Leviton A. Cerebral palsy. N Engl J Med 1994;330:188-195.

3. Stanley F, Blair E, Alberman E. How common are the cerebral palsies? In: Bax MCO, ed. Cerebral palsies: epidemiology and causal pathways. London: Mac Keith Press, 2000;22-39.

4. Surman G, Bonellie S, Chalmers J, Colver A, Dolk H, Hemming K, King A, Kurinczuk JJ, Parkes J, Platt MJ. UKCP: a collaborative network of cerebral palsy registers in the United Kingdom. J Public Health (Oxf) 2006;28:148-156.

5. Krigger KW. Cerebral palsy: an overview. Am Fam Physician 2006;73:91-100.

6. Lance JW. The control of muscle tone, reflexes, and movement: Robert Wartenberg Lecture. Neurology 1980;30:1303-1313.

7. Sheean G. Spasticity rehabilitation. London: Churchill Communications Europe Ltd., 1998.

8. Gilmartin R, Bruce D, Storrs BB, Abbott R, Krach L, Ward J, Bloom K, Brooks WH, Johnson DL, Madsen JR, McLaughlin JF, Nadell J. Intrathecal baclofen for management of spastic cerebral palsy: multicenter trial. J Child Neurol 2000;15:71-77.

9. Albright AL, Gilmartin R, Swift D, Krach LE, Ivanhoe CB, McLaughlin JF. Long-term intrathecal baclofen therapy for severe spasticity of cerebral origin. J Neurosurg 2003;98: 291-295.

10. Campbell WM, Ferrel A, McLaughlin JF, Grant GA, Loeser JD, Graubert C, Bjornson K. Longterm safety and efficacy of continuous intrathecal baclofen. Dev Med Child Neurol 2002;44:660-665.

11. Butler C, Campbell S. Evidence of the effects of intrathecal baclofen for spastic and dystonic cerebral palsy. AACPDM Treatment Outcomes Committee Review Panel. Dev Med Child Neurol 2000;42:634-645.

12. Organisation for Economic Co-operation and Development (OECD). Rising health costs put pressure on public finances, finds OECD. URL: http://www.oecd.org Site accessed on 11 August 2006.

13. Berger $\mathrm{M}$, Bingefors $\mathrm{K}$, Hedblom $\mathrm{E}$, Pashos $\mathrm{CL}$, Torrance GW. Cost-of-illness study. In: Berger M, Bingefors K, Hedblom E, Pashos CL, Torrance GW, eds. Health care costs, quality, and outcomes: ISPOR book of terms. Lawrenceville, NJ: ISPOR, 2003;43-44.

14. Tolpin HG, Bentkover JD. Economic cost of illness: decision-making applications and practical considerations. Adv Health Econ Health Serv Res 1983;4:165-198.

15. Hodgson TA. Costs of illness in cost-effectiveness analysis: a review of the methodology. Pharmacoeconomics 1994;6:536-552.

16. Hoving MA, van Raak EPM, Spincemaille GHJJ, Palmans LJ, Sleypen FAM, Vles JSH. Intrathecal baclofen in children with spastic cerebral palsy: a double-blind, randomized, placebocontrolled, dose-finding study. Dev Med Child Neurol 2007;49:654-9 (Chapter 3 of this thesis).

17. Oostenbrink JB, Bouwmans CAM, Koopmanschap MA, Rutten FFH. Manual for costing: methods and standard cost for economic evaluations in health care [in Dutch]. Actualized version ed. Amstelveen: College voor zorgverzekeringen, 2004.

18. Drummond MF, Sculpher MJ, Torrance GW, O'Brien B, Stoddard GL. Methods for the economic evaluation of health care. Third edition ed. New York: Oxford University Press, 2005.

19. Palisano R, Rosenbaum P, Walter S, Russell D, Wood E, Galuppi B. Development and reliability of a system to classify gross motor function in children with cerebral palsy. Dev Med Child Neurol 1997;39:214-223.

20. Expenditures on care growing more slowly in 2003. URL: http://www.cbs.nl Site accessed on 27 April 2006.

21. Koman LA, Smith BP, Shilt JS. Cerebral palsy. Lancet 2004;363:1619-1631.

22. Curran AL, Sharples PM, White C, Knapp M. Time costs of caring for children with severe disabilities compared with caring for children without disabilities. Dev Med Child Neurol 2001;43:529-533.

23. Roberts K, Lawton D. Acknowledging the extra care parents give their disabled children. Child Care Health Dev 2001;27:307-319. 
24. Ireys HT, Anderson GF, Shaffer TJ, Neff JM. Expenditures for care of children with chronic illnesses enrolled in the Washington State Medicaid program, fiscal year 1993. Pediatrics 1997;100:197-204.

25. Gerszten PC, Albright AL, Johnstone GF. Intrathecal baclofen infusion and subsequent orthopedic surgery in patients with spastic cerebral palsy. J Neurosurg 1998;88:1009-1013.

26. Drummond M. Cost-of-illness studies: a major headache? Pharmacoeconomics 1992;2:1-4. 



\section{CHAPTER 8}

Intrathecal baclofen therapy in children with

intractable spastic cerebral palsy:

a cost-effectiveness analysis

MA Hoving, SMAA Evers, AJHA Ament, EPM van Raak, JSH Vles, on behalf of the Dutch Study Group on Child Spasticity

Dev Med Child Neurol, accepted 


\section{ABSTRACT}

In a Dutch national study, we recently established the effectiveness and safety of continuous intrathecal baclofen infusion in children with intractable spastic cerebral palsy. Because prospective studies on the cost-effectiveness of continuous intrathecal baclofen infusion in children with spastic cerebral palsy are lacking, we conducted a costeffectiveness analysis alongside our prospective, national study. We compared the costs and health effects of continuous intrathecal baclofen infusion to those of standard treatment only, from the health care perspective for a one-year period. Health effects were expressed in terms of a visual analogue scale for individual problems and quality-adjusted life-years (QALYs). QALYs were derived from the EuroQol-5D. We included eight females and seven males, aged between 7 and 17 years (mean age 13y8m $\pm 3 y 0 \mathrm{~m}$ ). Eleven children had spastic cerebral palsy and four children had spastic-dyskinetic cerebral palsy. One child was classified on the Gross Motor Function Classification System at level III, two children at level IV and 12 at level V. Continuous intrathecal baclofen infusion was more effective and more costly than standard treatment only. Gaining one QALY cost on average $€ 32,737$. We conclude that based on the threshold-willingness to pay for one QALY in the Netherlands $(€ 80,000)$, our results sustain the cost-effectiveness of continuous intrathecal baclofen infusion for carefully selected children with intractable spastic cerebral palsy. 


\section{INTRODUCTION}

With a prevalence of about 2 per 1000 live births in Western countries, cerebral palsy (CP) is the most common cause of severe physical disability in childhood. ${ }^{1}$ Spasticity accounts for $70 \%$ to $91 \%$ of the motor disorders associated with CP and is intractable in a substantial group of children. ${ }^{2}$ Intractable spasticity can cause pain, sleeping disturbances, increased energy requirements, pressure sores, and interference with positioning, transfers, dressing, and body hygiene. Besides the negative impact on quality of life, serious spasticity involves high costs. In a cost of illness study (Chapter 7 of this thesis), we estimated the mean societal costs in Dutch children with intractable spastic CP at $€ 40,265$. $^{3}$ This is more than eleven fold the mean expenditures for care per Dutch capita. ${ }^{3}$

In a prospective Dutch national study, ${ }^{4-6}$ we recently established the effectiveness and safety of continuous intrathecal baclofen infusion (CITB) in children with intractable spastic CP (Chapters 4 and 5 of this thesis). Our randomised controlled trial showed that CITB significantly improved individually formulated problems, ease of care, pain and gross motor functioning. Moreover, healthrelated quality of life (HRQL) significantly improved for the domains of bodily pain/discomfort, mental health, psychosocial status and parents' personal time limitation. Our results are in keeping with those of non-randomised trials. ${ }^{7}$

Health care expenditures are rising and resources - people, time, facilities, equipment and knowledge - are scarce. Decision makers, including policy makers, health care insurers, health care providers, and even patients consider information on both costs and effects when choosing between different interventions. One way to control health care costs is to apply a transparent and rational decision-making process for the reimbursement of new therapies. For these reasons, it is important to be informed on the cost-effectiveness of a new intervention.

In a cost-effectiveness analysis (CEA), the additional costs of an intervention are compared with the additional health effects of that intervention. The additional health effects are expressed in clinical units related to the intervention, such as a decrease in pain as measured with a visual analogue scale (VAS). A cost-utility analysis (CUA) differs from a CEA in that the additional health effects are measured in quality-adjusted life-years (QALYs). ${ }^{8}$ A CUA reports the costs per QALY, which reflects how much money has to be spent in order to gain one life year in full health. The lower this amount, the more cost-effective the health intervention is.

Because prospective studies on the cost-effectiveness of CITB in children with intractable spastic CP are lacking, we conducted a cost-effectiveness analysis alongside our prospective Dutch national study. The aim of this combined CEA/CUA was to evaluate the cost-effectiveness of CITB in the treatment of children with intractable spastic CP. 


\section{METHODS}

This combined CEA/CUA was embedded in the Dutch national study on the efficacy and safety of CITB for intractable spasticity in children with CP. ${ }^{4}$ Medical specialists referred children from all parts of the Netherlands to the University Hospital Maastricht. In Maastricht, where all phases of the study took place, a multidisciplinary team decided whether the child met the eligibility criteria. ${ }^{4} \mathrm{We}$ planned a placebo-controlled intrathecal baclofen test treatment for the eligible children, which was successful in all. ${ }^{4}$ Subsequently, all children had a programmable infusion pump (Medtronic, Inc., Minneapolis, Minnesota, USA) implanted by always the same neurosurgeon. We programmed the pump to continuously infuse baclofen intrathecally, starting right after the implantation.

\section{Study design, time horizon and perspective}

We compared the costs and health effects of CITB and standard treatment with those of standard treatment only, for a one-year period. Children received only standard treatment in the year preceding the test treatment versus CITB in addition to standard treatment from the pump implantation onwards. Standard treatment included physical therapy, occupational therapy and/or rehabilitation. For the assessment of the additional costs of CITB, we compared the costs in the year before the test treatment to the costs in the first year after the pump implantation (before-after comparison). For the assessment of the additional health effects of CITB, we used the VAS for individual problems in the CEA and the EuroQol-5D (EQ-5D) in the CUA. We compared the values at the one-year follow-up visit with those obtained before pump implantation (baseline). The perspective of both the CEA and the CUA was that of the health care. This means that we took into account all relevant resources consumed within the care sector.

\section{Data collection, data sources and costs}

We included intervention costs and other health care costs. For the latter, data were collected by means of a questionnaire and a cost diary. The questionnaire included the following health care resources: general practitioner care, outpatient specialist medical care, alternative therapies, emergency department attendances, ambulance transfers, hospitalisations, tests and prescribed medication. Parents completed this questionnaire retrospectively for the year preceding the test treatment and prospectively for the first year with CITB. Retrospectively collected data were validated and completed by retrieving information from records of the involved health care institutions. The parents prospectively kept a cost diary twice; for one month in the year preceding the start of CITB and for one month in the year afterwards. This diary covered regular resource consumption, which we 
assumed to be stable during the two-year study period. The diary included the following resources: incontinence products, occupational therapy, physical therapy, speech therapy and outpatient rehabilitation. The data obtained from the diaries were extrapolated over a one-year period.

Intervention costs included expenditures for the test treatment phase, the pump implantation phase, and the pump refills. The intervention costs also included expenditures related to any adverse events that occurred during these phases. The test treatment and pump implantation unit data were obtained from registries of the University Hospital Maastricht. Considering the test treatment, we did not include costs related to the days on which we administered placebo. These costs were protocol-driven, because placebo is not used in regular clinical practice. We assumed that most children would be treated with CITB for at least 10 years, so we divided the costs of the test treatment by 10 to calculate the annual costs. Mortality across this 10-year period can be considered very low. ${ }^{1}$ Because the pump has to be replaced every 5 to 7 years depending on the lifetime of the battery, we divided the costs of the pump implantation phase by five to calculate the annual costs. ${ }^{9}$ Because of the roughness of these estimates, we did not take into account the interest over the depreciation periods. Pump refill costs included costs for specialist medical care, refill kits and baclofen during the first year after pump implantation.

The majority of costs were valued using the Dutch guidelines for pharmacoeconomic research ${ }^{10}$ and real unit prices excluding taxes, as assigned by the University Hospital Maastricht. Costs were estimated for the year 2003 in Euros. We discounted costs that were not available for the year 2003 with 4\% per year according to the Dutch guidelines. ${ }^{10}$ The Euro/Dollar exchange rate in 2003 was: 1 Euro $=1.12$ American Dollars. ${ }^{11}$

\section{Outcome measures}

The VAS is a valid and reliable measure for rating pain intensity in adults and children over six. ${ }^{12,13}$ In paediatric patients, aged 5-17 years, the VAS has also been applied to measure anxiety, sadness, anger, worry, happiness and fatigue. ${ }^{14,15}$ The VAS showed preliminary reliability and validity for both child self-report and parent-proxy report. ${ }^{14}$ Because the children in our study had different problems, we used a VAS for each individually formulated problem. ${ }^{4}$ We formulated three problems per child and used the average of these three VAS scores for statistical analysis (Table 8.1). ${ }^{14}$ The VAS is a straight $10-\mathrm{cm}$ horizontal line with anchor points 'very dissatisfied' (score 0 ) and 'very satisfied' (score 10). ${ }^{4}$ The VAS scores were rated by the caregivers for 13 children, while two children rated the VAS scores themselves.

The EQ-5D has been developed to generate a single index for health status for use in economic evaluations. ${ }^{16}$ The caregiver describes the child's health state of 
that day on five dimensions: mobility, self-care, usual activities, pain/discomfort and anxiety/depression. Each dimension has three response categories corresponding to no problem, some problem and extreme problem. The descriptive system defines a total of 243 possible health states to which two further states (dead and unconscious) were added. Any classified health state can then be converted into a single index value (EQ-5D index) by applying scores from one of the European valuation sets. ${ }^{16-18}$ The EQ-5D health indexes lie on a scale on which full health has the value 1 and dead has the value 0 . We used the Dutch valuation set (Dutch EQ-5D index) for the core analysis. ${ }^{17}$ The United Kingdom (UK) valuation set (UK EQ-5D index) was used in a sensitivity analysis. $^{18}$

Table 8.1 Individually formulated problems (three per child)

\begin{tabular}{lr}
\hline Individual problem & $\mathrm{n}$ \\
\hline Ease of care & 14 \\
Pain & 12 \\
Transfers & 4 \\
Sitting position & 2 \\
Use of wheelchair & 3 \\
Startle response & 2 \\
Urinating & 2 \\
Sleep & 1 \\
Tense body feeling & 1 \\
Right arm function & 1 \\
Extreme excitement during eating & 1 \\
Walking distance & 1 \\
Energy use during walking & 1 \\
\hline Total & 45 \\
\hline
\end{tabular}

\section{Cost-effectiveness}

Participants with both cost and effectiveness data were included in the CEA and CUA. For the intervention period, we calculated QALYs from the area under the curve of the mean EQ-5D health index as it changed from baseline. ${ }^{8}$ We assumed that utility values changed in a linear way in between the assessments at baseline and the follow-up visits at 6 and 12 months.

Because we included a relatively small group of children, we used the bootstrap method to verify the reliability of the results. ${ }^{19}$ During bootstrapping, the costs and effects were recalculated on the participants' sample several times. We ran 1000 replication bootstraps, which generated 1000 estimates of the costeffectiveness and cost-utility ratios. ${ }^{19}$ We plotted these estimates on a costeffectiveness and cost-utility plane. Cost-effectiveness and cost-utility planes have a horizontal axis representing the difference in effect and a vertical axis representing the difference in costs. CITB can be considered as more cost- 
effective than standard treatment only, in one of the following situations: 1) it is more effective and less costly, 2) it is more effective and more costly, but the additional costs per QALY are worth paying by decision makers, and 3 ) it is less effective and less costly, but the additional costs per extra QALY of standard treatment only are not worth paying by decision makers. ${ }^{8}$ The point estimates on the cost-utility plane identify whether one of these situations applies.

\section{Statistical analysis}

We used SPSS for Windows statistical package, Release 11.0.1. for statistical analysis. We used the non-parametric Wilcoxon Signed Rank Test to compare the results of the VAS for individual problems and the EQ-5D at the one-year followup visit with those obtained before pump implantation (baseline). ${ }^{20}$ We considered results with $p \leq 0.05$ statistically significant. For bootstrapping, we used a specially designed macro on Microsoft Excel software.

\section{Ethics}

The study was approved by the medical ethical committee of the University Hospital Maastricht and the Maastricht University. In accordance with local legislation, we obtained written informed consent from the parents, and also from the children if they were aged 12 years or older and capable of understanding the nature and impact of the study. The informed consent also included permission for the retrieval of economic data.

\section{RESULTS}

We included 15 children, eight girls and seven boys, aged between 7 and 17 years at time of the pump implantation (mean age $13 \mathrm{y} 8 \mathrm{~m} \pm 3 \mathrm{y} 0 \mathrm{~m}$ ). Eleven children had spastic CP and four children spastic-dyskinetic CP. One child was classified on the Gross Motor Function Classification System (GMFCS) at level III, two children at level IV, and 12 children at level V. All data were collected between January 2002 and May 2006. All questionnaires and diaries were completed by the parents. There were no missing VAS or EQ-5D data.

\section{Costs}

The mean health care costs were $€ 5296$ for the year during which the children received standard treatment only and $€ 9028$ for the year during which the children also received CITB. The mean additional annual health care costs of CITB were $€ 3732$ (Table 8.2). 
We estimated the mean intervention related health care costs at $€ 4226$ per year (Table 8.2). The mean annual costs for the test treatment phase, the pump implantation phase and the pump refills accounted for, respectively, $€ 335, € 3412$ and $€ 479$ (Tables 8.2 and 8.3). During the test treatment phase, hospitalisation accounted for the highest annual costs (€189; Table 8.3). The children were on average hospitalised for 5 days (range 3 to 8). Fourteen of the 15 children had symptoms that could fit in with the diagnosis of lowered cerebrospinal fluid pressure. ${ }^{4}$ As a result of this complication, some children had a prolonged stay in hospital. During the pump implantation phase, the pumps accounted for the highest annual costs ( $€ 2300$; Table 8.3 ), followed by the hospitalisation costs (€738). The children were on average hospitalised for 10 days (range 9 to 14). Two children required a second operation to solve a catheter related adverse event. Within the expenditures for the pump refills, specialist medical care accounted for the highest costs (€377; Table 8.2).

The other health care costs remained fairly stable, except for the medication costs, which decreased from $€ 516$ to $€ 289$ with CITB (Table 8.2).

Table 8.2 Annual health care costs (2003 Euro)

\begin{tabular}{lrr}
\hline Resource category & \multicolumn{2}{c}{ Mean annual costs } \\
\cline { 2 - 3 } & $\begin{array}{r}\text { Standard treatment CITB and standard } \\
\text { treatment }\end{array}$ \\
\hline Intervention related health care costs & $\mathbf{0}$ & $\mathbf{4 2 2 6}$ \\
Test treatment phase & 0 & 335 \\
Pump implantation phase & 0 & 3412 \\
Refills & 0 & 479 \\
- Refill kits & 0 & 57 \\
- Baclofen & 0 & 45 \\
- Specialist medical care & 0 & 377 \\
Other health care costs & $\mathbf{5 2 9 6}$ & 0 \\
Hospitalisation & 70 & 8 \\
Emergency department care & 0 & $\mathbf{4 8 0 2}$ \\
Specialist medical care & 760 & 50 \\
General practitioner care & 57 & 54 \\
Tests & 64 & 289 \\
Medication & 516 & 0 \\
Alternative medicine & 20 & 547 \\
Incontinence products & 547 & 3066 \\
Therapy and rehabilitation & 3262 & $\mathbf{9 0 2 8}$ \\
\hline Total & $\mathbf{5 2 9 6}$ & $\mathbf{3 7 3 2}$ \\
\hline Additional mean annual costs of CITB & & 59 \\
\hline
\end{tabular}


Table 8.3 Costs (2003 Euro) related to the test treatment and the pump implantation phase

\begin{tabular}{|c|c|c|c|c|c|}
\hline Resource & Unit cost & $\begin{array}{l}\text { Quantity } \\
\text { test } \\
\text { treatment } \\
\text { phase }\end{array}$ & $\begin{array}{c}\text { Mean } \\
\text { costs test } \\
\text { treatment } \\
\text { phase }\end{array}$ & $\begin{array}{c}\text { Quantity } \\
\text { pump } \\
\text { implantation } \\
\text { phase }\end{array}$ & $\begin{array}{c}\text { Mean costs } \\
\text { pump } \\
\text { implantation } \\
\text { phase } \\
\end{array}$ \\
\hline Admission costs & 28.00 & 1.07 & 30 & 1.07 & 30 \\
\hline Hospitalisation per day & 364.00 & 5.20 & 1893 & 10.13 & 3689 \\
\hline Paediatrician & 86.40 & 1.07 & 92 & 1.07 & 92 \\
\hline Neurologist; consultation & 6.10 & 5.20 & 32 & 10.13 & 62 \\
\hline Neurologist; administration test bolus & 41.00 & 1.40 & 57 & & \\
\hline Neurosurgeon; insertion lumbar catheter & 107.00 & 1.00 & 107 & & \\
\hline Anaesthetist; pre-op consultation & 48.20 & 1.00 & 48 & & \\
\hline Anaesthetist; insertion catheter & 109.00 & 1.00 & 109 & & \\
\hline External lumbar catheter ${ }^{a}$ & 299.88 & 1.00 & 300 & & \\
\hline Laboratory tests & variable & - & 14 & & \\
\hline Operation room & 452.00 & 1.00 & 452 & 1.13 & 512 \\
\hline X-ray; catheter position peroperative & 114.70 & 0.07 & 7 & 1.13 & 129 \\
\hline Soleus H-reflex measurement & 86.20 & 2.41 & 207 & 1.00 & 86 \\
\hline Anaesthetist; pump implantation & 144.00 & & & 1.13 & 163 \\
\hline Neurosurgeon; pump implantation & 378.50 & & & 1.13 & 429 \\
\hline Synchromed EL pump ${ }^{b}$ & 9363.00 & & & 0.27 & 2497 \\
\hline Synchromed II pump & $12,280.12$ & & & 0.73 & 9005 \\
\hline Intrathecal catheter model $8731^{\mathrm{b}}$ & 359.75 & & & 0.80 & 288 \\
\hline Intrathecal catheter model $8709^{b}$ & 329.29 & & & 0.20 & 66 \\
\hline Baclofen $20 \mathrm{cc}$ & 11.00 & & & 1.00 & 11 \\
\hline Absolute mean costs & & & 3349 & & 17,059 \\
\hline Annual mean costs ${ }^{\mathrm{C}}$ & & & 335 & & 3412 \\
\hline
\end{tabular}

${ }^{a}$ Perifix $^{\circledR} 300$ Mini Set; B.Braun, Melsungen, Germany; ${ }^{b}$ Medtronic, Inc., Minneapolis, Minnesota, USA; ${ }^{\mathrm{C}}$ Absolute mean costs of the test treatment phase divided by 10 and mean costs of the pump implantation phase divided by 5 (see text for explanation).

\section{Cost-effectiveness}

On the cost-effectiveness plane all point estimates are found in the same quadrant (Figure 8.1). This means that CITB was more effective and more costly than standard treatment only. The VAS for individual problems improved from $2.3 \pm 1.1$ at baseline to $7.2 \pm 1.7$ after one year of CITB $(p=0.001)$. 


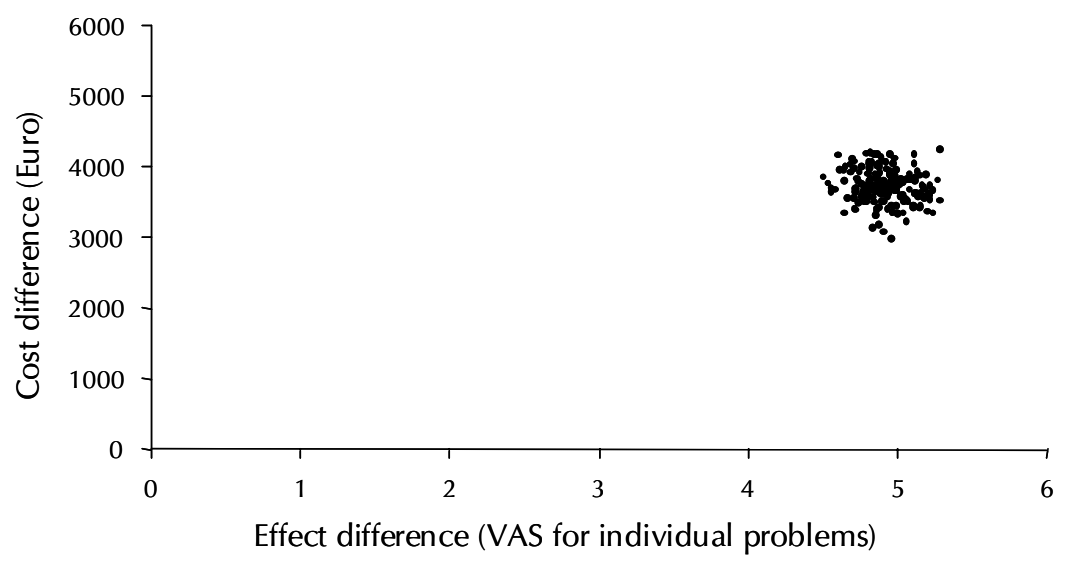

Figure 8.1 Cost-effectiveness plane. CITB is more effective and more costly than standard treatment only.

\section{Cost-utility}

On the cost-utility plane derived from the Dutch EQ-5D index, all point estimates are found in the same quadrant (Figure 8.2). This means that CITB was more effective and more costly than standard treatment only. The cost-utility plane derived from the UK EQ-5D index showed no appreciable difference. One QALY cost on average $€ 32,737$, using the Dutch EQ-5D index and $€ 28,273$, using the UK EQ-5D index.

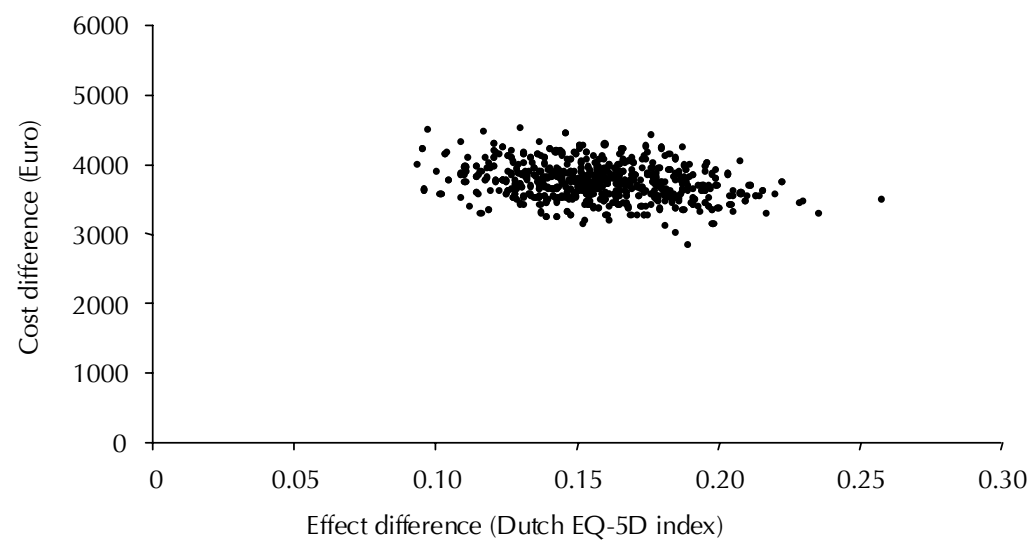

Figure 8.2 Cost-utility plane. CITB is more effective and more costly than standard treatment only. 


\section{DISCUSSION}

This is the first cost-effectiveness analysis on CITB in children with intractable spastic CP that was conducted alongside a prospective clinical study. CITB was both more effective and costly than standard treatment only. In the CEA, the VAS for individual problems significantly improved with 4.9 on average. In the literature, the minimal clinically important change on a 0-10 VAS for pain ranged from 0.9 to $1.8 .{ }^{21}$ The mean additional annual health care costs of CITB were $€ 3732$.

In the CUA, CITB cost $€ 32,737$ per QALY, using the Dutch EQ-5D index. The costs per QALY using the UK EQ-5D index were $€ 28,273$, which is in the same order of magnitude. There is no consensus on the cost per QALY that represents acceptable value for money. The Council for Public Health and Health Care proposed $€ 80,000$ per QALY as a reasonable benchmark in the Netherlands. ${ }^{22}$ Therefore, CITB can be considered cost-effective. However, cost-effectiveness is one of many factors in any assessment of a new intervention. Other important factors are the disease burden, the expected number of treatment recipients, the total health budget, society's moral and ethical values and whether or not effective treatment alternatives exist. ${ }^{8}$ Most children eligible for CITB suffer from intractable spasticity without any effective treatment alternative available. The health status of children with moderate to severe CP (GMFCS levels III-V) is significantly lower than that of children without CP. ${ }^{23}$ The disease burden of intractable spasticity is usually high for both the children and their caregivers. Moreover, treatment with CITB is confined to a carefully selected group of children, resulting in a very limited impact on the total health budget. We expect to start CITB in at most 20 children per year in the Netherlands, resulting in a burden on the Dutch total health budget of about $€ 75,000$ per year. In conclusion, our results sustain the cost-effectiveness of CITB for carefully selected children with intractable spastic $\mathrm{CP}$ and, from an economic point of view, justify the reimbursement of CITB for this group of children in the Netherlands.

Our results are in keeping with those of two retrospective studies. ${ }^{9,24}$ Sampson et al. reviewed the cost-effectiveness of CITB in a heterogeneous, mainly adult patient group with spasticity. ${ }^{9}$ They considered the cost-benefit ratio acceptable in comparison with other interventions that are funded by the health service in the UK. The results of a cost-effectiveness analysis in American children with severe spasticity of cerebral origin also indicated that CITB offers good value for money. ${ }^{24}$ By means of mathematical modelling and computer simulation, the investigators estimated the additional costs of CITB per QALY at $\$ 42,000$. This amount is less than the widely accepted range of $\$ 50,000$ to $\$ 100,000$ in the United States. ${ }^{24}$

Our cost-effectiveness analysis has a few limitations. First, the generalisability of the results is confined to relatively older children with intractable spastic $\mathrm{CP}$, who 
rely on wheeled mobility (GMFCS levels IV and V). However, in clinical practice CITB is mostly indicated for children with GMFCS levels IV and V. The generalisability of the results beyond the Netherlands may be limited by differences in the behaviour of patients and health care providers and differences in unit cost prices, financing and supply of health care. The second limitation concerns the use of the EQ-5D in the CUA. The EQ-5D is a broad, generic HRQL measure that may be insensitive to some of the HRQL-changes experienced by children with intractable spastic CP. ${ }^{25}$ Therefore, the cost-effectiveness of CITB may be more favourable than we have estimated. Thirdly, because of the limited time-horizon of our study, any long-term effects and complications of CITB could not be addressed. Factors that increased the external validity of our results are the following: 1) the exclusion of protocol-driven resource use, 2) the inclusion of children from all parts of the Netherlands, 3) the used eligibility criteria for treatment with CITB also apply to regular clinical practice, and 4) there was no artificially enhanced compliance.

In conclusion, the results of this combined CEA/CUA sustain the costeffectiveness of CITB for carefully selected children with intractable spastic CP. 


\section{REFERENCES}

1. Koman LA, Smith BP, Shilt JS. Cerebral palsy. Lancet 2004;363:1619-1631.

2. Surman G, Bonellie S, Chalmers J, Colver A, Dolk H, Hemming K, King A, Kurinczuk JJ, Parkes J, Platt MJ. UKCP: A collaborative network of cerebral palsy registers in the united kingdom. J Public Health (Oxf) 2006;28:148-156.

3. Hoving MA, Evers SMAA, Ament AJHA, van Raak EPM, Vles JSH, on behalf of the Dutch Study Group on Child Spasticity. Intractable spastic cerebral palsy in children: a Dutch cost of illness study. Dev Med Child Neurol 2007;49:397-398 (Chapter 7 of this thesis).

4. Hoving MA, van Raak EPM, Spincemaille GHJJ, Palmans LJ, Sleypen FAM, Vles JSH, on behalf of the Dutch Study Group on Child Spasticity. Intrathecal baclofen in children with spastic cerebral palsy: a double-blind, randomized, placebo-controlled, dose-finding study. Dev Med Child Neurol 2007;49:654-659 (Chapter 3 of this thesis).

5. Hoving MA, Smulders NM, Abdul Fatah B, van Kroonenburgh MJ, van Raak EPM, Spincemaille GHJJ, Vles JSH, on behalf of the Dutch Study Group on Child Spasticity. The use of an Indium111 DTPA flow study in the evaluation of a lumbar swelling in a girl with a baclofen pump. Neuropediatrics 2006;37:99-101 (Chapter 6 of this thesis).

6. Hoving MA, van Kranen-Mastenbroek VHJM, van Raak EPM, Spincemaille GHJJ, Hardy ELM, Vles JSH, on behalf of the Dutch Study Group on Child Spasticity. Placebo controlled utility and feasibility study of the $\mathrm{H}$-reflex and flexor reflex in spastic children treated with intrathecal baclofen. Clin Neurophysiol 2006;117:1508-1517 (Chapter 2 of this thesis).

7. Albright AL, Ferson SS. Intrathecal baclofen therapy in children. Neurosurg Focus 2006;21:E3.

8. Drummond MF, Sculpher MJ, Torrance GW, O'Brien B, Stoddard GL. Methods for the economic evaluation of health care. New York: Oxford University Press; 2005.

9. Sampson FC, Hayward A, Evans G, Morton R, Collett B. Functional benefits and cost/benefit analysis of continuous intrathecal baclofen infusion for the management of severe spasticity. J Neurosurg 2002;96:1052-1057.

10. Oostenbrink JB, Bouwmans CAM, Koopmanschap MA, Rutten FFH. Manual for costing: methods and standard cost for economic evaluations in health care [in Dutch]. Amstelveen: College voor zorgverzekeringen; 2004.

11. Worldbank. World development indicators, states and market. Site accessed on 11 January 2008. URL: http://devdata.worldbank.org/wdi2005/Table5_7.htm.

12. Chapman CR, Casey KL, Dubner R, Foley KM, Gracely RH, Reading AE. Pain measurement: an overview. Pain 1985;22:1-31.

13. Stinson JN, Kavanagh T, Yamada J, Gill N, Stevens B. Systematic review of the psychometric properties, interpretability and feasibility of self-report pain intensity measures for use in clinical trials in children and adolescents. Pain 2006;125:143-157.

14. Sherman SA, Eisen S, Burwinkle TM, Varni JW. The PedsQL present functioning visual analogue scales: preliminary reliability and validity. Health Qual Life Outcomes 2006;4:75.

15. Hunt $O$, Burden D, Hepper P, Stevenson M, Johnston C. Parent reports of the psychosocial functioning of children with cleft lip and/or palate. Cleft Palate Craniofac J 2007;44:304-311.

16. Rabin R, de Charro F. EQ-5D: a measure of health status from the EuroQol Group. Ann Med 2001;33:337-343.

17. Dolan P, Gudex C, Kind P, Williams A. The time trade-off method: results from a general population study. Health Econ 1996;5:141-154.

18. Lamers LM, Stalmeier PF, McDonnell J, Krabbe PF, van Busschbach JJ. [Measuring the quality of life in economic evaluations: The Dutch EQ-5D tariff]. Ned Tijdschr Geneeskd 2005;149: 1574-1578.

19. Efron B, Tibshirani R. An introduction to the bootstrap. New York: Chapman \& Hall; 1993.

20. Kirkwood B. Essentials of medical statistics. Oxford, London, Edinburgh: Blackwell scientific publications; 1988.

21. Clark E, Plint AC, Correll R, Gaboury I, Passi B. A randomized, controlled trial of acetaminophen, ibuprofen, and codeine for acute pain relief in children with musculoskeletal trauma. Pediatrics 2007;119:460-467. 
22. Raad voor de volksgezondheid en zorg. Zinnige en duurzame zorg. Den Haag, 2006

23. Liptak GS, O'Donnell M, Conaway M, Chumlea WC, Wolrey G, Henderson RC, Fung E, Stallings VA, Samson-Fang L, Calvert R, Rosenbaum P, Stevenson RD. Health status of children with moderate to severe cerebral palsy. Dev Med Child Neurol 2001;43:364-370.

24. de Lissovoy G, Matza LS, Green H, Werner M, Edgar T. Cost-effectiveness of intrathecal baclofen therapy for the treatment of severe spasticity associated with cerebral palsy. J Child Neurol 2007;22:49-59.

25. Dijkers M. Measuring quality of life: methodological issues. Am J Phys Med Rehabil 1999;78:286-300. 
Cost-effectiveness analysis 135 



\section{CHAPTER 9}

General discussion 
138 Chapter 9 


\section{GENERAL DISCUSSION}

A substantial group of children with cerebral palsy (CP) suffer from serious spasticity, which does not respond to regular treatments. This so-called intractable spasticity can be well treated with continuous infusion of intrathecal baclofen (CITB). ${ }^{1}$ However, evidence for the use of CITB in the treatment of children with spasticity is lacking. ${ }^{2}$ This thesis addresses the results of a Dutch national study, in which we studied the efficacy and safety of intrathecal baclofen therapy in children with intractable spastic CP. The Dutch ITB study comprised four phases: 1) the selection phase, 2) the test treatment phase, 3) the pump implantation phase, and 4) the follow-up phase. Furthermore, the Dutch ITB study embedded a clinical neurophysiological study and a cost analysis. ${ }^{3-5}$

\section{Selection phase}

During the selection phase, medical specialists referred children from all parts of the Netherlands to the University Hospital Maastricht for possible participation in the study. In Maastricht, our multidisciplinary team decided whether the children met the eligibility criteria. We expected that hundreds of children would be eligible for intrathecal baclofen therapy in the Netherlands. Therefore, we were surprised to see that only 21 children were referred to our team between January 2002 and December 2003. During these two years, we included only seven children. The other 14 children did not meet the eligibility criteria for one or more of the following reasons: age over 16 years $(n=1)$; weight less than $20 \mathrm{~kg}$ $(\mathrm{n}=4)$; insufficient cognitive abilities $(\mathrm{n}=6)$; intractable epileptic seizures $(\mathrm{n}=3)$; insufficient motivation for study participation $(\mathrm{n}=2)$; and/or spasticity which did not seem to result in a decreased quality of life $(n=4)$. It was interesting to see that 10 of the 21 referred children beforehand did not meet one or more of the eligibility criteria. We had several explanations for the disappointingly low inclusion. First, the most frequent mentioned spasticity associated problems were 'pain' and 'problems with ease of care' and not so much 'problems with functioning'. Therefore, we decided to widen the eligibility criteria from January $2004 \mathrm{on}$. Children did not need to understand and carry out instructions anymore and we also dropped the weight criterion. We subsequently gave a few presentations in the Netherlands to explain the new eligibility criteria. During these presentations we found out that some of our colleagues were sceptical about ITB therapy and therefore were hesitant to refer their patients to our study team. Nevertheless, 17 children were referred in 2004 of whom eight were included in our study. We excluded nine children for the following reasons: age over 16 years $(n=1)$; insufficient motivation for study participation $(n=1)$; spasticity which did not seem to result in a decreased quality of life $(n=3)$; spasticity was not the most prominent sign in a mixed CP syndrome $(n=2)$; and 
serious axial hypotonia $(n=2)$. Owing to the widened eligibility criteria, we could still include two children who under the first criteria were excluded.

\section{Test treatment phase}

We included 17 children during the selection phase. ${ }^{6}$ They all participated in the double-blind, randomised, placebo-controlled, dose-finding test treatment phase. The aims of the test treatment were to: 1) further select children eligible for CITB, 2) assess the effective ITB bolus dose, and 3) evaluate the effects, side effects, complications, and procedures. The test treatment was successful in all 17 children. Intrathecal bolus administration of baclofen and not placebo reduced both muscle tone and the individually formulated problems, significantly. A satisfying clinical effect was achieved with ITB bolus doses ranging between 12.5 $\mu \mathrm{g}$ and $50 \mu \mathrm{g}$. The older and heavier children more often required ITB $50 \mu \mathrm{g}$. Although ITB bolus administration via an external lumbar catheter turned out to be safe, 14 of the 17 children suffered from symptoms of lowered cerebrospinal fluid pressure. The three children with a tunnelled catheter did not have these symptoms.

What do our results add to the existing literature? First, it was the first placebocontrolled study in children with spastic CP. We provided evidence that the established effects resulted from the intrathecal administration of baclofen and not placebo. Second, other investigators usually started the test treatment in children with the administration of an ITB $50 \mu \mathrm{g}, 75 \mu \mathrm{g}$, or $100 \mu \mathrm{g}$ bolus. ${ }^{7-11}$ The results of our study showed that the majority of children positively responded to an ITB bolus dose half that of the usual adult ITB $50 \mu \mathrm{g}$ starting dose. Even with relatively low ITB bolus doses, one has to take into account that children might temporarily become slightly lethargic. Third, the test treatment was highly appreciated by most children and their parents in spite of symptoms of lowered cerebrospinal fluid pressure.

\section{Pump implantation and follow-up phase}

After a successful test treatment, all 17 children were admitted to the randomised, controlled, open-label, pump implantation phase. Because of the varying nature of the children and the numerous outcomes of primary interest, others have considered a randomised controlled trial (RCT) practically impossible or inappropriate for evaluating treatment in children with CP. ${ }^{12}$ We endorsed these problems, but succeeded to conduct an ethically sound RCT in which we studied the 6-month efficacy of CITB in comparison with standard treatment only. CITB reduced individually formulated problems, it relieved pain, and it improved both ease of care and gross motor functioning, significantly. Moreover, health related quality of life significantly improved for the domains of bodily pain/discomfort, mental health, psychosocial status and parents' personal time limitation. After the 
RCT, the children in the control group also received a pump for CITB. Subsequently, all 17 children participated in the follow-up phase. In this phase, we prospectively studied the one-year efficacy of CITB and its safety from pump implantation up to 24 months of follow-up. The results were in keeping with those of the RCT. Adverse events frequently occurred, but were for the greater part short-lasting and non-serious. Overall patient satisfaction was high.

What makes our research special? Most of all, this was the first RCT establishing the efficacy of CITB in the treatment of children who suffer from problems caused by intractable spastic CP. Our follow-up study furthermore showed that effects lasted or became even stronger after 12 months and that CITB was safe. Our study also distinguishes itself from previous reports for the inclusion of a broad choice of outcome measures. For example, we illustrated how children were able to extend their activities and participation after spasticity and pain had been controlled. It was interesting to see that these clear individual improvements were not always manifested by objective outcome measures such as the Gross Motor Function Measure or the Pediatric Evaluation of Disability Inventory. This phenomenon also applied to ease of care, which was the most reported spasticity related problem. Contrary to the unchanged Pediatric Evaluation of Disability Inventory self-care domain scores, the visual analogue scale for ease of care showed an enormous improvement. This means that the facilitation in ease of care did not comprise that the children could take better care of themselves, nor that they needed less assistance. However, the caregivers experienced that pain relief and the decrease in muscle tone facilitated ease of care and made care less time consuming. Another novelty of the Dutch ITB study was that it showed important effects of CITB on health related quality of life.

\section{Clinical neurophysiological study}

When treating a child with CITB, we are most of all interested in the clinical benefits, for example whether the child reaches his or her individual treatment goals. However, there are clinical situations in which there is doubt about the effectiveness of ITB therapy. Therefore, we needed an objective and sensitive test, which: 1) can quantify the spinal cord neuronal response to ITB administration; 2) can be easily applied in clinical practice; and 3) is feasible in spastic children. From a pathophysiological point of view, both the soleus $\mathrm{H}$-reflex and the flexor reflex could be suitable. Our study was the first randomised, double-blind, placebo-controlled, dose-escalation study in children. It showed that the H-reflex is a feasible, useful, and objective test to quantify the decreasing motoneuron excitability in response to ITB bolus administration. There are several useful applications for the H-reflex during different phases of ITB therapy. If a patient for example does not respond to increasing ITB doses, the $\mathrm{H}$-reflex values can confirm or negate successful ITB delivery. ${ }^{13}$ Recording an individual H-reflex 
profile can also be useful, because sudden or gradual increases in the H-reflex values can early identify pump and catheter system malfunction. ${ }^{14}$ It is very important to detect complications at an early stage, as abrupt interruption of ITB delivery can result in the potentially life threatening ITB withdrawal syndrome. ${ }^{15,16}$

\section{Cost analysis}

The Dutch national ITB study included a cost of illness study and a costeffectiveness analysis. We started with a cost of illness study to define the magnitude of intractable spastic $\mathrm{CP}$ in children in monetary terms and to categorise the costs. In this bottom-up, prevalence based study, data were collected by a patient survey and by consulting files of health care institutions and local governments for a one-year period. From the societal perspective, mean annual costs were $€ 40,265$ per child, which is more than eleven fold the mean expenditures on care per capita in the Netherlands. ${ }^{17}$ The societal costs were for $71 \%$ borne by the health insurers, for $24 \%$ by the Dutch government, and for $5 \%$ by the families. For an individual family, this amounts to a large burden of about $€ 2000$ a year, including approximately $€ 1500$ for a wheelchair van. We conclude that the government could for instance assist in the family costs by (further) subsidising the expenditures for a wheelchair van.

We subsequently categorised the costs and found out that $95 \%$ of the costs fell outside the medical care sector. These costs were largely related to the motor impairments, including expenditures for home care and guidance, special equipment and aids, therapy and rehabilitation, and transportation. We were impressed that the parents had to address so many different health care organisations and governmental institutions to try to get the necessary arrangements and finance to be able to care for their children. This situation leaves much to be desired. Some of the parents did not even find their way in the jungle of red tape and regulations. Moreover, lengthy application procedures and disproportional delivery periods for wheelchairs add to the frustration of the children and their parents. Recently, these problems were addressed in the Dutch national media. Hopefully, things will improve soon. We believe that some improvements in this field would add to the quality of life of people with disabilities.

Prospective studies on the cost-effectiveness of CITB in children with spastic CP are lacking. Therefore, we conducted a prospective cost-effectiveness analysis alongside our Dutch ITB study. The analysis showed that CITB cost about $€ 30,000$ per quality-adjusted life-year (QALY). The Council for Public Health and Health Care proposed $€ 80,000$ per QALY as a reasonable bench-mark in the Netherlands. ${ }^{18}$ Therefore, we established CITB to be cost-effective. Besides its cost-effectiveness, more factors are in favour of reimbursement of CITB for 
children with intractable spastic CP. These factors comprise the high disease burden and the lack of effective treatment alternatives in most children. ${ }^{19,20}$ Moreover, we expect to start CITB in at most 20 children a year in the Netherlands, resulting in a small burden on the Dutch total health care budget of about $€ 75,000$ per year. We conclude that the results of our study comprise the cost-effectiveness of CITB for carefully selected children with intractable spastic $\mathrm{CP}$ and, from an economic point of view, justify the reimbursement of CITB for this group of children in the Netherlands.

\section{Future}

The results of our Dutch ITB study establish CITB to be (cost)-effective and safe in the treatment of carefully selected children with problems caused by intractable spastic CP. Therefore, CITB merits a place in regular health care. Our proposal for the Netherlands would be to start confining ITB therapy for children to two or three health care centres.

A future challenge regarding CITB treatment is to select the right children at the right age. Strictly speaking, the generalisability of the results of the Dutch ITB study is confined to relatively older children with intractable spastic $\mathrm{CP}$ who rely on wheeled mobility. In clinical practice, CITB is most frequently applied in this group of children. ${ }^{21,22}$ We reported a successful test treatment and subsequent pump implantation in all 17 included children. This means that our multidisciplinary team succeeded in selecting the right children. However, it may also mean that we unjustly withheld a test treatment from part of the excluded children. For example, we excluded two older children in whom spasticity seemed to be mostly replaced by stiffness. Based on our current experiences, we would probably have offered these children a test treatment at that time. During the inclusion period of the Dutch ITB study, we widened the eligibility criteria for treatment with CITB. Currently, available pumps are sufficiently small so that there is no longer a need for any size or weight restrictions. ${ }^{23}$ However, younger, malnourished and the most seriously affected spastic children seem to be more vulnerable to adverse events. ${ }^{21,24,25}$ On the other hand, early treatment with CITB can prevent contractures, dislocations and the subsequent need for orthopaedic procedures. ${ }^{11,26}$ Moreover, we do not consider intractable epilepsy as an absolute contraindication for ITB therapy anymore.

We believe the indication for CITB goes beyond children with intractable spastic CP who rely on wheeled mobility. CITB should certainly be considered in children with a spastic diplegia in whom spasticity interferes with standing, walking and/or cycling. We reported on an ambulant boy who suffered from worsened gait in spite of multilevel treatment with botulinum toxin. He saw his goals fulfilled as with CITB the pain in his hamstrings disappeared and walking took him less energy. Bleyenheuft et al. reported on seven children and young 
adults with diplegic and tetraplegic $\mathrm{CP}$ in whom spasticity resulted in a progressive decrease in walking abilities. ${ }^{27}$ With CITB, walking improved in all patients. ${ }^{27}$ Another treatment option for children with spastic diplegia is selective dorsal rhizotomy. ${ }^{28}$ CITB is the treatment of choice for children with both dystonia and spasticity, because selective dorsal rhizotomy does not improve dystonia. CITB is also recommended in children with spastic quadriplegic $\mathrm{CP}$, because CITB can decrease both upper and lower limb spasticity. The best candidates for selective dorsal rhizotomy are children, aged between 3 and 8 years, with spastic diplegia and reasonably well-preserved leg strength. ${ }^{28}$ In case both CITB and selective dorsal rhizotomy are considered, their pros and contras have to be weighed for the individual child. CITB has the unique advantage of being reversible and titratable to meet individual needs. Disadvantages of CITB are the required pump refills, re-operation for battery failure and possible additional operations to solve complications. In comparison with CITB, selective dorsal rhizotomy is a more invasive procedure. However, it does not require reoperation or repeated visits to a medical centre for refills.

Recently, experts in the field brought the status of an ITB test treatment in children up for discussion. ${ }^{1}$ Albright and Ferson stated that they no longer indicate an ITB test treatment preceding pump implantation in children with spasticity only. ${ }^{1}$ Their experience is that almost all spastic children respond to an ITB bolus dose. We also reported a successful test treatment in all, but carefully selected children who all had one or more realistic treatment goals. Nevertheless, we advocate maintaining the test treatment for the following reasons. First, CITB therapy comprehends more than the implantation of a pump and catheter system. It most of all implies a long-standing contract with medical care, including regular pump refills, which cannot be missed out once. Second, in our centre most children and/or their parents attached great value to the test treatment. Before having a pump implanted, they wanted proof of the anticipated ITB effect. Third, the nature of the response to the ITB test bolus helps to assess the initial CITB daily dose, which usually is twice the effective ITB bolus dose. Lastly, thanks to the test treatment more children can be eligible for CITB therapy. For example, in children with a less straightforward treatment goal, the test treatment can show whether or not ITB gives the desired effect.

Having expounded the rationale of an ITB test treatment, we put forward some ideas to optimise its design and to decrease the incidence of cerebrospinal fluid leakage. From now on, we shall no longer use placebo. Because a placebo-effect has been reported, outcome measures are important for sustaining a clinically observed positive effect. ${ }^{10,29}$ We suggest using the original Ashworth scale, the soleus H-reflex, and the visual analogue scale for this goal. The Ashworth scale is useful, because it quickly provides information on muscle tone and can be easily measured several times a day by one assessor. The soleus H-reflex should be measured once before the test treatment, and at each test day, about four hours 
after ITB bolus administration. The visual analogue scale is a feasible measure to assess any change in the individually formulated problems, including pain and ease of care. ${ }^{6}$

The high incidence of symptoms of cerebrospinal fluid leakage is a major problem, which needs to be addressed. One solution might be to avoid the use of an external catheter and administer the ITB test bolus by lumbar puncture instead. We believe the effective ITB dose can be fairly predicted considering the child's age, weight, CP type, and individual treatment goals. ${ }^{1}$ Because most children will require only one ITB test dose, bolus administration by lumbar puncture may be considered in children who understand the procedure and are able to cooperate. In case ITB administration by an external catheter is required, we would suggest tunnelling the catheter subcutaneously. General anaesthesia is often required in that case. We conclude that the design of each test treatment should be tailored to the characteristics and treatment goals of the individual child.

Considering the implantation of the pump and catheter system for CITB, a challenge is to predict which catheter tip level is best for the individual child. Experts in the field advise to position the catheter tip between levels T10-T12 for spastic diplegia and between levels C5-T2 for spastic tetraplegia. ${ }^{30}$ In our study, the tip was positioned between levels T5-T7 in all children. In two children with tetraplegia and axial hypotonia, and one child with tetraplegia and bulbar side effects, we might better have positioned the tip between levels T10-T12. On the other hand we reported on a girl with a diplegic distribution, who said to have normal upper extremity function before pump implantation. Nevertheless, with CITB she could clearly move her fingers quicker, which facilitated her computer work and thus participation. Therefore, we do not advocate standard tip levels.

We emphasise the role of multidisciplinary teams in specialised centres to make well considered, child centred treatment plans. Individual treatment goals should be clear, relevant and realistic. Outcome measures should include: 1) a highly individualised, subjective measure to evaluate any change in the individual treatment goals such as a visual analogue scale, 2) one or more standardised measures such as relevant GMFM dimensions or PEDI scales, and 3) a measure of health related quality of life, because clinical measurements fail to reflect the well-being of the child and his or her family. ${ }^{31-35}$ Recently, the European KIDSCREEN and DISABKIDS projects have developed a new instrument to assess the health related quality of life of children and adults who suffer from chronic medical conditions. ${ }^{36,37}$ This instrument includes seven condition-specific modules, including a module addressing $\mathrm{CP} .{ }^{37}$

Children treated with CITB will need long-term follow-up in order to answer questions regarding long-term efficacy, safety, and functional outcome. Other questions still to be addressed are whether tolerance would play a role or, conversely, the need for CITB would decrease by age. The efficacy and safety of 
CITB in children with spasticity due to traumatic brain injury, near drowning, spinal cord lesions, and neurodegenerative diseases furthermore should be studied more extensively. A prospective, multicentre approach may be best to study these select paediatric populations. 


\section{REFERENCES}

1. Albright AL, Ferson SS. Intrathecal baclofen therapy in children. Neurosurg Focus 2006;21: 1-6.

2. Butler C, Campbell S. Evidence of the effects of intrathecal baclofen for spastic and dystonic cerebral palsy. AACPDM Treatment Outcomes Committee Review Panel. Dev Med Child Neurol 2000;42:634-645.

3. Hoving MA, van Kranen-Mastenbroek VHJM, van Raak EPM, Spincemaille GHJJ, Hardy ELM, Vles JSH, on behalf of the Dutch Study Group on Child Spasticity. Placebo controlled utility and feasibility study of the H-reflex and flexor reflex in spastic children treated with intrathecal baclofen. Clin Neurophysiol 2006;117:1508-1517 (Chapter 2 of this thesis).

4. Hoving MA, Evers SMAA, Ament AJHA, van Raak EPM, Vles JSH, on behalf of the Dutch Study Group on Child Spasticity. Intractable spastic cerebral palsy in children: a Dutch cost of illness study. Dev Med Child Neurol 2007;49:397-398 (Chapter 7 of this thesis).

5. Hoving MA, Evers SMAA, Ament AJHA, van Raak EPM, Vles JSH, on behalf of the Dutch Study Group on Child Spasticity. Intrathecal baclofen therapy in children with intractable spastic cerebral palsy: a cost-effectiveness analysis. Dev Med Child Neurol; accepted (Chapter 8 of this thesis).

6. Hoving MA, van Raak EPM, Spincemaille GHJJ, Palmans LJ, Sleypen FAM, Vles JSH, on behalf of the Dutch Study Group on Child Spasticity. Intrathecal baclofen in children with spastic cerebral palsy: a double-blind, randomized, placebo-controlled, dose-finding study. Dev Med Child Neurol 2007;49:654-659 (Chapter 3 of this thesis).

7. Awaad Y, Tayem H, Munoz S, Ham S, Michon AM, Awaad R. Functional assessment following intrathecal baclofen therapy in children with spastic cerebral palsy. J Child Neurol 2003;18: 26-34.

8. Campbell WM, Ferrel A, McLaughlin JF, Grant GA, Loeser JD, Graubert C, Bjornson K. Longterm safety and efficacy of continuous intrathecal baclofen. Dev Med Child Neurol 2002;44:660-665.

9. Scheinberg A, O'Flaherty S, Chaseling R, Dexter M. Continuous intrathecal baclofen infusion for children with cerebral palsy: a pilot study. J Paediatr Child Health 2001;37:283-288.

10. Gilmartin R, Bruce D, Storrs BB, Abbott R, Krach L, Ward J, Bloom K, Brooks WH, Johnson DL, Madsen JR, McLaughlin JF, Nadell J. Intrathecal baclofen for management of spastic cerebral palsy: multicenter trial. J Child Neurol 2000;15:71-77.

11. Gerszten PC, Albright AL, Johnstone GF. Intrathecal baclofen infusion and subsequent orthopedic surgery in patients with spastic cerebral palsy. J Neurosurg 1998;88:1009-1013.

12. Stanley F, Blair E, Alberman E. Epidemiological issues in evaluating the management of cerebral palsy. In: Bax MCO, ed. Cerebral palsies: epidemiology and causal pathways. Vol. 151. London: Mac Keith Press, 2000;176-194.

13. Yablon SA, Stokic DS. Neurophysiologic evaluation of spastic hypertonia: implications for management of the patient with the intrathecal baclofen pump. Am J Phys Med Rehabil 2004;83(10 Suppl):S10-18.

14. Yablon SA, Hayes A, Stokic DS. The utility of H-reflex for monitoring the delivery of continuous intrathecal baclofen (CITB) in patients with dysfunctional spasticity: 2. Dose adjustment and troubleshooting. Neurorehabil Neural Repair 2001;15:328.

15. Coffey RJ, Edgar TS, Francisco GE, Graziani V, Meythaler JM, Ridgely PM, Sadiq SA, Turner MS. Abrupt withdrawal from intrathecal baclofen: recognition and management of a potentially lifethreatening syndrome. Arch Phys Med Rehabil 2002;83:735-741.

16. Zuckerbraun NS, Ferson SS, Albright AL, Vogeley E. Intrathecal baclofen withdrawal: emergent recognition and management. Pediatr Emerg Care 2004;20:759-764.

17. Expenditures on care growing more slowly in 2003. URL: http://www.cbs.nl Site accessed on 27 April 2006.

18. Raad voor de Volksgezondheid en Zorg. Zinnige en duurzame zorg. Den Haag, 2006.

19. Liptak GS, O'Donnell M, Conaway M, Chumlea WC, Wolrey G, Henderson RC, Fung E, Stallings VA, Samson-Fang L, Calvert R, Rosenbaum P, Stevenson RD. Health status of children with moderate to severe cerebral palsy. Dev Med Child Neurol 2001;43:364-370. 
20. Drummond MF, Sculpher MJ, Torrance GW, O'Brien B, Stoddard GL. Methods for the economic evaluation of health care. Third edition ed. New York: Oxford University Press, 2005.

21. Motta F, Buonaguro V, Stignani C. The use of intrathecal baclofen pump implants in children and adolescents: safety and complications in 200 consecutive cases. J Neurosurg 2007;107(1 Suppl):32-35.

22. Vender JR, Hester S, Waller JL, Rekito A, Lee MR. Identification and management of intrathecal baclofen pump complications: a comparison of pediatric and adult patients. J Neurosurg 2006;104(1 Suppl):9-15.

23. Albright AL. Intrathecal baclofen for childhood hypertonia. Childs Nerv Syst 2007;23:971-979.

24. Albright AL, Awaad Y, Muhonen M, Boydston WR, Gilmartin R, Krach LE, Turner M, Zidek KA, Wright E, Swift D, Bloom K. Performance and complications associated with the synchromed 10-ml infusion pump for intrathecal baclofen administration in children. J Neurosurg 2004;101(1 Suppl):64-68.

25. Murphy NA, Irwin MC, Hoff C. Intrathecal baclofen therapy in children with cerebral palsy: efficacy and complications. Arch Phys Med Rehabil 2002;83:1721-1725.

26. Morton RE, Scott B, McClelland V, Henry A. Dislocation of the hips in children with bilateral spastic cerebral palsy, 1985-2000. Dev Med Child Neurol 2006;48:555-558.

27. Bleyenheuft C, Filipetti P, Caldas C, Lejeune T. Experience with external pump trial prior to implantation for intrathecal baclofen in ambulatory patients with spastic cerebral palsy. Neurophysiol Clin 2007;37:23-28.

28. Steinbok P. Selection of treatment modalities in children with spastic cerebral palsy. Neurosurg Focus 2006;21:e4.

29. Van Schaeybroeck P, Nuttin B, Lagae L, Schrijvers E, Borghgraef C, Feys P. Intrathecal baclofen for intractable cerebral spasticity: a prospective placebo-controlled, double-blind study. Neurosurgery 2000;46:603-9; discussion 609-612.

30. Albright AL, Turner M, Pattisapu JV. Best-practice surgical techniques for intrathecal baclofen therapy. J Neurosurg 2006;104(4 Suppl):233-239.

31. Ostensjo S, Bjorbaekmo W, Carlberg EB, Vollestad NK. Assessment of everyday functioning in young children with disabilities: an ICF-based analysis of concepts and content of the Pediatric Evaluation of Disability Inventory (PEDI). Disabil Rehabil 2006;28:489-504.

32. Bjornson KF, McLaughlin JF. The measurement of health-related quality of life (HRQL) in children with cerebral palsy. Eur J Neurol 2001;8 Suppl 5:183-193.

33. Rosenbaum P, Stewart D. The World Health Organization International Classification of Functioning, Disability, and Health: a model to guide clinical thinking, practice and research in the field of cerebral palsy. Semin Pediatr Neurol 2004;11:5-10.

34. Engelen V, Ketelaar M, Gorter JW. Selecting the appropriate outcome in paediatric physical therapy; how individual treatment goals of children with cerebral palsy are reflected in GMFM88 and PEDI. J Rehabil Med 2007;39:225-231.

35. Steenbeek D, Ketelaar M, Galama K, Gorter JW. Goal attainment scaling in paediatric rehabilitation: a critical review of the literature. Dev Med Child Neurol 2007;49:550-556.

36. Ravens-Sieberer U, Auquier P, Erhart M, Gosch A, Rajmil L, Bruil J, Power M, Duer W, Cloetta B, Czemy L, Mazur J, Czimbalmos A, Tountas Y, Hagquist C, Kilroe J. The KIDSCREEN-27 quality of life measure for children and adolescents: psychometric results from a cross-cultural survey in 13 European countries. Qual Life Res 2007;16:1347-1356.

37. Baars RM, Atherton $\mathrm{Cl}$, Koopman HM, Bullinger M, Power M. The European DISABKIDS project: development of seven condition-specific modules to measure health related quality of life in children and adolescents. Health Qual Life Outcomes 2005;3:70. 



\section{Summary}




\section{SUMMARY}

This thesis addresses the results of a Dutch national study, in which we prospectively studied the efficacy and safety of intrathecal baclofen (ITB) therapy in children with intractable spastic cerebral palsy (CP). Intractable spasticity can be well treated with continuous infusion of intrathecal baclofen (CITB). However, evidence for the use of CITB in the treatment of children with spasticity is lacking. The Dutch ITB study comprised the selection phase, the test treatment phase, the pump implantation phase, and the follow-up phase. Furthermore, the Dutch ITB study embedded a clinical neurophysiological substudy and a cost analysis.

In daily clinical practice, there has been no objective outcome measure yet to evaluate the effect of ITB therapy in spastic children. In spite of its clear limitations, the standard clinical scale for measuring spasticity is the Ashworth scale. Chapter 2 addresses the clinical neurophysiological study on the utility and feasibility of the soleus $\mathrm{H}$-reflex and flexor reflex in identifying spinal cord neuronal response to ITB bolus administration in children with intractable spastic CP. During a randomised, double-blind, placebo-controlled, dose-escalation test treatment, maximum $\mathrm{H}$-amplitude/maximum $\mathrm{M}$-amplitude ( $\mathrm{H} / \mathrm{M}$ ratio) and flexor reflex parameters were bilaterally recorded at baseline and 2 to 3 hours after intrathecal bolus administration of placebo and increasing doses of baclofen until both an improvement in the individual treatment goal(s) and a one-point reduction on the Ashworth scale were observed. We studied the electrophysiological data of 14 children. The H-reflex was feasible in 13 children, the flexor reflex threshold area in nine and the flexor reflex, elicited with supramaximal stimulation, in only one child. After administration of ITB the $\mathrm{H} / \mathrm{M}$ ratio significantly decreased (left: $0.67 \pm 0.47$ to $0.15 \pm 0.18, p=0.005$; right: $0.55 \pm 0.32$ to $0.14 \pm 0.19, p=0.002$ ) without placebo effect. The flexor reflex threshold area only decreased significantly after ITB administration in children not taking oral baclofen (left: $146 \pm 53 \mathrm{mVms}$ to $41 \pm 54 \mathrm{mVms}$, $p=0.000$; right: $156 \pm 80 \mathrm{mVms}$ to $66 \pm 48 \mathrm{mVms}, p=0.002$ ). We concluded that this first randomised, double-blind, placebo-controlled, dose-escalation study in spastic children demonstrated the soleus H-reflex to be a feasible and objective measure to quantify the decreasing motoneuron excitability in response to ITB bolus administration. Only in children not taking oral baclofen, the flexor reflex threshold area could also be used as an objective outcome measure, yet feasibility is limited. We suggested introducing the H-reflex as the electrophysiological gold standard for the evaluation of the effect of ITB in spastic children. 
Chapter 3 describes the double-blind, randomised, placebo-controlled, dosefinding ITB test treatment. The aims were to select children eligible for CITB, to assess the effective ITB bolus dose and evaluate the effects, side effects and complications. Outcome measures included the original Ashworth scale and the visual analogue scale (VAS) for individually formulated problems. We included nine girls and eight boys, aged between 7 and 16 years (mean $13 y 2 \mathrm{~m} \pm 2 \mathrm{y} 9 \mathrm{~m}$ ). Twelve children had spastic CP and five children spastic-dyskinetic CP. One child was classified on the Gross Motor Function Classification System (GMFCS) at level III, two at level IV and 14 at level V. The test treatment was successful in all 17 children with an effective ITB bolus dose of $12.5 \mu \mathrm{g}$ in one child, $20 \mu \mathrm{g}$ in another, $25 \mu \mathrm{g}$ in ten and $50 \mu \mathrm{g}$ in five children. ITB significantly reduced muscle tone, diminished pain and facilitated ease of care. Placebo did not have these effects. We registered nine side effects of ITB, including slight lethargy in seven children. Fourteen children had symptoms of lowered cerebrospinal fluid pressure. This complication did not occur in three children in whom the neurosurgeon had tunnelled the catheter subcutaneously. We concluded that ITB bolus administration is effective and safe for carefully selected children with intractable spastic CP.

Chapter 4 is about the prospective, randomised controlled, open-label, implantation phase. In a randomised controlled trial (RCT), we studied the 6-month efficacy of CITB in comparison with standard treatment only. After the test treatment, the 17 children were randomised to receive a Synchromed pump for CITB after either one month (CITB group) or six months (Control group). Primary outcomes were the 6-month-change scores on the 0-10 VAS for individually formulated problems and the Caregiver Assistance scale of the Pediatric Evaluation of Disability Inventory (PEDI) self-care domain. One of the secondary outcome measures was health related quality of life as measured with the Child Health Questionnaire (CHQ)-PF50. Nine children were randomly assigned to the CITB group and eight to the Control group. The VAS for individual problems improved with $4.0 \pm 1.7$ in the CITB group and changed with $-0.2 \pm 1.3$ in the Control group $(p=0.001)$. The VAS for pain improved with $4.2 \pm 2.9$ in the CITB group and worsened with $-1.3 \pm 2.4$ in the Control group $(p=0.016)$. The VAS for ease of care improved with $3.9 \pm 2.2$ in the CITB group and with $0.1 \pm 1.6$ in the Control group $(p=0.008)$. PEDI scores did not change significantly. The CHQ-PF50 domain score of bodily pain/discomfort improved with $24.4 \pm 20.7$ points in the CITB group and worsened with $-10.6 \pm 26.8$ points in the Control group $(p=0.014)$. This also counted for the domains of mental health (CITB group $9.1 \pm 9.1$ points versus Control group $-3.5 \pm 15.1$ points; $p=0.045$ ), parental impact-time (CITB group $5.2 \pm 18.1$ points versus Control group $-19.8 \pm 29.0$ points; $p=0.043$ ) and the psychosocial summary score (CITB group $3.4 \pm 7.9$ points versus Control group $-5.7 \pm 8.8$ points; $p=0.027$ ). 
Summarising, CITB reduced individually formulated problems, it relieved pain, and it improved ease of care, significantly. Moreover, health related quality of life significantly improved for the domains of bodily pain/discomfort, mental health, psychosocial status, and parents' personal time limitation. We concluded that the results of this RCT establish CITB to be effective in carefully selected children with problems caused by intractable spastic CP.

Chapter 5 comprises the follow-up phase, in which we prospectively studied the one-year efficacy of CITB, and its safety from pump implantation up to 24 months of follow-up. The test treatment had been successful in all 17 children and they all had a Synchromed pump implanted for CITB. The outcome measures included the 0-10 VAS for individual problems, Gross Motor Function Measure (GMFM) and health related quality of life as measured with the CHQ-PF50. CITB for 12 months significantly improved the VAS for individual problems with $4.7 \pm 2.0(p=0.000)$, VAS for ease of care with $5.2 \pm 2.1(p=0.000)$, VAS for pain with $5.4 \pm 2.7(p=0.002)$; GMFM sitting dimension with 3.3 points (range -4.0 to $22.0(p=0.022)$, GMFM goal dimension with 4.0 points (range 0.0 to 26.0; $p=0.007$ ); and CHQ-PF50 domains of bodily pain/discomfort with $25.6 \pm 35.9$ points $(p=0.016)$ and mental health with $9.8 \pm 11.3$ points $(p=0.007)$. During a mean follow-up of 18.4 months, we recorded 51 nonprocedure or device related adverse events (incidence 0.16 per patient-month; $95 \% \mathrm{Cl}$ 0.12-0.20) and 29 procedure or device related adverse events (incidence 0.09 per patient-month; 95\% Cl: 0.06-0.12). Eight adverse events were serious, but not life threatening. None of the children had a wound infection or meningitis and none of the pumps had to be removed. We concluded that CITB was effective at 12 months and safe up to 24 months for carefully selected children with intractable spastic CP. CITB relieved pain, facilitated ease of care and improved mental health. The majority of children could extend their activities and participation.

Chapter 6 comprises a case report on the use of an indium ${ }^{111}$ diethylenetriaminepentaacetic acid (DTPA) flow study in the evaluation of a lumbar swelling in a 16-year-old girl with spastic CP, who was treated with CITB. We used the indium ${ }^{111}$ DTPA flow study to rule out damage or a disconnection of the catheter, which could have led to leakage of baclofen into the lumbar swelling. The indium ${ }^{111}$ DTPA flow study did not interrupt the continuous infusion of ITB. We concluded that an indium ${ }^{111}$ DTPA flow study is a noninvasive, safe and patient friendly diagnostic method, which can be of great help in the evaluation of pump- or catheter-related complications and does not need to interfere with CITB. 
Because health care expenditures are rising and resources are scarce, economic evaluations become increasingly important in order to justify the introduction of expensive therapies. In chapter 7 we describe our cost of illness (COI) study, which was a substudy of the Dutch ITB study. A COI study defines the magnitude of an illness in monetary terms and can serve as a basis for any economic evaluation. The aims of our COI study were to estimate and categorise the expenditures for children with intractable spastic CP by conducting a bottom-up, disease specific, and prevalence based COI study from the societal perspective. Data were collected by a patient survey and by consulting files of health care institutions and local governments for a one-year period. We included eight girls and seven boys, aged between 7 and 16 years (mean $13 y 2 \mathrm{~m} \pm 2 \mathrm{y} 11 \mathrm{~m}$ ). Eleven children had spastic CP and four children had spastic-dyskinetic CP. One child was classified on the GMFCS at level III, two children at level IV and 12 at level $\checkmark$. From the societal perspective, mean annual costs were $€ 40,265$, which is more than eleven fold the mean expenditures on care per Dutch capita. Home care and guidance accounted for the highest expenditures (€23,000; 57\%), followed by special equipment and aids (€6927; 17\%), therapy and rehabilitation $(€ 3262 ; 8 \%)$, and transportation (€3101; 8\%). The expenditures for medical care were relatively small ( $€ 1573 ; 4 \%$ ). We concluded that the economic impact of intractable spastic CP in children is relatively high and largely related to the motor impairments.

Prospective studies on the cost-effectiveness of CITB in children with spastic CP are lacking. Therefore, we conducted a cost-effectiveness analysis (chapter 8) alongside our prospective Dutch ITB study. We compared the costs and health effects of CITB to those of standard treatment only, from the health care perspective for a one-year period. Health effects were expressed in terms of a VAS for individual problems and quality-adjusted life-years (QALYs). QALYs were derived from the EuroQol-5D. We verified the robustness of the results with bootstrap and sensitivity analyses. This cost-effectiveness analysis included the same 15 children as the COI study (chapter 7). CITB was more effective and more costly than standard treatment only. Gaining one QALY cost on average $€ 32,737$. We concluded that based on the threshold-willingness to pay for one QALY in the Netherlands (€80,000), our results sustain the cost-effectiveness of CITB for carefully selected children with intractable spastic CP.

The results of our Dutch ITB study established CITB to be (cost)-effective and safe in the treatment of carefully selected children with problems caused by intractable spastic CP. Therefore, CITB merits a place in regular health care. In the general discussion (chapter 9) we put forward some ideas to optimise ITB therapy in children with spastic CP. We also discussed future challenges on this subject. 

Samenvatting 


\section{SAMENVATTING}

Dit proefschrift beschrijft de resultaten van een Nederlandse nationale studie waarin we prospectief hebben onderzocht of toediening van intrathecale baclofen (ITB) een effectieve en veilige behandeling is voor kinderen met onbehandelbare spastische cerebrale parese (CP). Het is bekend dat onbehandelbare spasticiteit goed kan worden behandeld met continue intrathecale toediening van baclofen (CITB). $\mathrm{Er}$ is echter onvoldoende bewijskracht voor toepassing van CITB als behandeling voor kinderen met spasticiteit. De Nederlandse ITB studie bestond achtereenvolgens uit de selectiefase, proefbehandelingsfase, pompimplantatiefase en follow-up fase. Daarnaast verrichtten we binnen de Nederlandse ITB studie een klinisch neurofysiologische substudie en een kostenanalyse.

In de kliniek ontbrak tot op heden een objectieve test om de effecten van ITB als behandeling voor kinderen met spasticiteit te meten. Een vaak gebruikte klinische schaal voor het meten van spasticiteit was en is de Ashworth schaal, waarmee in wezen spiertonus op subjectieve wijze wordt gemeten. Hoofdstuk 2 betreft een klinisch neurofysiologische studie met als vraagstelling of de soleus $\mathrm{H}$-reflex en de flexor reflex het effect van ITB op het niveau van het ruggenmerg kunnen meten. Daarnaast onderzochten we de toepasbaarheid van deze testen in kinderen met onbehandelbare spastische CP. Het onderzoek vond plaats tijdens de gerandomiseerde, dubbelblinde, placebogecontroleerde, dose-finding proefbehandelingsfase. Voor aanvang van de proefbehandeling bepaalden we de uitgangswaarden van de maximum $\mathrm{H}$-amplitude/maximum $\mathrm{M}$-amplitude $(\mathrm{H} / \mathrm{M}$ ratio) en de flexor reflex parameters voor beide benen. Vervolgens werd op iedere testdag, 2 tot 3 uren na intrathecale bolus toediening van placebo en toenemende doseringen baclofen, gemeten tot en met de dag dat er zowel een verbetering in de individueel gestelde behandelingsdoelen als een verbetering van minimaal één punt op de Ashworth schaal werd geobserveerd. We bestudeerden de elektrofysiologische data van 14 kinderen. De H-reflex was toepasbaar in 13 kinderen, de flexor reflex drempel area in negen en de flexor reflex, opgewekt met supramaximale stimulatie, in één kind. Na toediening van ITB daalde de $\mathrm{H} / \mathrm{M}$ ratio significant (links van $0.67 \pm 0.47$ naar $0.15 \pm 0.18$, $p=0.005$; rechts van $0.55 \pm 0.32$ naar $0.14 \pm 0.19, p=0.002)$ zonder placebo effect. De flexor reflex drempel area daalde alleen significant in de groep kinderen die oraal geen baclofen gebruikten (links van $146 \pm 53 \mathrm{mVms}$ naar $41 \pm 54 \mathrm{mVms}, p=0.000$; rechts van $156 \pm 80 \mathrm{mVms}$ naar $66 \pm 48 \mathrm{mVms}$, $p=0.002$ ). De resultaten van deze eerste gerandomiseerde, dubbelblinde, placebogecontroleerde, dose-finding studie in spastische kinderen hebben aangetoond dat de soleus $\mathrm{H}$-reflex een objectieve en toepasbare test is om de afnemende excitabiliteit van het motoneuron in respons op ITB bolus toediening 
te kwantificeren. Alleen in kinderen die oraal geen baclofen gebruiken, kan ook de flexor reflex drempel area worden gebruikt als objectieve uitkomstmaat; de toepasbaarheid is echter beperkt. Ons voorstel is de H-reflex te introduceren als elektrofysiologische gouden standaard in de evaluatie van het effect van ITB in spastische kinderen.

Hoofdstuk 3 beschrijft de gerandomiseerde, dubbelblinde, placebogecontroleerde, dose-finding proefbehandeling. De doelen waren het selecteren van kinderen voor CITB, het vaststellen van de effectieve ITB bolus dosering en het registreren van effecten, bijwerkingen en complicaties. Als uitkomstmaten gebruikten we de originele Ashworth schaal en een visueel analoge schaal (VAS) voor individuele doelen. We includeerden negen meisjes en acht jongens tussen de 7 en 16 jaar oud (gemiddeld $13 \mathrm{j} 2 \mathrm{~m} \pm 2 \mathrm{j} 9 \mathrm{~m}$ ). Twaalf kinderen hadden spastische CP en vijf kinderen spastisch-diskinetische CP. Volgens het Grof Motorisch Functionerings Classificatie Systeem (GMFCS) classificeerden we één kind in niveau III, twee kinderen in niveau IV en 14 in niveau V. De proefbehandeling slaagde in alle 17 kinderen. De effectieve ITB bolus dosering bedroeg $12.5 \mu \mathrm{g}$ in één kind, $20 \mu \mathrm{g}$ in een ander, $25 \mu \mathrm{g}$ in tien kinderen en $50 \mu \mathrm{g}$ in vijf kinderen. ITB had een significant gunstig effect op spiertonus, pijn en verzorging. Placebo had deze effecten niet. We registreerden negen bijwerkingen waaronder geringe lethargie in zeven kinderen. Veertien kinderen hadden symptomen passend bij een verlaagde liquordruk. Deze complicatie trad niet op in drie kinderen waarbij de neurochirurg de katheter subcutaan had getunneld. We concludeerden dat ITB bolus toediening effectief en veilig is in zorgvuldig geselecteerde kinderen met problemen als gevolg van onbehandelbare spastische CP.

Hoofdstuk 4 betreft de prospectieve, gerandomiseerde, gecontroleerde, openlabel implantatiefase. In een gerandomiseerd gecontroleerd onderzoek (RCT) vergeleken we de effectiviteit van 6 maanden CITB met die van standaard behandeling alleen. Na de proefbehandeling vond randomisatie plaats. Eén groep kinderen kreeg de Synchromed pomp na 1 maand (CITB groep) en de andere groep na zes maanden (Controle groep). Primaire uitkomsten waren de 6maanden-verschilscores binnen de 0-10 VAS voor individuele problemen en de Verzorgersassistentie schaal in het domein Zelfverzorging van de Pediatric Evaluation of Disability Inventory (PEDI). Een van de secundaire uitkomstmaten was kwaliteit van leven gemeten met de Child Health Questionnaire (CHQ)PF50. Negen kinderen kwamen na randomisatie in de CITB groep en acht in de Controle groep. De VAS voor individuele problemen verbeterde met $4.0 \pm 1.7$ in de CITB groep en verslechterde met $-0.2 \pm 1.3$ in de Controle groep $(p=0.001)$. De VAS voor pijn verbeterde met $4.2 \pm 2.9$ in de CITB groep en verslechterde met $-1.3 \pm 2.4$ in de Controle groep $(p=0.016)$. De VAS voor verzorging 
verbeterde met $3.9 \pm 2.2$ in de CITB groep en met $0.1 \pm 1.6$ in de Controle groep $(p=0.008)$. PEDI scores lieten geen significante verandering zien. De CHQ-PF50 score voor lichamelijke pijn en klachten verbeterde met $24.4 \pm 20.7$ punten in de CITB groep en verslechterde met $-10.6 \pm 26.8$ punten in de Controle groep $(p=0.014)$. Dit patroon gold ook voor de CHQ-PF50 score voor mentale gezondheid (CITB groep $9.1 \pm 9.1$ punten versus Controle groep $-3.5 \pm 15.1$ punten; $p=0.045$ ), impact op tijd ouders (CITB groep $5.2 \pm 18.1$ punten versus Controle groep $-19.8 \pm 29.0$ punten; $p=0.043$ ) en de psychosociale samenvattingscore (CITB groep $3.4 \pm 7.9$ punten versus Controle groep $-5.7 \pm 8.8$ punten; $p=0.027)$. Samenvattend had CITB een significant gunstig effect op pijn, verzorging en de individuele problemen. Daarnaast verbeterde CITB de kwaliteit van leven significant op de gebieden van lichamelijke pijn en klachten, mentale gezondheid, psychosociale toestand en de tijdsbeperking die de ouders ervaren door de handicap van hun kind. De resultaten van deze RCT laten zien dat CITB een effectieve behandeling is voor zorgvuldig geselecteerde kinderen met problemen veroorzaakt door onbehandelbare spastische $\mathrm{CP}$.

In hoofdstuk 5 beschrijven we de resultaten van de follow-up fase. We onderzochten prospectief zowel de 1-jaars effectiviteit van CITB als de veiligheid vanaf pompimplantatie tot een follow-up van maximaal 24 maanden. Alle 17 kinderen hadden een geslaagde proefbehandeling en kregen een Synchromed pomp voor CITB. Als uitkomstmaten gebruikten we de 0-10 VAS voor individuele problemen, de Gross Motor Function Measure (GMFM) en kwaliteit van leven gemeten met de CHQ-PF50. CITB gedurende 12 maanden verbeterde de VAS voor individuele problemen met $4.7 \pm 2.0(p=0.000)$, de VAS voor verzorging met $5.2 \pm 2.1(p=0.000)$, de VAS voor pijn met $5.4 \pm 2.7(p=0.002)$; de GMFM dimensie zitten met 3.3 punten (range -4.0 tot $22.0(p=0.022)$ en de GMFM doeldimensie met 4.0 punten (range 0.0 tot 26.0; $p=0.007$ ). Daarnaast verbeterden de CHQ-PF50 scores voor lichamelijke pijn en klachten met $25.6 \pm 35.9$ punten $(p=0.016)$ en voor mentale gezondheid met $9.8 \pm 11.3$ punten $(p=0.007)$. Gedurende een gemiddelde follow-up van 18.4 maanden registreerden we 51 niet-procedure of pompsysteem gerelateerde adverse events (incidentie 0.16 per patiëntmaand; $95 \% \mathrm{Cl}$ 0.12-0.20) en 29 procedure of pompsysteem gerelateerde adverse events (incidentie 0.09 per patiëntmaand; 95\% Cl: 0.06-0.12). Acht adverse events waren ernstig, maar niet levensbedreigend. Geen van de kinderen kreeg een wondinfectie of meningitis en geen van de pompen hoefde te worden verwijderd. Concluderend bleek CITB na 1 jaar effectief en daarnaast veilig gedurende de follow-up die in dit onderzoek maximaal 24 maanden duurde. CITB resulteerde in een vermindering van pijn, vergemakkelijking van de verzorging en een verbetering van de mentale gezondheid van de kinderen. De meerderheid van de kinderen kon zijn of haar activiteiten uitbreiden waarbij participatie in het dagelijks leven toenam. 
Hoofdstuk 6 betreft een case report over toepassing van een indium ${ }^{111}$ diethylenetriaminepentaacetic acid (DTPA) flow onderzoek ter evaluatie van een lumbale zwelling in een 16 jaar oud meisje met spastische CP die werd behandeld met CITB. We gebruikten het indium ${ }^{111}$ DTPA flow onderzoek om onaannemelijk te maken dat door een katheterprobleem liquor en baclofen de zwelling inlekten. Tijdens het indium ${ }^{111}$ DTPA onderzoek werd de continue intrathecale toediening van baclofen niet onderbroken. We concludeerden dat een indium ${ }^{111}$ DTPA flow onderzoek een non-invasieve, veilige en patiëntvriendelijke test is welke van nut kan zijn in de evaluatie van pomp- of katheter gerelateerde complicaties zonder te interfereren met CITB.

Aangezien de kosten van de gezondheidszorg toenemen en middelen beperkt zijn, worden economische evaluaties steeds belangrijker om het invoeren van dure behandelmethoden te rechtvaardigen. In hoofdstuk 7 beschrijven we een cost of illness (COI) studie als onderdeel van de Nederlandse ITB studie. Een COI studie drukt de omvang van een ziekte uit in financiële termen en kan dienen als basis voor elke economische evaluatie. Onze doelen waren het schatten en indelen van de uitgaven voor kinderen met onbehandelbare spastische CP middels het uitvoeren van een bottum-up, ziektespecifieke en prevalentie gebaseerde $\mathrm{COI}$ studie, verricht vanuit maatschappelijk perspectief. De gegevens werden voor een periode van een jaar verzameld middels een patiëntenvragenlijst en het consulteren van gezondheidsinstellingen en lokale overheden. We includeerden acht meisjes en zeven jongens tussen de 7 en 16 jaar oud (gemiddeld $13 \mathrm{j} 2 \mathrm{~m} \pm 2 \mathrm{j} 11 \mathrm{~m}$ ). Elf kinderen hadden spastische CP en vier hadden spastisch-diskinetische CP. Volgens het GMFCS classificeerden we één kind in niveau III, twee kinderen in niveau IV en 12 in niveau V. Vanuit maatschappelijk perspectief waren de gemiddelde jaarlijkse kosten €40,265 wat neerkomt op meer dan 11 maal de gemiddelde uitgaven per hoofd van de Nederlandse bevolking. De hoogste uitgaven waren voor thuiszorg en begeleiding (€23,000; 57\%), gevolgd door speciale apparatuur en hulpmiddelen (€6927; 17\%), therapie en revalidatie (€3262; 8\%) en transport (€3101; 8\%). De kosten van de medische zorg waren relatief bescheiden (€1573; 4\%). Onze conclusie luidde dat de economische gevolgen van onbehandelbare spastische $\mathrm{CP}$ bij kinderen relatief groot zijn en hoofdzakelijk gerelateerd aan de motorische beperkingen.

Parallel aan de Nederlandse ITB studie verrichtten we een kosteneffectiviteitanalyse, omdat prospectieve studies naar de kosteneffectiviteit van CITB in kinderen met spastische CP ontbreken (hoofdstuk 8). Gedurende een jaar vergeleken we de kosten en de gezondheidseffecten van CITB met die van standaard behandeling alleen vanuit het perspectief van de gezondheidszorg. We 
drukten gezondheidseffecten uit in termen van de VAS voor individuele problemen en quality-adjusted life-years (QALYs). QALYs werden afgeleid van de EuroQol-5D. We verifieerden de resultaten met bootstrap en gevoeligheidsanalyses. Aan de kosteneffectiviteitanalyse deden dezelfde 15 kinderen mee als aan de COI studie (hoofdstuk 7). CITB was effectiever en duurder dan standaard behandeling alleen. Eén QALY verbetering kostte gemiddeld $€ 32,737$. In het licht van de Nederlandse 'threshold-willingness to pay' voor één QALY (€80,000) concludeerden we dat CITB een kosteneffectieve behandeling is voor zorgvuldig geselecteerde kinderen met problemen veroorzaakt door onbehandelbare spastische CP.

De Nederlandse ITB studie heeft aangetoond dat CITB een (kosten)effectieve en veilige behandeling is voor zorgvuldig geselecteerde kinderen met problemen veroorzaakt door onbehandelbare spastische CP. CITB verdient daarom een plaats binnen de reguliere gezondheidszorg. In de algemene discussie (hoofdstuk 9) hebben we ideeën naar voren gebracht over het optimaliseren van ITB therapie in kinderen met spastische CP. Daarnaast komen toekomstige uitdagingen rond dit onderwerp aan de orde. 

Dankwoord 


\section{DANKWOORD}

Een promotieonderzoek is als de terugreis van Odysseus naar Ithaka:

Als je doel lthaka is en je vertrekt daarheen,

dan hoop ik dat je tocht lang zal zijn

en vol nieuwe kennis, vol avontuur.

Verwacht niet dat Ithaka je meer rijkdom geeft.

Ithaka gaf je een prachtige reis,

zonder Ithaka zou je nooit vertrokken zijn.

Mijn reis is tot een rijke ervaring geworden dankzij de volgende mensen die me op weg stuurden, mijn koers bijstelden, stukken meevoeren of onderweg voor vertier zorgden. Bedankt!

Allereerst de deelnemende kinderen en hun families. Voor jullie was deelname aan het onderzoek in Maastricht zowel letterlijk als figuurlijk een spannende reis. Jullie hebben me geraakt door jullie moed, doorzettingsvermogen en vrolijkheid. Dankzij jullie kunnen nu ook andere kinderen met ernstige spasticiteit behandeld worden met intrathecale baclofen.

De Raad van Bestuur van het azM en in het bijzonder oud-voorzitter dr. Carpay. Dankzij uw vertrouwen in onze plannen en de financiële steun van het Profileringsfonds hebben we de Nederlandse nationale ITB studie in het azM kunnen uitvoeren.

Prof. dr. Vles, beste Hans. Als voorzitter van de Landelijke Werkgroep voor Spasticiteit bij Kinderen vertrouwde je mij dit fantastische onderzoek toe. Het was het begin van een hechte samenwerking en een mooie tijd. Het is een voorrecht dat ik zoveel van je heb mogen leren over zowel neurologie als het leven. Je begeleiding was perfect. Je gaf me de ruimte mezelf te ontplooien, daarbij te vallen en weer op te staan. Maar wat er ook gebeurde, je was altijd bereikbaar.

Dr. van Raak, beste Lisette. Samen met Hans maakte je deel uit van het dagelijks onderzoeksbestuur. Hoe druk je het ook had, jouw deur stond altijd voor me open. Je bijdrage aan het onderzoek is tijdsintensief en onmisbaar geweest. Ik bewonder je geduld, precisie en scherpe blik. Het was buitengewoon plezierig met je samen te werken. 
Dr. Spincemaille en prof. dr. Beuls. Goede neurochirurgische faciliteiten, flexibiliteit en laagdrempelig overleg hebben bijgedragen aan het positieve verloop van de studie. Daarbij was het een geruststellende gedachte dat de kinderen door $\mathrm{u}$ werden geopereerd.

De Landelijke Werkgroep voor Spasticiteit bij Kinderen en het Spasticiteitsteam voor Kinderen in het azM. Bedankt voor de fijne samenwerking en hetgeen ik van jullie heb geleerd.

Liesbeth Palmans. De kinderen waren dol op je en sommige zelfs een beetje verliefd. We waren een goed team en ik heb genoten van je altijd goede humeur.

De mensen van de afdeling KNF en speciaal dr. Vivianne van Kranen. Bedankt voor jullie expertise, flexibiliteit, gezelligheid en persoonlijke aandacht voor de kinderen.

Dr. Evers en dr. Ament, beste Silvia en André. Het kostenonderzoek bleek een pittige uitdaging, maar is succesvol afgerond. Bedankt voor jullie hulp en aanmoedigingen.

De vakgroep kindergeneeskunde en de verpleging van afdelingen MC-B2 en MCC5. Bedankt voor jullie enthousiasme en de prettige samenwerking op de afdeling. De meeste kinderen waren ver van huis, maar jullie zorg en aandacht maakten veel goed.

De dames van de secretariaten neurologie, neurochirurgie, KNF, fysiotherapie en in het bijzonder Desiree Serpenti. Bedankt voor de secretariële en logistieke ondersteuning.

Drs. van den Bergh, beste Fons. Tijdens mijn opleiding geneeskunde heb je me als wetenschapper ontgroend. Je begeleiding was inspirerend en het was altijd gezellig. Bijzonder leuk dat we dit jaar allebei promoveren.

Prof. dr. Troost en prof. dr. Limburg. Mijn opleiding neurologie en het promotieonderzoek liepen parallel. Gelukkig had ik uw steun en is de kwaliteit van mijn opleiding bewaakt gebleven.

Arjen van Prooijen. Dankzij jou is het proefschrift kunst geworden.

Tiny Wouters. Jouw hulp is vele malen verder gegaan dan het maken van de layout. Na elk consult Tiny wist ik weer dat alles goed zou komen. Je bent een engel. 
De assistenten neurologie van het azM. We hebben samen veel lol gehad tijdens werk, borrels, etentjes, azM assistentenfeesten en promotieparty's. Wordt vervolgd! Anita, Elske, Manuela en Tatjana, bedankt voor jullie speciale vriendschap.

Annemarie Vlaar, paranimf. Vele fietstochten door de heuvels, Parijs, zwemmen, toneel, Costa Brava, hapje eten, film, skiën, klassiek concert, wandelen in Bemelen, borrelen ... dat we nog tijd hadden voor promotieonderzoek?!

Anne Starreveld. Friends for life. Ik vind het geweldig dat je voor mijn promotie overkomt uit Canada.

Tennisvrienden van TC Ready. Geen betere ontspanning dan lekker meppen op de tennisbaan.

Pieter en Maarten, bovenburen. Op de Gerechtigheidslaan 4 altijd leven in de brouwerij.

De maatschap neurologie van het Diaconessenhuis Leiden; beste Elske, Job en Richard. Bedankt dat ik twee maanden later kon beginnen en daardoor tijd kreeg voor het afronden van mijn proefschrift.

Petra, Coen en Quinten. Pé, jij hebt de kwaliteit van het Engels bewaakt en je bent mijn paranimf. Fijn dat je als zus er altijd voor me bent en gezellig dat we nu zo dicht bij elkaar wonen.

Kees, Priska, Tim, Casper en Kiki. De zonnige, culinair hoogstaande verwenweekenden in Villa Sant Elm waren de perfecte energie booster tussen de onderzoeksactiviteiten door. Ik verheug me jullie straks veel meer te zien.

De liefste oma van de wereld. Hoezo 91 jaar? Zelfstandig, modern, alle familienieuwtjes paraat; radio Slochteren is altijd een feest om naar te luisteren. Bedankt voor uw liefde, warmte en de energie die u me geeft tijdens onze wekelijkse telefonades.

Lieve pa en ma, jullie liefde en onvoorwaardelijke steun betekenen heel veel voor me. Jullie geven me alle vrijheid, maar in Hotel Hoving is altijd een kamer vrij.

Liefste Stefan. Aan het einde van mijn promotiereis kwam jij aan boord. Bij jou zijn en samen alles kunnen delen is de ultieme rijkdom. Ik verheug me op alle nieuwe avonturen die we samen gaan beleven! 

Curriculum vitae 


\section{CURRICULUM VITAE}

Marjanke Hoving werd op 7 juli 1976 geboren in Oosterhesselen. Na afronding van het Gymnasium aan het Christelijk Lyceum te Emmen studeerde zij Geneeskunde aan de Rijksuniversiteit Groningen. De propedeuse en doctoraalbul werden cum laude behaald. Naast de studie verrichtte zij onder leiding van radiotherapeut drs. A.C.M. van den Bergh wetenschappelijk onderzoek naar visusstoornissen bij patiënten met acromegalie. Na het doctoraal volgden de co-schappen in de Deventer Ziekenhuizen. Het keuze co-schap neurologie werd gevolgd aan The University Hospital of Alberta, Edmonton, Canada. Haar begeleiders waren E. Starreveld, MD FRCP(C), Associate Professor en M.G. Elleker, MD FRCP(C), Associate Professor. In 2000 behaalde Marjanke cum laude de artsenbul aan de Rijksuniversiteit Groningen. De opleiding tot neuroloog volgde zij in het Academisch Ziekenhuis Maastricht met als opleiders prof. dr. J. Troost en prof. dr. M. Limburg. Tijdens de opleiding verrichtte zij onder leiding van kinderneuroloog prof. dr. J.S.H. Vles wetenschappelijk onderzoek met dit proefschrift als resultaat. Een deel van het promotieonderzoek werd bekroond met de Assistentenprijs 2006 van de Nederlandse Vereniging voor Klinische Neurofysiologie en de Pelerinprijs 2006 van het Academisch Ziekenhuis Maastricht. Per 1 maart 2008 is Marjanke haar carrière als neuroloog begonnen in het Diaconessenhuis Leiden. 